\title{
DESENVOLVIMENTO DE UM AMBIENTE COMPUTACIONAL INTERATIVO E ADAPTATIVO PARA APOIAR O APRENDIZADO DE GEOMETRIA DESCRITIVA
}

Tese apresentada à Escola Politécnica da Universidade de São Paulo para obtenção do título de Doutor em Engenharia.

SÃO PAULO

2003 


\section{DESENVOLVIMENTO DE UM AMBIENTE COMPUTACIONAL INTERATIVO E ADAPTATIVO PARA APOIAR O APRENDIZADO DE GEOMETRIA DESCRITIVA}

Tese apresentada à Escola Politécnica da Universidade de São Paulo para obtenção do título de Doutor em Engenharia.

Área de Concentração:

Engenharia de Construção Civil e Urbana

Orientador:

Prof. Dr. Eduardo Toledo Santos

SÃO PAULO

2003 


\section{Para Luiz Octávio}

e nosso bebê que está chegando...

com todo meu amor. 


\section{AGRADECIMENTOS}

Aos Mestres que me iluminaram;

Ao Prof. Dr. Eduardo Toledo Santos, por sua orientação incansável e muita compreensão;

Aos meus pais que, com exemplos, me ensinaram que heróis são aqueles que mais persistem;

À minha "tiamiga" Idalina, pela acolhida cheia de carinho durante todos estes anos em São Paulo;

Aos professores do Departamento de Engenharia de Construção Civil da PoliUSP, pela presença e contribuições;

Aos colegas do LabCad, pela solidariedade e incentivo;

Ao Prof. Dr. Leônidas Brandão, do IME-USP, pela participação ativa na integração da ferramenta de desenho que desenvolveu com o sistema elaborado nesta tese;

Ao Robson Martins, meu mestre de PHP;

Ao Prof. Dr. José Brás Barreto de Oliveira, Diretor da Faculdade de Ciências da UNESP de Bauru, pelo apoio e confiança;

Ao Eng. Mitsuo Katsuki, pelas inúmeras vezes que defendeu meu trabalho;

Aos colegas do Serviço Técnico de Informática pela cumplicidade;

Ao Prof. Dr. José Misael Ferreira do Vale, pelos exemplos de como ser educador e pela idealização do Núcleo de Pesquisa e Produção em Multimeios para a Educação;

Aos professores do Departamento de Representação Gráfica da UNESP de Bauru pela amizade e incentivo;

A minha grande amiga Maria Antonia, companheira de mestrado, doutorado e muitos milhares de quilômetros me ensinando Geometria Descritiva;

A toda minha família que, naquelas inevitáveis desanimadas, me empurrou para frente e sempre entendeu minha ausência;

Eternamente, obrigada! 
"Ora et Labora"

(São Bento) 


\section{RESUMO}

Esta pesquisa teve como objetivo fundamentar e implementar um Ambiente Computacional de Suporte ao Aprendizado de Geometria Descritiva (GD) capaz de se adaptar às necessidades de aprendizagem do aluno.

No sistema proposto, o aluno interage via Internet e desenvolve seu aprendizado por meio da resolução de exercícios.

Este ambiente tem como suporte uma biblioteca de exercícios de GD e, seguindo uma estratégia pedagógica, sugere caminhos para conduzir o aprendiz a níveis cada vez mais aprofundados em seus estudos.

A cada interação, são avaliados os conceitos que o aluno já conhece e, com base nestes dados, novos exercícios são sugeridos de modo gradual, bem como, quando for o caso, uma lista das teorias básicas que ele deverá estudar.

O referido ambiente de aprendizagem, além de ser uma ferramenta de estudo, também pode apoiar os docentes e pesquisadores da área, oferecendo um repositório de exercícios de GD que pode ser acessado e incrementado por eles. Este módulo, chamado de Biblioteca de Exercícios, permite a busca de exercícios específicos por meio de filtros de seleção como conceitos envolvidos ou complexidade da solução, entre outros.

Espera-se que o sistema desenvolvido se constitua numa ferramenta de grande valia para apoiar à aprendizagem de Geometria Descritiva, uma disciplina importante que tradicionalmente representa um desafio significativo aos estudantes. 


\section{ABSTRACT}

This research aims to establish the basis for a Descriptive Geometry Computer Learning Environment able to adapt itself to the student's learning needs as well as to implement it.

The student interacts with the proposed system through the Internet and learns by solving exercises.

This learning environment is supported by a Descriptive Geometry (DG) exercise library and, by following a pedagogical strategy, it suggests paths to conduct the student to mastering the target contents.

The concepts learned by the student are evaluated at each iteration and, based on these data, the system gradually proposes new exercises to the learner, as well as, sometimes, offers a list of theory topics that should be studied.

The proposed learning environment, besides being a learning tool, can support DG instructors and researchers by offering them a DG exercise repository that may be used and increased by them. This module, called Exercise Library, allows searching for an exercise through concept and level of complexity filters, among others.

It is hoped that this developed system constitutes an expressive instrument to support DG learning, a content that traditionally represents a challenge to students. 


\section{SUMÁRIO}

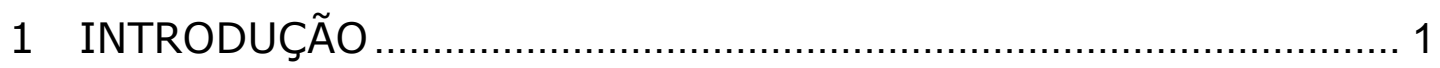

2 O ENSINO DE GD APOIADO PELA INFORMÁTICA ....................... 14

2.1 Sistemas Tutores Inteligentes............................................................19

3 FUNDAMENTAÇÕES PEDAGÓGICAS PARA UMA PROPOSTA DE AMBIENTE DE APRENDIZADO COMPUTACIONAL ...................... 24

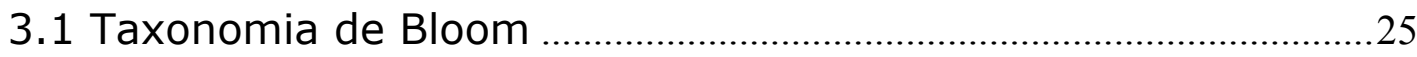

3.2 Objetivos educacionais de GD propostos aos alunos de Engenharia

3.3 Objetivos educacionais nos cursos de GD 27

3.4 Aspectos Pedagógicos a serem considerados no aprendizado de Geometria Descritiva

3.5 Modelos Pedagógicos que aplicam a Aprendizagem por

Resolução de Problemas

4 ARQUITETURA DO AMBIENTE COMPUTACIONAL DE SUPORTE AO APRENDIZADO DE GEOMETRIA DESCRITIVA.

4.1 Requisitos de software para instalação e utilização do

Ambiente de Aprendizado de GD 38

4.2 Módulos que compõem o Ambiente de Aprendizado de GD......40

4.3 Biblioteca de Exercícios de GD 44

4.3.1 Utilização e alimentação da Biblioteca de Exercícios 45 
5 APRENDIZADO POR RESOLUÇÃO DE EXERCÍCIOS COM TUTORIA

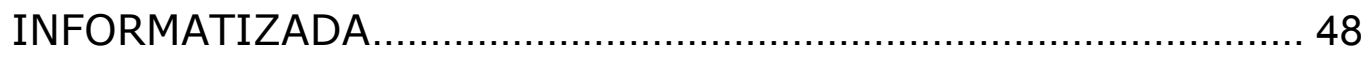

5.1 Desenvolvimento de um Sistema Tutor de Geometria

Descritiva 48

5.2 Domínio de Geometria Descritiva ..........................................................50

5.3 Relacionamento entre Conceitos .........................................................52

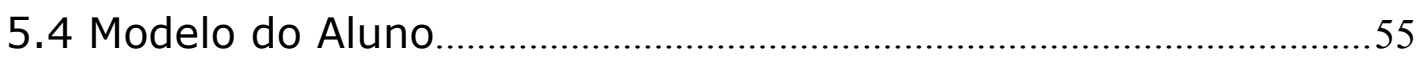

5.5 Informações que o Modelo do Aluno passa ao Módulo Tutor ...60

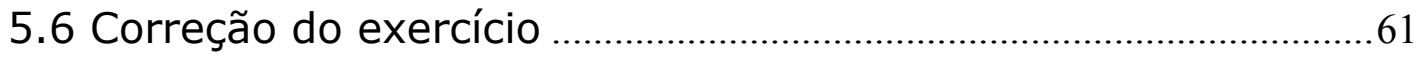

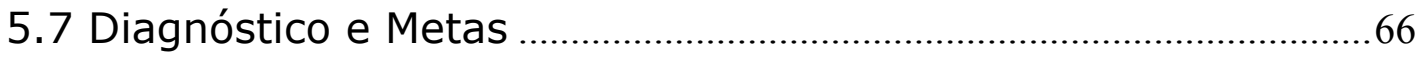

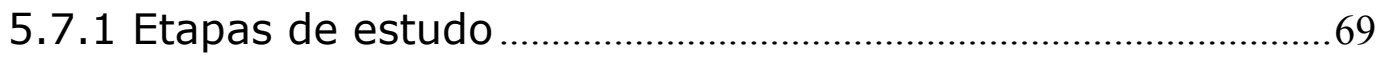

5.7.2 Metas a serem atingidas pelo aluno ……………………............70

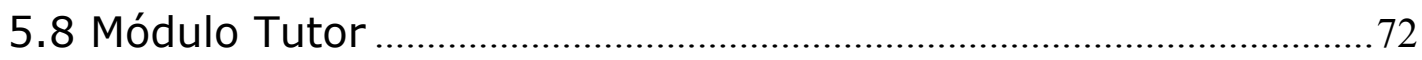

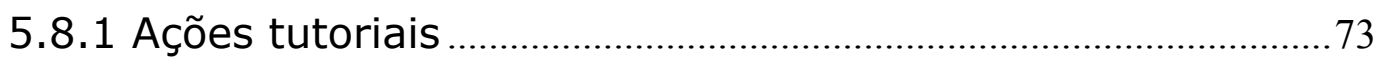

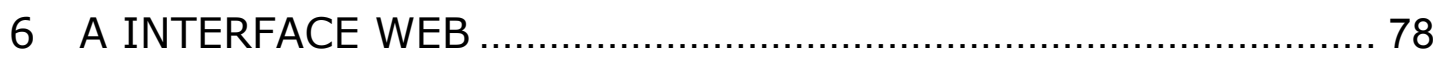

$6.1 \mathrm{~A}$ área pública

6.2 A área restrita

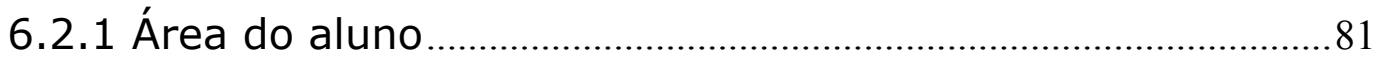

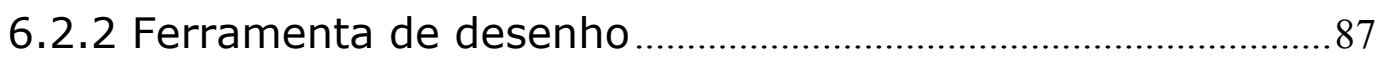

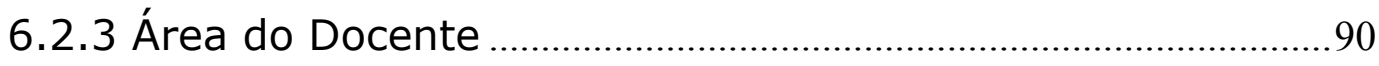

6.2.4 Área do Administrador do sistema ...........................................98 
7 CONCLUSÕES E TRABALHOS FUTUROS 102

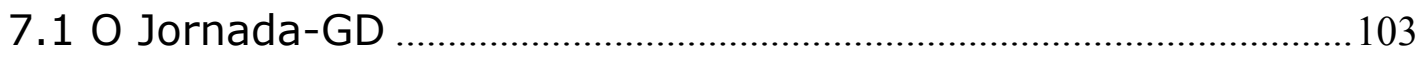

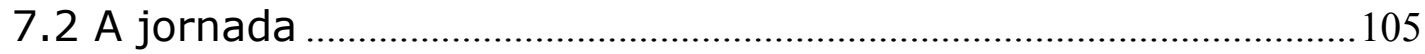

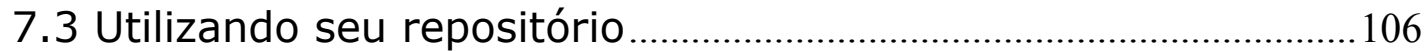

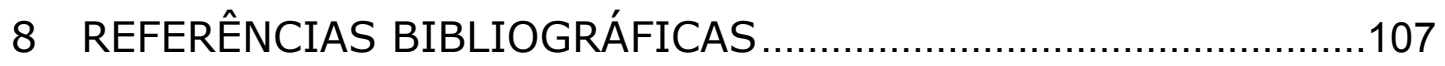

ANEXO 1 - Base de Dados do Sistema ..........................................113

ANEXO 2 - Funções do Sistema....................................................129 


\section{LISTA DE FIGURAS}

Figura 1 - Telas do sistema Hypergeo …………………………………....15

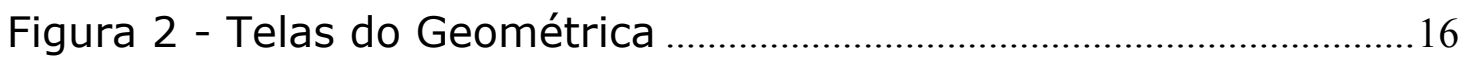

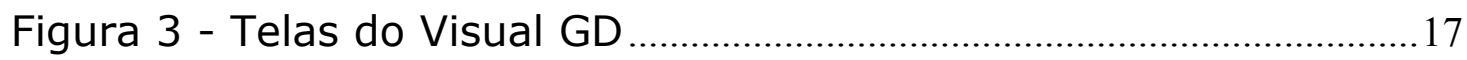

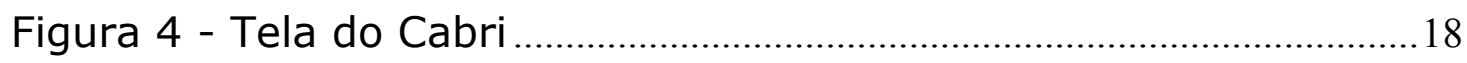

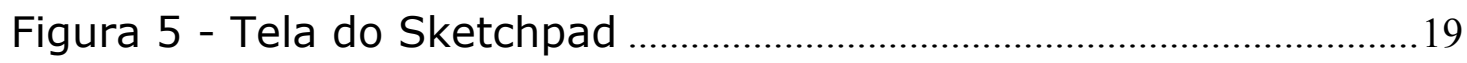

Figura 6 - Representação dos elementos básicos de um STI ................23

Figura 7 - Divisão dos níveis hierárquicos evolutivos ................................29

Figura 8 - Esquema Cliente/Servidor............................................................

Figura 9 - Módulos que compõe o Ambiente de Aprendizado de GD

Figura 10 - Diagrama de Blocos do Ambiente Computacional de Suporte ao Aprendizado de GD

Figura 11 - Tela da Ferramenta de Desenho - applet................................44

Figura 12 - Opções de filtros para a busca de exercícios ........................46

Figura 13 - Grafo dos relacionamentos dos conceitos de GD................54

Figura 14 - Relacionamento de Pré-requisitos dos conceitos de GD 55

Figura 15 - Faixa de evolução cognitiva aplicada ao ambiente de acordo com a Taxonomia de Bloom ........................................59

Figura 16 - Exemplo da trajetória de um aluno ..........................................69

Figura 17 - Esquema do funcionamento do Módulo Tutor ......................73

Figura 18 - Diagrama de fluxo de dados do Sistema Tutor - Parte 1 
Figura 19 - Diagrama de fluxo de dados do Sistema Tutor - Parte 2

Figura 20 - Diagrama de fluxo de dados do Sistema Tutor - Parte 3

Figura 21 - Diagrama de fluxo de dados do Sistema Tutor - Parte 4

Figura 22 - Tela inicial do Ambiente de Aprendizado.................................78

Figura 23 - Tela de Cadastro de Usuário.....................................................80

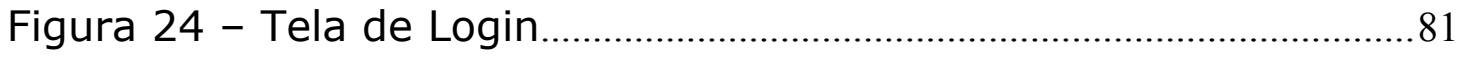

Figura 25 - Menu da área do aluno ………………....................................8

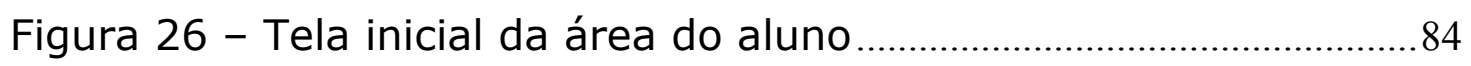

Figura 27 - Questão do Pré-teste 1 sem imagem .......................................84

Figura 28 - Questão do Pré-teste $1 \mathrm{com}$ imagem ......................................85

Figura 29 - Tela do aluno quando completar o pré-teste 1 ..................85

Figura 30 - Tela do aluno quando completar o pré-teste 2...................86

Figura 31 - Área do aluno com sugestões do Tutor ...................................86

Figura 32 - Tela do aluno quando completar a fase de aplicação de

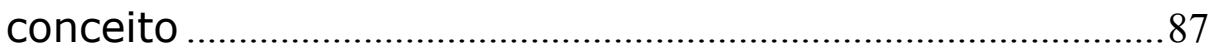

Figura 33 - Ferramenta gráfica para resolução de exercícios ...............87

Figura 34 - Botões da ferramenta de desenho...........................................90

Figura 35 - Menu da área do Docente …………………...........................90

Figura 36 - Tela para cadastro de turmas .................................................92

Figura 37 - Tela de cadastro de turma preenchida...................................93

Figura 38 - Tela inicial para cadastro de exercício ......................................94

Figura 39 - Tela de cadastro de exercício …………………………….......94 
Figura 40 - Inclusão do enunciado gráfico ……………………….............95

Figura 41 - Resolução do exercício ...............................................................96

Figura 42 - Seleção do resultado ………………………………………....96

Figura 43 - Seleção de conceitos abrangidos pelo exercício ..................97

Figura 44 - Busca de exercícios ......................................................................97

Figura 45 - Menu do administrador ............................................................98

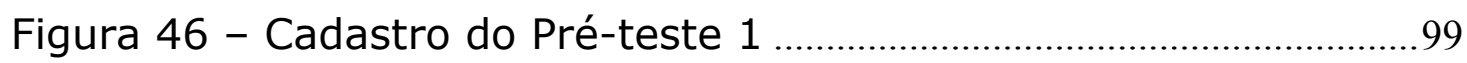

Figura 47 - Parâmetros de tempo para liberação do Pré-teste .........100

Figura 48 - Parâmetros Pedagógicos …………………………………....... 100

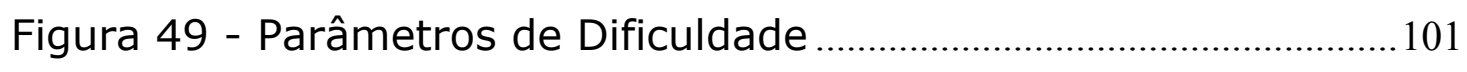

Figura 50 - Parâmetros de Erro para correção do exercício ..................101 


\section{LISTA DE TABELAS}

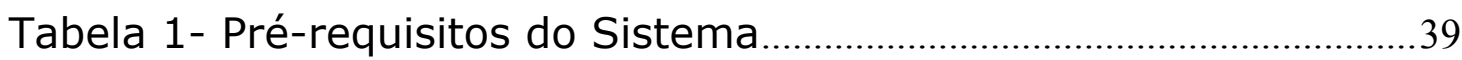

Tabela 2 - Conceitos de Geometria Descritiva ..........................................52

Tabela 3 - Pré-requisitos entre os conceitos de GD ...............................54

Tabela 4 - Estados assumidos pelos conceitos no histórico do aluno

Tabela 5 - Relação da codificação dos objetos da resposta do exercício 63

Tabela 6 - Ações possíveis armazenadas por exercício no histórico do aluno. 


\section{LISTA DE QUADROS}

Quadro 1 - Níveis da Taxonomia de Bloom e Colaboradores...............26

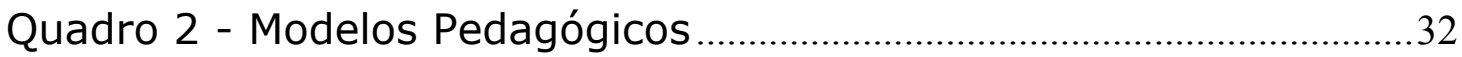

Quadro 3 - Metodologia para o desenvolvimento do ambiente de

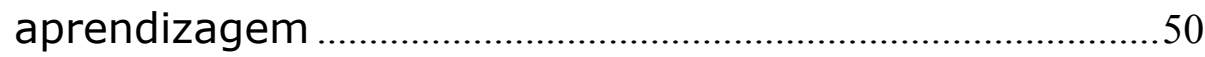

Quadro 4 - Script com a resolução de um exercício.....................................62

Quadro 5 - Interpretação da resposta do exercício .......................................64

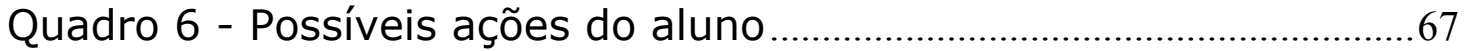

Quadro 7 - Possíveis causas das ações dos alunos......................................68 


\section{LISTA DE ABREVIATURAS E SIGLAS}

ARP - Aprendizado por Resolução de Problemas

CAI - Computer Assisted Instruction (Instrução Baseada em Computador)

CBT - Computer-Based Training (Treinamento Baseado em Computador)

CGI - Common Gateway Interface

EAD - Educação à Distância

GD - Geometria Descritiva

HTML - HyperText Markup Language

IA - Inteligência Artificial

ITS - Intelligent Tutoring Systems

PBL - Problem Based Learning

PHP - Hypertext PreProcessor

SGML - Standard Generalized Mark-up Language

STI - Sistemas Tutores Inteligentes

URL - Uniform Resource Locator

WWW - World Wide Web 


\section{INTRODUÇÃO}

Quando são mencionadas as palavras engenheiro e arquiteto, logo vem em mente a palavra "projeto". Esta associação faz-se em função da linguagem gráfica utilizada por estes profissionais em sua comunicação.

"Todo e qualquer projeto de Engenharia, Arquitetura ou Desenho Industrial precisa ser desenhado para ser construído. Esse desenho éo diálogo entre quem projeta e quem executa". (Pereira, 2001)

No entanto, para que a comunicação gráfica seja eficiente, a representação deve ser precisa. Desenhar imagens descritivas em uma superfície plana que representem de maneira clara, inequívoca e com exatidão objetos tridimensionais foi um desafio ilustrado desde os tempos mais remotos nos registros da história da civilização.

Hoje, os problemas de representação podem ser resolvidos por meio da Geometria Descritiva (GD), técnica amplamente recomendada e divulgada por Marmo:

"A Geometria Descritiva é o meio mais satisfatório para estabelecer um 'diálogo gráfico' entre um projetista e um executante de obras técnicas, permitindo ao primeiro transmitir e ao segundo captar as idéias sobre FORMA, TAMANHO e POSIÇÃO das referidas obras; sem essa 'linguagem gráfica', seria impraticável o exercício da Engenharia $e$ Arquitetura". (MARMO, 1974)

Na maioria dos cursos universitários de Engenharia, a disciplina Desenho Técnico é ministrada com o objetivo de fornecer os subsídios necessários para a representação de objetos e interpretação de projetos. 
Porém, dentro da sua carga horária curricular, geralmente pouco espaço é reservado à Geometria Descritiva, fato que causa uma série de dificuldades aos alunos. A importância da GD é enfatizada por Ulbricht:

"A disciplina de Geometria Descritiva é matéria formativa e imprescindivel para a formação dos profissionais que trabalham com a relação espaço-forma". (ULBRICHT, 1997)

Os obstáculos encontrados durante o estudo do Desenho Técnico são gerados, em grande parte, devido à falta dos conceitos precisos da Geometria Descritiva, sem os quais os problemas mais complexos dificilmente são resolvidos.

O ensino das representações por vistas ortográficas, fundamentadas nos conceitos de GD, tem como escopo capacitar os alunos a representar objetos espaciais no plano com formas e dimensões bem definidas. Porém, durante as aulas, nota-se que os aprendizes apresentam grande dificuldade em compreender estas representações gráficas. Um dos fatores que dificultam o entendimento do aluno é a falta de visão espacial devidamente desenvolvida.

Para Rondon (1994), a heterogeneidade das turmas não se fazia tão significativa quando disciplinas de Geometria Descritiva eram ministradas nos cursos de $1^{\circ}$ e $2^{\circ}$ graus.

Outro fator gerador de transtornos nas classes de GD é que a aquisição de novas habilidades (mentais e motoras) exige um tempo 
diferente para cada indivíduo, ou seja, o ritmo de aprendizagem não é o mesmo para todos. Por isto, o modelo tradicional de ensino presencial nem sempre atende a todos os estudantes e causa, muitas vezes, dificuldade em acompanhar as aulas e adquirir o conhecimento desejado provocando a sensação de fracasso.

"O fracasso do aluno em qualquer disciplina ocasiona, não somente sua perda de interesse pelo assunto, como também o desenvolvimento de uma aversão a ele". (OLIVEIRA E CHADWICK, 2001)

Considerando a variabilidade no ritmo de aprendizagem e a motivação dos alunos, chega-se à conclusão de que estes são alguns dos motivos pelos quais o ensino individualizado e de qualidade tem sido a razão de muitas pesquisas e projetos. A personalização do ensino também pode reverter quadros de aversões a disciplinas, induzindo o aprendiz a situações de sucesso naquela área.

Afirmações dos pesquisadores Chadwick e Oliveira de que ao mudar o ritmo de recepção de informações muda-se o nível de aprendizagem sugerem que, se o aprendiz puder utilizar o tempo que precisar, então ele conquistará o conhecimento esperado.

"Pesquisas indicam que, se uma pessoa recebe as informações necessárias em um ritmo que Ihe é adequado, seu desempenho melhora. Se ela é obrigada a trabalhar em um ritmo mais rápido, dificilmente obterá o domínio pleno dos objetivos pretendidos pelo professor. Isto não significa deixar o aluno por sua própria conta esperando que ele aprenda algum dia. O acompanhamento de sua evolução e o oferecimento de conteúdos alternativos utilizando diversas linguagens e meios o motivarão 
O parâmetro tempo também foi analisado, além de outros, por Dib (2002) em uma pesquisa desenvolvida para a UNESCO. Ele e sua equipe acompanharam o desenvolvimento de alunos, em sala de aula, onde utilizavam materiais didáticos de física do tipo auto-instrutivo. Foi concedido aos aprendizes o tempo que precisavam para concluir seus estudos. Todos os alunos, ao serem avaliados no final do trabalho, atingiram no mínimo $90 \%$ dos objetivos estabelecidos. Observaram então que, a liberação do tempo e a utilização de um material instrucional de qualidade diminuíram as diferenças individuais e fizeram com que todos os alunos alcançassem resultados uniformemente elevados.

Sabe-se que nos cursos tradicionais de Engenharia, em função do número excessivo de alunos e da carga horária pré-estabelecida, não há como praticar o ensino individualizado nem anular o fator limitante tempo. Sendo assim, uma sugestão para contornar este quadro é oferecer aos alunos ferramentas que se fundamentem nos princípios de Educação a Distância (EAD) como extensor do curso presencial. Técnicas de EAD podem possibilitar aos aprendizes a continuidade de seus estudos durante o tempo que precisarem para atingir o conhecimento desejado em GD.

"Educação a Distância pode ser entendida como uma forma de aprendizado onde as ações do professor e do aluno estão separadas no espaço e/ou no tempo". (SANTOS e RODRIGUES, 1999) 
De acordo com Santos e Rodrigues (1999), são algumas das características fundamentais de cursos à distância:

- Flexibilidade de horário: o que permite ao aprendiz dedicar-se ao curso nos horários que lhe for mais apropriado, considerando também a freqüência e a duração das suas sessões de estudo.

- Flexibilidade de lugar: ou seja, possibilitar ao estudante acessar o material do curso independentemente do local em que estiver, sem que para isto precise deslocar-se à escola.

- Flexibilidade de ritmo: o que permite ao estudante evoluir no estudo do conteúdo didático de acordo com sua velocidade de aprendizado pessoal.

- Acompanhamento: diz respeito à monitoração das atividades de cada aluno por instrutores ou pelo sistema.

Apesar de modalidades de EAD já existirem desde antes das tecnologias de informática, com o advento da Internet, as possibilidades e velocidade de interação dos aprendizes aumentaram substancialmente.

Sabe-se que a World Wide Web (WWW) é um importante canal de comunicação que pode ser utilizado para a disseminação em larga escala de cursos e treinamentos adaptáveis aos estudantes. Sendo assim, o início deste projeto foi pesquisar os cursos de Geometria Descritiva disponíveis na Internet. Verificou-se que muitos deles contemplam a parte teórica do ensino 
deste tema. Na maioria destes casos, a prática é apenas sugerida. Cursos assim são chamados de "livros eletrônicos", cujos conteúdos geralmente são as exposições de conceitos repletas de animações para exemplificar os teoremas de GD. Alguns destes cursos oferecem avaliações na forma de testes de múltipla escolha para que os alunos verifiquem seu aprendizado e sugerem listas de exercícios.

Para o aprendizado de Geometria Descritiva, no entanto, é necessário que os alunos, além de conhecerem as regras, possuam também habilidades para utilizá-las de maneira apropriada como ferramentas para a solução de problemas práticos em suas atividades projetuais. Sendo assim, para que os estudantes adquiram a capacidade desejada, uma das metodologias mais utilizadas nos cursos presenciais de GD tem sido a Resolução de Problemas.

Em várias áreas de conhecimento, os Sistemas Tutores Inteligentes (Intelligent Tutoring Systems - ITS) têm sido empregados no desenvolvimento de ambientes de ensino adaptáveis, os quais interagem com os usuários e encaminham seu aprendizado. Eles são arquitetados com base em estratégias pedagógicas e empregam técnicas de Inteligência Artificial (IA).

Considerando a falta de ferramentas computacionais que amparem o estudo da Geometria Descritiva e que ela é fundamental para o desenvolvimento dos futuros engenheiros e arquitetos, justifica-se a 
importância do desenvolvimento de ambientes computacionais interativos e inteligentes que se dediquem a este fim. Sendo assim, esta pesquisa teve como objetivo fundamentar, desenvolver e implementar um Ambiente Computacional de Suporte ao Aprendizado de Geometria Descritiva capaz de se adaptar à trajetória do aluno, direcionando-o nos estudos de acordo com sua necessidade.

O sistema, com base em uma biblioteca de exercícios de GD e seguindo uma estratégia pedagógica, sugere caminhos que conduzirá o aprendiz a níveis cada vez mais elevados em seus estudos. Desta forma, os conceitos teóricos são assimilados e experimentados aos poucos, habilitando os alunos de modo que possam seguir para desafios cada vez mais complexos.

A cada interação, serão avaliados quais conceitos o aluno já conhece e, com base nestes dados, novos exercícios serão sugeridos de modo gradual, bem como, quando for o caso, uma lista com as teorias básicas que ele deverá estudar.

Desta forma, os principais objetivos durante o desenvolvimento desta pesquisa foram:

- Auxiliar e motivar os alunos, em nível de graduação, no aprendizado de Geometria Descritiva, oferecendo-lhes uma área personalizada, com sugestões e dicas de estudos 
individualizados e que interaja respondendo de acordo com a necessidade de cada um, de modo a encaminhá-los durante seu aprendizado;

- Possibilitar aos estudantes de GD que o acompanhamento de suas atividades seja feito por um Sistema Tutor, que respeite seu ritmo de aprendizado e nível de desenvolvimento;

- Fornecer ferramentas computacionais que contemplem as necessidades específicas do ensino a distância de disciplinas relacionadas à representação gráfica;

- Disponibilizar uma Biblioteca de Exercícios de GD on-line onde docentes e alunos possam buscar e gravar exercícios específicos sobre determinado tópico ou enfoque;

Concluindo, o ambiente de aprendizagem sugerido nesta tese consiste na composição de vários módulos computacionais que permitem a interação do aprendiz, via web, com um Sistema Tutor de Geometria Descritiva por meio da resolução de exercícios. 
O escopo desta pesquisa engloba os seguintes tópicos:

- Modelagem do domínio de GD;

- Fundamentação teórica dos modelos educacionais;

- Desenvolvimento de uma estratégia pedagógica para ser implementada no módulo de tutoria do ambiente de aprendizagem;

- Integração da Ferramenta de Desenho interativa, já desenvolvida, ao ambiente de aprendizagem;

- Criação e desenvolvimento da Interface web do ambiente de aprendizagem;

- Elaboração e implementação das tabelas e relacionamentos do Banco de Dados do sistema desenvolvido;

- Desenvolvimento e população da Biblioteca de Exercícios de GD.

A metodologia utilizada para a realização deste trabalho envolveu:

- Definição do domínio de conhecimento de GD bem como conceitos básicos de representação gráfica, para estabelecer o escopo exato a ser abrangido pelo sistema;

- Realização de um estudo sobre metodologias educacionais 
para definição das estratégias pedagógicas que possibilitem o auto-aprendizado de GD;

- Elaboração de um grafo de pré-requisitos para nortear o aprendizado e possibilitar o desenvolvimento do sistema tutor;

- Modelagem e implementação de uma biblioteca de exercícios de GD;

- Elaboração e desenvolvimento dos bancos de dados envolvidos no ambiente de aprendizado;

- Estudo da Ferramenta de Desenho (applet java), desenvolvida em parceria com o IME-USP.

- Modelagem da interface de acesso para entrada, gerenciamento e saída de dados, bem como a manipulação do ambiente.

A seguir, está descrita a organização desta tese.

O capítulo 2 apresenta uma caracterização do ensino tradicional de Geometria Descritiva e de como programas e ambientes de hipermídia podem apoiá-lo.

O capítulo 3 discute as Teorias de Instrução e as fundamentações 
pedagógicas que se aplicam a ambientes interativos de aprendizado, bem como Aprendizagem por Resolução de Problemas, Descoberta Guiada e Abordagem Investigativa.

O capítulo 4 descreve a arquitetura do Ambiente Computacional de Suporte ao Aprendizado de Geometria Descritiva e a utilização da ferramenta de desenho desenvolvida pelos departamentos de Ciência da Computação (IME) e de Engenharia de Construção Civil (Poli) da USP.

O capítulo 5 descreve e fundamenta o Módulo Pedagógico do Ambiente Computacional de Suporte ao Aprendizado de Geometria Descritiva baseado em Sistema Tutor.

O capítulo 6 apresenta a Biblioteca de Exercícios de Geometria Descritiva, sua estrutura, seu funcionamento e suas aplicações.

O capítulo 7 apresenta a Interface web, bem como sua arquitetura, seguindo diretrizes de usabilidade, suas possibilidades de utilização e sugestões para seu aprimoramento.

O capítulo 8 engloba conclusões e sugestões para trabalhos futuros. 


\section{Contribuições desta tese}

Ao término deste projeto, o piloto de um novo ambiente computacional de aprendizado estará disponível (aberto) para a comunidade. Sua utilização, a princípio nos cursos da Escola Politécnica, da Faculdade de Arquitetura e Urbanismo e do Instituto de Geociências da USP, irá gerar dados estatísticos importantes que poderão subsidiar novas pesquisas e trabalhos relacionados ao ensino presencial ou à distância de Geometria Descritiva.

Espera-se ao final desta tese de doutorado:

- Ter modelado o domínio de Geometria Descritiva de uma forma lógica e organizada hierarquicamente;

- Ter definido a estratégia pedagógica para um Sistema Tutor de GD;

- Ter um protótipo do Ambiente computacional de Aprendizado de Geometria Descritiva implementado e pronto para ser utilizado;

- Ter a Biblioteca de Exercícios de Geometria Descritiva em funcionamento, alimentada com vários exercícios de cada assunto e com acesso livre via Internet. 
Esta tese pretende gerar publicações nas áreas de educação, educação à distância, representação gráfica e engenharia e sobre o funcionamento deste ambiente computacional de aprendizado, no intuito de contribuir positivamente para a elaboração de novos programas de ensino. 


\section{O ENSINO DE GD APOIADO PELA INFORMÁTICA}

As dificuldades específicas da disciplina de GD, a heterogeneidade das turmas e o pouco tempo atribuído a ela nos currículos dos cursos de Engenharia e Arquitetura têm motivado a utilização de ferramentas computacionais para auxiliar os alunos nos estudos de GD.

Muitos aplicativos computacionais e materiais didáticos que inicialmente foram elaborados para serem utilizados como apoio ao ensino presencial, hoje em dia são aplicados em programas de educação à distância e estão disponíveis na Internet.

Pesquisando por material instrucional apoiado por computadores a respeito de Geometria Descritiva, verificou-se que grande parte do conteúdo encontrado contempla a parte teórica do ensino tradicional, sendo a prática apenas sugerida.

No entanto, nos cursos presenciais de GD, a prática necessariamente mescla-se à teoria. Em conjunto, elas fornecem aos alunos conceitos, teoremas, definições, notações e procedimentos que propiciam a aquisição de habilidades de concepção e representação gráfica. A prática é que possibilita aos alunos a construção, solidificação e fixação do seu conhecimento em GD.

Um exemplo de tutorial disponível na Internet é o Hypergeo 
(http://www.fc.unesp.br/nucleos/multimeios/cursos/hypergeo) - Figura 1, desenvolvido no Departamento de Representação Gráfica da UNESP Campus de Bauru, pelas professoras Maria Antonia B. Giunta e Vânia C. P. N. Valente.

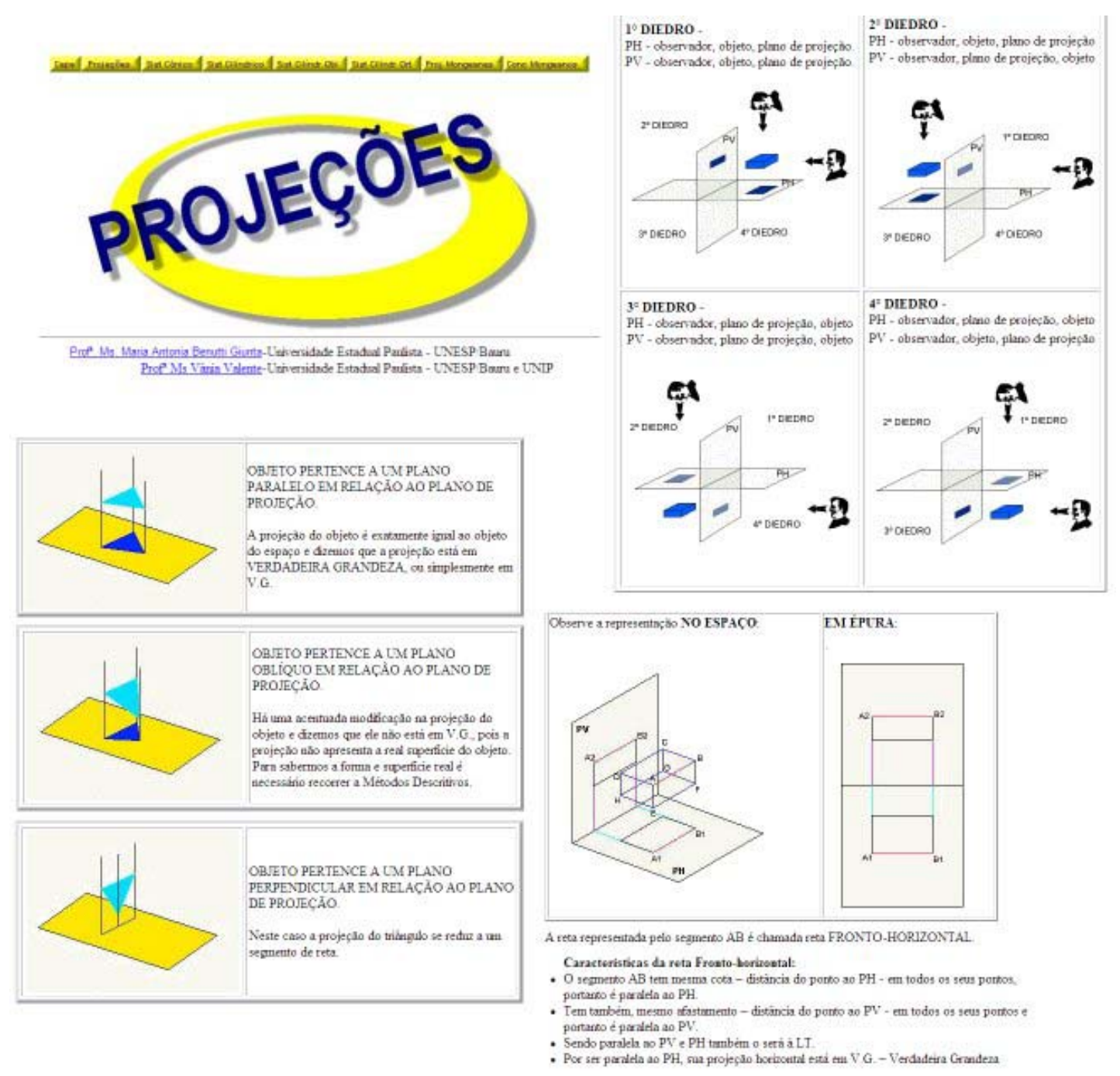

Figura 1 - Telas do sistema Hypergeo

As animações contidas na maioria destes "livros eletrônicos" demonstram como as projeções são utilizadas para a representação de objetos tridimensionais no plano. Recursos deste tipo auxiliam muito os alunos com dificuldade de abstração e visão espacial. 
Outro exemplo é o portal Geométrica - Figura 2, desenvolvido pela Professora Maria Bernadete Barison do Departamento de Matemática da Universidade Estadual de Londrina (http://www.mat.uel.br/geometrica).

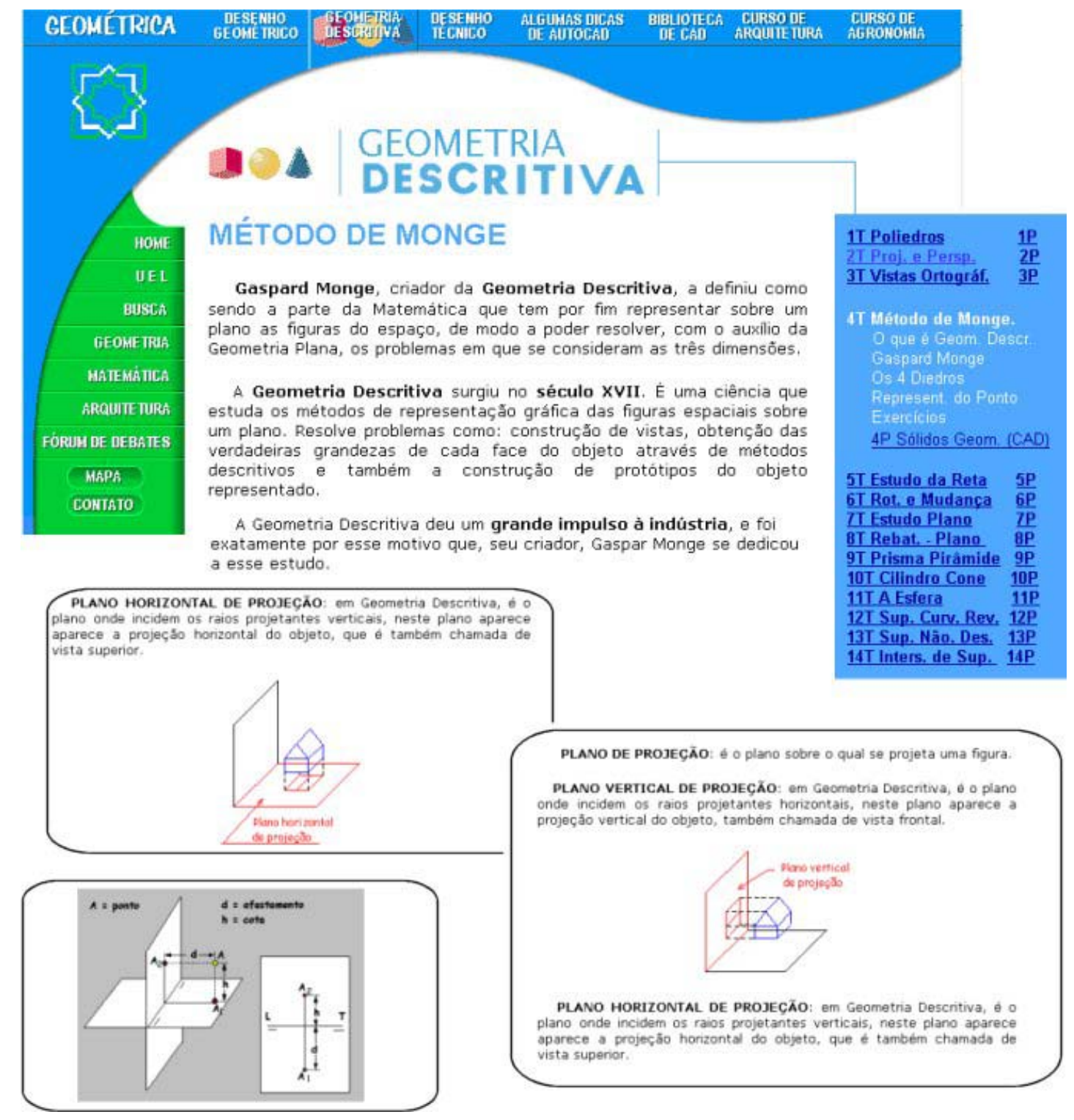

Figura 2 - Telas do Geométrica

Os anais dos congressos que abrangem temas de Representação Gráfica, como o "Graphica 98", "Graphica 2000", "Graphica 2001" e "Graphica 2003", demonstram a preocupação dos docentes de disciplinas 
relacionadas a estas técnicas, em fornecer cada vez mais subsídios educacionais para seus alunos. Isto comprova-se nos artigos referentes a experiências de desenvolvimento de sistemas próprios e da utilização de aplicativos gráficos comerciais como AutoCAD, 3DStudio e CorelDraw nos cursos tradicionais.

O Visual GD, desenvolvido pelas professoras Marília M. Gonçalves e Vânia Ribas Ulbricht da Universidade Federal de Santa Catarina, é um ambiente hipermídia para o estudo dos conteúdos básicos da Geometria Descritiva.

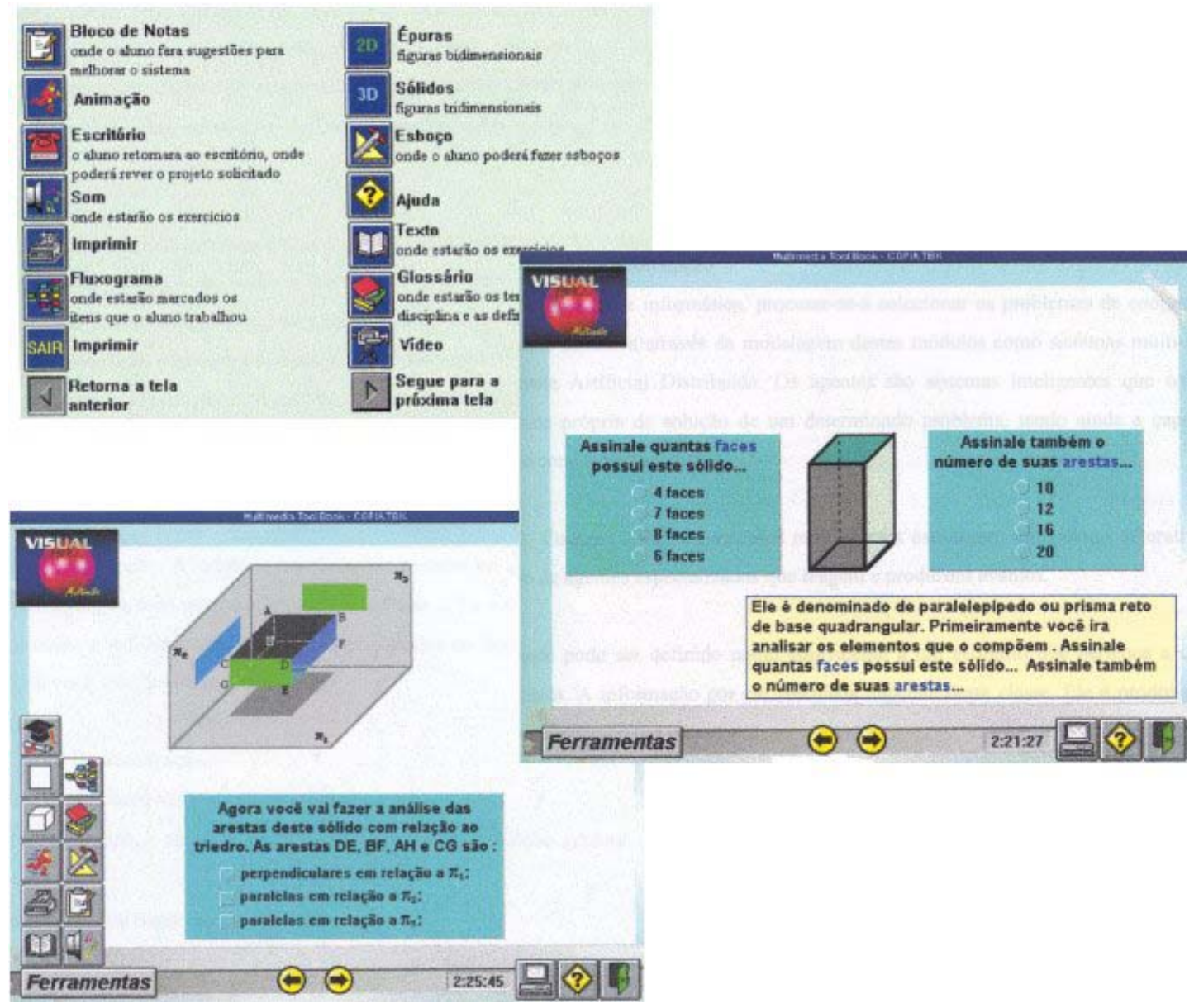

Figura 3 - Telas do Visual GD 
O Visual GD possibilita ao estudante interagir construtivamente em atividades projetuais, utilizando um escritório de apoio como metáfora do ambiente. Foi implementado através do software de autoria ToolBook, apoiado no Auto-CAD e 3D Studio.

Também têm sido inseridos com freqüência nas aulas de GD dois programas especificamente desenvolvidos para o ensino da Geometria gráfica: o Cabri-géomètre e o Geometer's Sketchpad.

O Cabri-géomètre (http://www-cabri.imag.fr/), cuja interface está ilustrada na Figura 4, foi desenvolvido na Universidade Joseph Fourier de Genebra por Yves Baulac, Frank Bollemain e Jean-Marie Laborde.

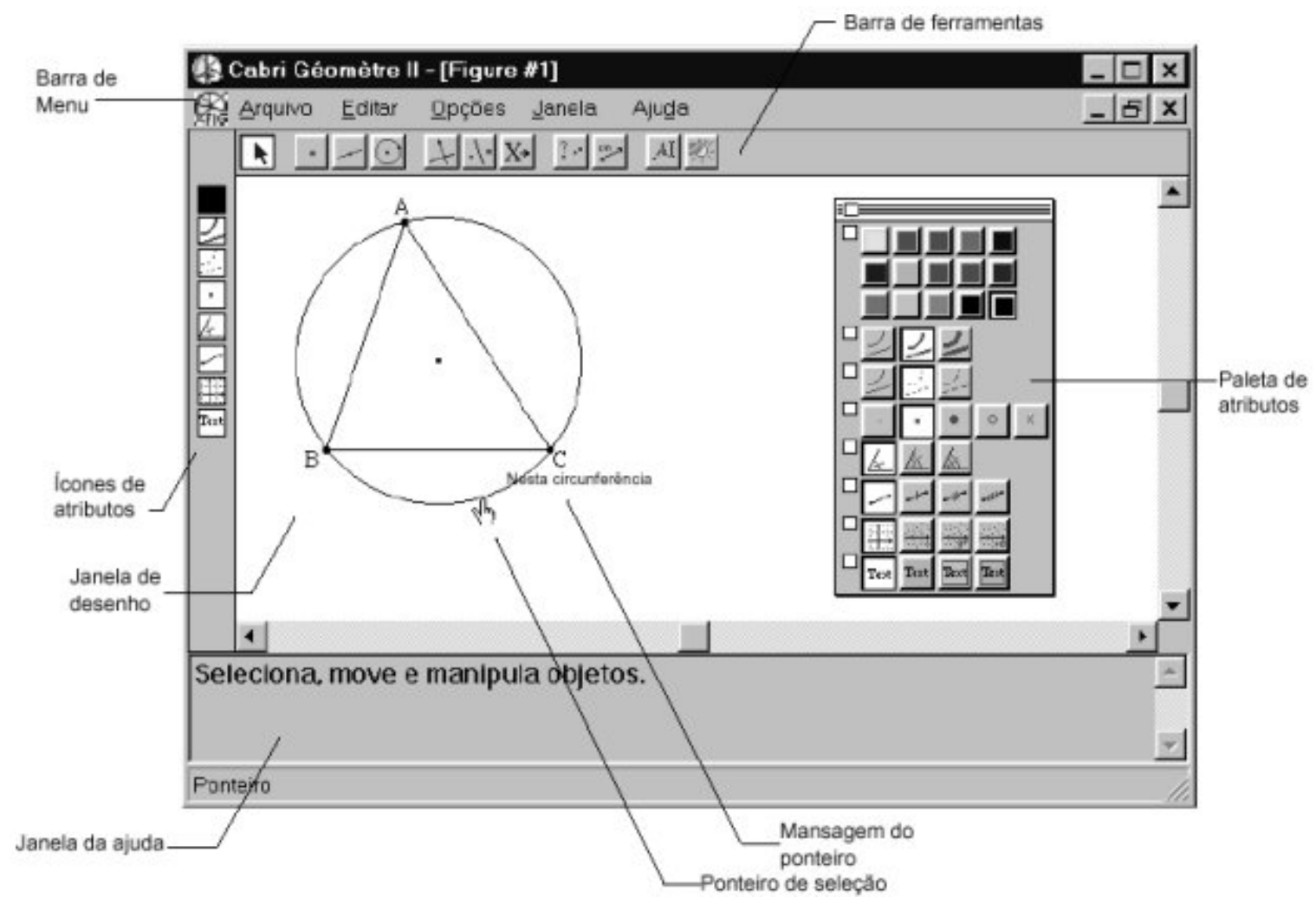

Figura 4 - Tela do Cabri 
Já o Geometer's Sketchpad cuja interface está representada na

Figura 5, foi desenvolvido por Nicholas Jackiw e é comercializado pela Key Curriculum Press dos EUA (http://www.keypress.com/sketchpad/index.html).

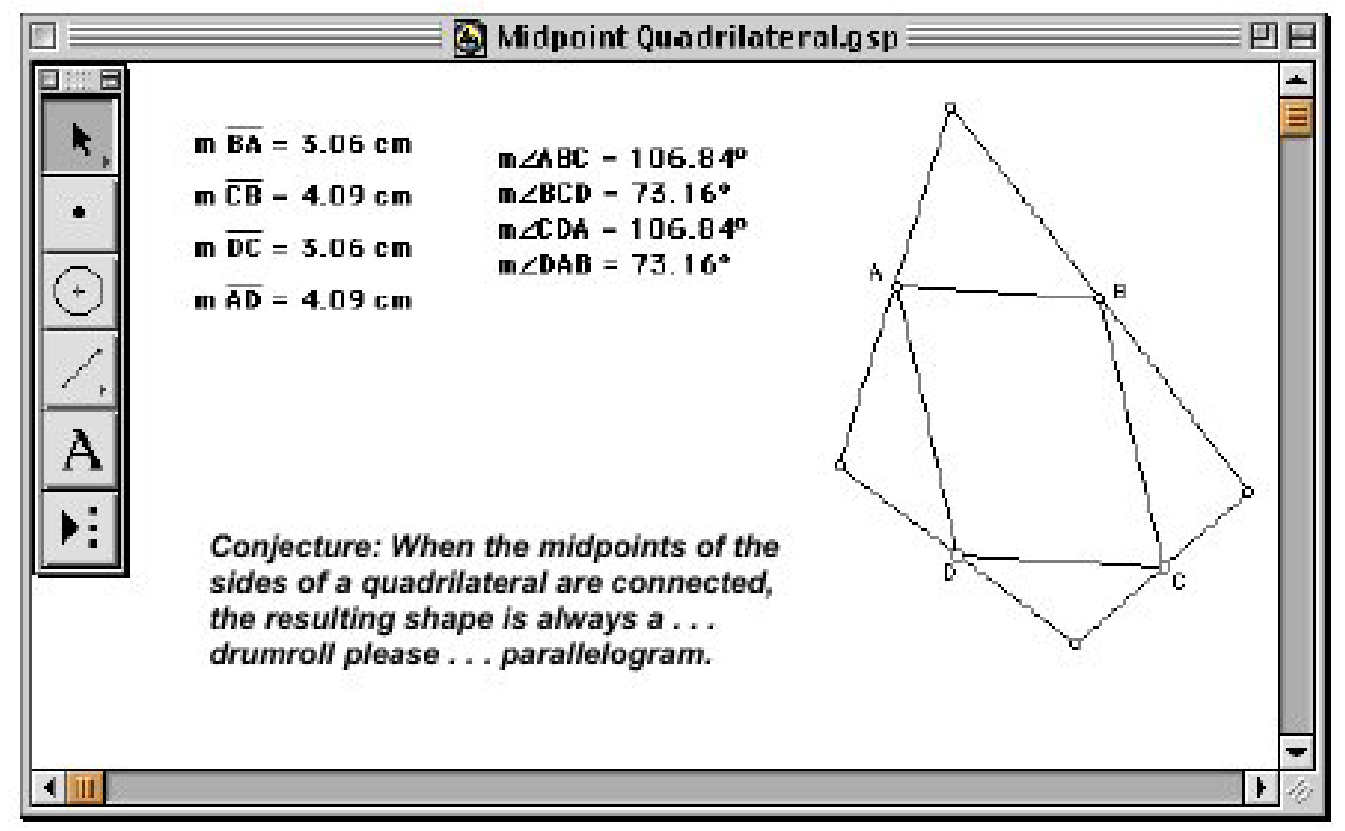

Figura 5 - Tela do Sketchpad

\subsection{Sistemas Tutores Inteligentes}

Desde a década de 60, recursos computacionais têm sido utilizados como ferramentas auxiliares às práticas de ensino. De acordo com McArthur (1993) e Beck (1998), os primeiros sistemas voltados para aplicações educacionais utilizando computadores foram o "Treinamento Baseado em Computador" (Computer-Based Training - CBT) e a "Instrução Baseada em Computador" (Computer Assisted Instruction - CAI). 
Urban-Lurain (1998) descreve que sistemas CAI e CBT, aplicavam um conjunto de problemas para auxiliar os estudantes a aumentarem seu desempenho, porém as instruções não eram individualizadas, ou seja, não consideravam a necessidade de cada aluno.

McArthur (1993) considera ainda que a atenção individualizada que faltava nos sistemas CAI e CBT, poderia ser oferecida por sistemas que, além de ter foco no conteúdo, considerassem o conhecimento do estudante sobre o domínio em questão. Neste sentido, surgiu uma nova proposta de sistema: os Sistemas Tutores Inteligentes (Intelligent Tutoring Systems ITS).

De acordo com Viccari (1991), um sistema tutor inteligente é um sistema que possui a capacidade de ensinar e aprender. Ou seja, um sistema que possibilita adequar as estratégias de ensino às necessidades de cada aluno a partir da simulação do comportamento de um instrutor humano e da simulação do estado cognitivo do aluno.

Segundo Polson (1988), estes sistemas surgiram da aplicação da Inteligência Artificial (IA) na educação e vieram aprimorar a tradicional instrução assistida por computador. O objetivo do emprego de técnicas de tutoria inteligente é proporcionar uma instrução adaptada ao aluno.

Sistemas Tutores Inteligentes (STI) são sistemas instrucionais baseados em computadores cujos modelos de conteúdos especificam o que 
ensinar e as estratégias de ensino especificam como ensinar (Wenger 1987; Ohlsson 1987 apud Murray 1999). São sistemas computacionais que permitem um ambiente onde se pretende fornecer instruções personalizadas ao aprendiz.

STI's buscam simular certos aspectos da inteligência humana com o auxílio do computador. Segundo Lermen (1994), esta simulação seria a de um verdadeiro professor (humano) cujo papel seria realizado pela máquina.

Desde o surgimento dos STI's, na década de 70, até os dias de hoje, muitas pesquisas vêm sendo conduzidas a fim de se modelar e implementar ambientes que possam atingir os propósitos de tutoria com o maior grau de qualidade pedagógica e técnica.

Quando se fala em STI, imediatamente emerge a questão da complexidade inerente à modelagem e, conseqüentemente, implementação destes sistemas.

Segundo Viccari (1991), no processo de tutoria através de um STI, o aluno aprende fazendo. O sistema não ensina, o aluno é que aprende. Nestes sistemas existe uma interação entre o tutor e o aluno, onde informações são trocadas entre ambos, oferecendo um ambiente onde o tutor possa monitorar o progresso do estudante. 
Os Sistemas Tutores Inteligentes devem apresentar três características que denotam inteligência:

1. Ter capacidade de fazer inferências sobre o domínio, ou seja, o conteúdo a ser conhecido pelo aluno;

2. Possuir mecanismos de avaliação do aluno;

3. Operar de acordo com estratégias pedagógicas de modo a minimizar a diferença entre o aprendiz e o especialista.

As arquiteturas de STI variam de uma implementação para outra e, segundo Oliveira (1994), possuem uma organização básica com alguns componentes funcionais (ilustrados na Figura 6) que podem ser observados na maioria dos casos.

Os componentes básicos de um STI são:

- Modelo do conhecimento ou domínio - define o conhecimento contido no domínio a ser ensinado. Neste módulo está armazenado todo o conhecimento que o sistema tem sobre um determinado assunto. A principal preocupação na implantação deste módulo é como o domínio ficará representado e poderá ser acessado.

- Modelo de aluno ou aprendiz - é capaz de definir o conhecimento do aluno em cada ponto durante a instrução. Ele 
é responsável por manter informações detalhadas sobre a evolução do estudante no assunto. Vale ressaltar que ele guarda informações individualizadas, ou seja, é personalizado para cada estudante que utiliza o sistema.

- Módulo tutor - responsável pelas estratégias de ensinoaprendizagem. Ele, de acordo com o perfil do aluno e do conhecimento armazenado no módulo do domínio, seleciona o assunto a ser apresentado e possui estratégias para determinar quando o estudante necessita de ajuda e fornecer a ajuda necessária.

- Interface com o usuário - permite a interação do estudante com os módulos do STI.

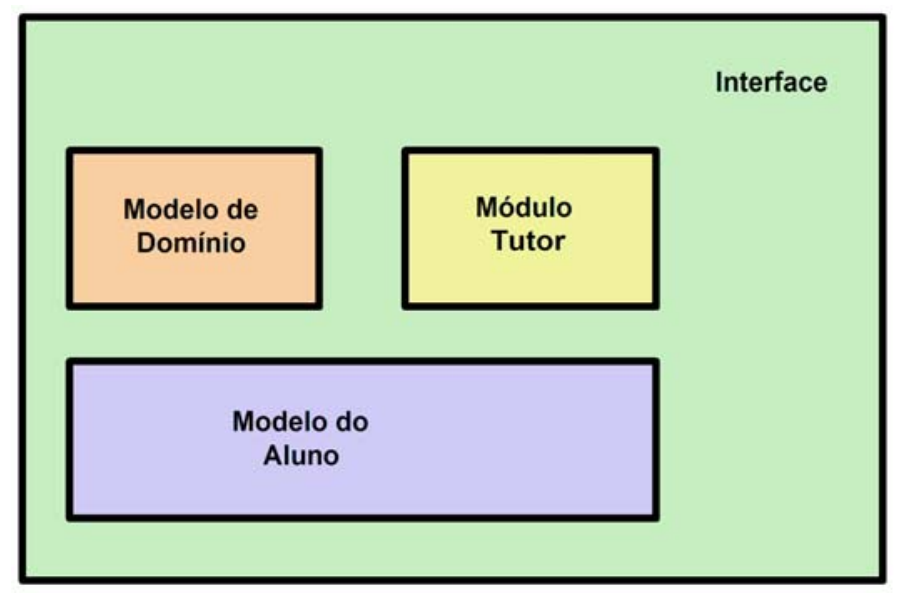

Figura 6 - Representação dos elementos básicos de um STI 


\section{FUNDAMENTAÇÕES PEDAGÓGICAS PARA UMA PROPOSTA DE AMBIENTE DE APRENDIZADO COMPUTACIONAL}

"Se você não está certo de para onde vai, pode chegar a qualquer lugar". (MAGER, 1962)

Esta frase ilustra, com muita propriedade, a necessidade de objetivos e metas e se aplica às atividades de ensino. Antes de adotar qualquer estratégia pedagógica, é necessário estabelecer os objetivos educacionais, ou seja, as competências que o aluno deve ter ao término do curso.

"A explicitação dos objetivos, além de direcionar as atividades didáticas, também fornece subsídios para avaliações, tanto do desempenho dos alunos quanto da eficácia do método de ensino". (OLIVEIRA, 1988)

Nesta pesquisa, onde é proposto um ambiente de aprendizagem de Geometria Descritiva, a importância em definir claramente os objetivos desejáveis que os alunos alcancem é enfatizada pelo fato destes fornecerem um guia para o desenvolvimento do material de estudo.

O sistema adotado neste trabalho para direcionar a classificação dos objetivos na área de GD foi a Taxonomia de Bloom por este, conforme expõe Dib (1974), apresentar de forma sistemática os diferentes níveis de comportamentos que podem ser alcançados pelos aprendizes. 


\subsection{Taxonomia de Bloom}

Segundo Pfromm (1987), em 1948 os educadores Benjamin S. Bloom, M. Englehart, E. Furst, W. Hill, e D Krathwohl, propuseram-se a desenvolver um sistema de classificação para três domínios: o cognitivo, o afetivo e o psicomotor. A razão desta pesquisa era sistematizar uma classificação de objetivos educacionais, para fins de avaliação escolar e planejamento de currículo.

Largamente disseminado, o trabalho no domínio cognitivo foi concluído em 1956 e é normalmente referenciado como "Taxonomia do Domínio Cognitivo de Bloom", ou "Taxonomia de Bloom", ou ainda "Taxonomia de Bloom e colaboradores". O título completo da referida obra é "Taxonomia de objetivos educacionais: Uma classificação de metas educacionais. Manual I: Domínio Cognitivo".

A idéia central desta taxonomia é que objetivos educacionais podem ser declarados do mais simples ao mais complexo. Bloom (1972) enfatiza também que existem vários tipos de aprendizado, do mais superficial ao mais profundo.

A taxonomia é apresentada no Quadro 1 - com amostras de verbos e de declarações de desempenho para cada nível. 


\begin{tabular}{|c|c|c|c|}
\hline Nível & $\begin{array}{l}\text { Classificação } \\
\text { Taxonômica }\end{array}$ & Definição do aprendizado em cada nível & $\begin{array}{l}\text { Exemplos de } \\
\text { infinitivos } \\
\text { utilizados para } \\
\text { mensurar o } \\
\text { aprendizado }\end{array}$ \\
\hline 1 & CONHECIMENTO & $\begin{array}{l}\text { Neste nível de aprendizado o aluno armazena em } \\
\text { sua memória as informações, idéias e princípios na } \\
\text { forma em que Ihes foram apresentados. }\end{array}$ & $\begin{array}{l}\text { Definir, identificar, } \\
\text { listar, rotular, } \\
\text { nomear. }\end{array}$ \\
\hline 2 & COMPREENSÃO & $\begin{array}{l}\text { A partir deste nível o aluno inicia o processo de } \\
\text { entendimento, no qual ele traduz, compreende ou } \\
\text { interpreta as informações. }\end{array}$ & $\begin{array}{l}\text { Traduzir, explicar, } \\
\text { resumir, ordenar, } \\
\text { diferenciar. }\end{array}$ \\
\hline 3 & APLICAÇÃO & $\begin{array}{l}\text { Neste nível o aluno deve ser capaz de aplicar os } \\
\text { conceitos adquiridos. }\end{array}$ & $\begin{array}{l}\text { Resolver, aplicar, } \\
\text { construir, } \\
\text { desenvolver. }\end{array}$ \\
\hline 4 & ANÁLISE & $\begin{array}{l}\text { A partir deste nível o aluno deve tornar-se apto a } \\
\text { analisar, separar e hierarquizar os conceitos } \\
\text { adquiridos anteriormente. }\end{array}$ & $\begin{array}{l}\text { Analisar, classificar, } \\
\text { comparar, deduzir }\end{array}$ \\
\hline 5 & SÍNTESE & $\begin{array}{l}\text { Neste nível o aluno já é capaz de gerar idéias de } \\
\text { modo a formar novas estruturas. }\end{array}$ & $\begin{array}{l}\text { Planejar, propor, } \\
\text { elaborar, formular, } \\
\text { modificar. }\end{array}$ \\
\hline 6 & AVALIAÇÃO & $\begin{array}{c}\text { Aqui o aluno aprecia, avalia ou faz julgamentos } \\
\text { com base nos padrões formulados } \\
\text { anteriormente. }\end{array}$ & $\begin{array}{l}\text { Julgar, argumentar, } \\
\text { comparar, } \\
\text { contrastar. }\end{array}$ \\
\hline
\end{tabular}

Quadro 1 - Níveis da Taxonomia de Bloom e Colaboradores

\subsection{Objetivos educacionais de GD propostos aos alunos de Engenharia}

Os objetivos em um programa educacional direcionam as

atividades de aprendizagem e fornecem critérios para a avaliar sua ocorrência.

Para os alunos de Engenharia, as disciplinas de representação gráfica têm como propósito desenvolver sua capacidade de representação e interpretação de projetos.

A Geometria Descritiva, em especial, contribui na formação dos 
futuros engenheiros fornecendo teoremas e procedimentos que permitem a resolução de problemas relativos às representações gráficas de elementos tridimensionais no plano.

Sendo assim, podem ser considerados como objetivos principais a serem alcançados no estudo da Geometria Descritiva o desenvolvimento das seguintes competências:

- Visão espacial;

- Capacidade de representar elementos tridimensionais no plano, indicando corretamente sua forma, tamanho e posição relativa;

- Capacidade de interpretar representações gráficas no plano e

- Resolver problemas geométricos espaciais no plano.

\subsection{Objetivos educacionais nos cursos de GD}

De acordo com as competências desejáveis que o aluno adquira em um programa de aprendizado de Geometria Descritiva, foram inicialmente selecionados neste trabalho, como metas de aprendizado, os seguintes conceitos que ele deve, ao fim dos estudos, conhecer e saber aplicar:

- Conceito de ponto;

- Conceito de reta; 
- Conceito de posições relativas entre retas;

- Conceito de plano;

- Conceito de posições relativas entre planos;

- Conceito de posições de reta em relação ao plano;

- Indicação de plano;

- Conceito de projeção, projeção cilíndrica;

- Sistema de Projeção Mongeano;

- Propriedade da conservação do perpendicularismo;

- Propriedade da conservação do paralelismo;

- Conceito e propriedade da Verdadeira Grandeza;

- Conceito de projeções horizontal e vertical;

- Conceito de projeção de ponto;

- Conceito de projeção de reta;

- Conceito de Traço, Traço de reta, Traço de plano;

- Retas em posições particulares e respectivas épuras

- Planos em posições especiais;

- Conceito de reta de maior declive;

- Conceito e propriedades de pertinência;

- Ponto em reta;

- Ponto em plano;

- Reta em plano;

- Conceito de intersecção (duas retas, reta e plano, dois planos);

- Projeções de reta perpendicular a plano (point view);

- Mudança de Plano de Projeção.

Com foco nestes tópicos, foram traçadas metas graduais de aprendizado com base na Taxonomia de Bloom. 
A Figura 7 representa a divisão dos níveis hierárquicos evolutivos a serem galgados pelo aprendiz durante seu estudo de GD.

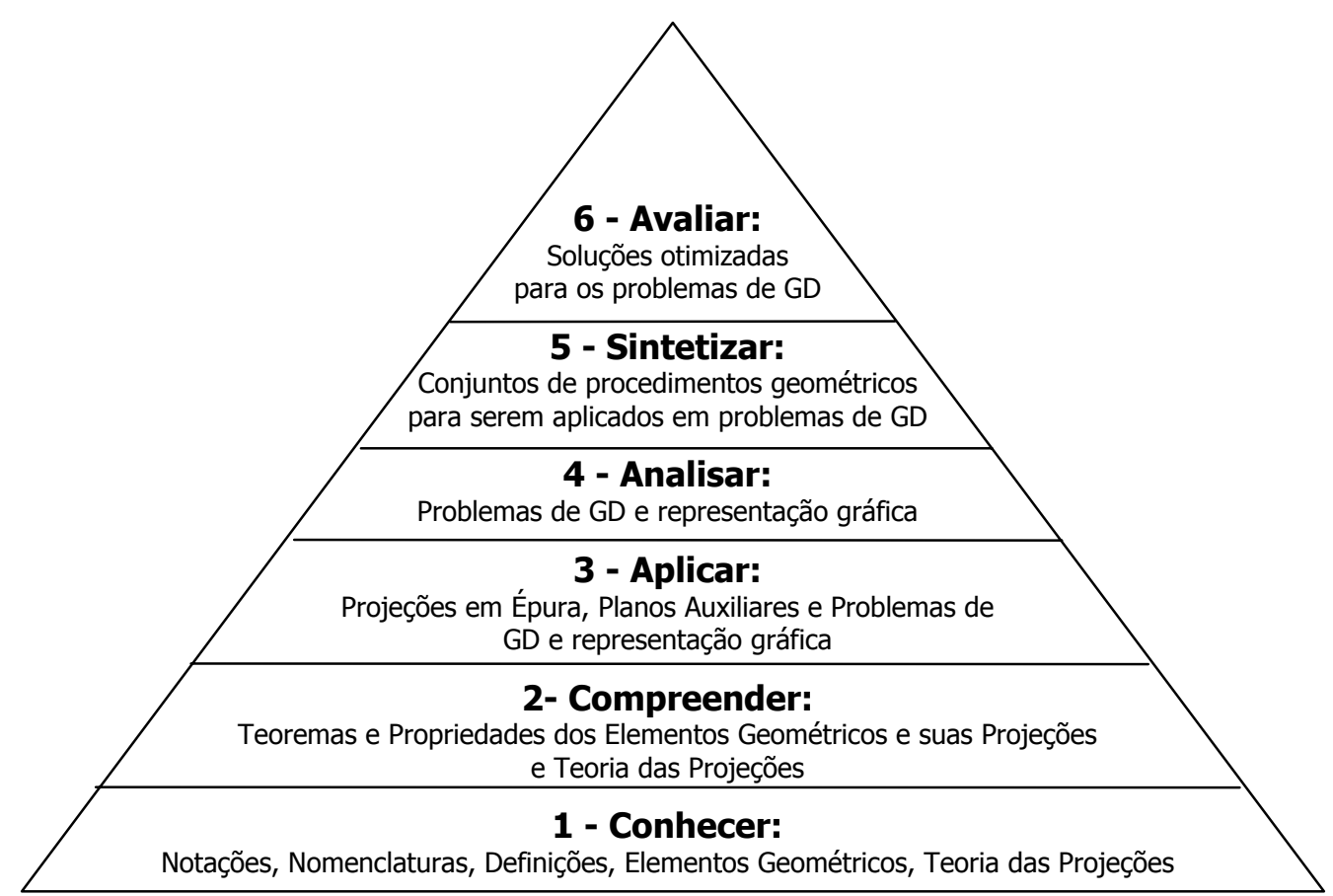

Figura 7 - Divisão dos níveis hierárquicos evolutivos

O ambiente computacional proposto neste trabalho contempla os níveis de aprendizado 3 e 4 da Taxonomia de Bloom, ou seja, propicia aos alunos o desenvolvimento de capacidades de Aplicação e Análise, em relação à representação gráfica subsidiada pela Geometria Descritiva. Isto se justifica devido à estratégia pedagógica adotada em sua idealização totalmente fundamentada na aprendizagem por resolução de problemas.

Por outro lado, os conteúdos especificados nos níveis 1 e 2 do gráfico acima, ou seja, de Conhecimento e de Compreensão, englobam os conceitos teóricos de GD que devem ser assimilados pelos alunos. Para 
tal, como enfatizado anteriormente, existem vários materiais disponíveis em mídias expositivas, como livro, livro eletrônico e multimídia educativa que abrangem esta etapa de aquisição conceitual.

\subsection{Aspectos Pedagógicos a serem considerados no aprendizado de Geometria Descritiva}

Considerando as metas selecionadas, fica evidente que os alunos precisam conhecer os conceitos de Geometria Descritiva, bem como seus teoremas e possuir habilidades para concepções estratégicas. Sendo assim, para que os alunos adquiram a capacidade desejada, uma das metodologias mais utilizadas nos cursos de GD tem sido a Resolução de Problemas.

A aprendizagem pela resolução de problemas em GD implica em uma tarefa na qual os alunos constroem seu conhecimento manipulando os elementos gráficos e seguindo regras teóricas, de modo a integrá-lo às suas estruturas cognitivas até descobrir suas associações e inter-relações.

"Em psicologia, problema geralmente significa uma situação na qual o organismo, motivado para atingir algum alvo, é bloqueado nesse empenho em virtude da existência de um ou vários obstáculos. É interessante notar que, de acordo com um antigo e emérito estudioso, resolver problemas e aprender são processos que praticamente se confundem. Ambos supõem a existência de uma situação problemática e um processo de ajustamento ou adaptação do organismo a essa situação". (DASHIEL, 1935 apud PFROMM, 1987).

A citação acima, de 1935, confirma que, de longa data, a resolução de problemas é reconhecidamente um caminho eficiente para o 
aprendizado. Este consenso fundamentou a elaboração de várias estratégias pedagógicas que foram sintetizadas e registradas. Cada qual com suas especificidades gerou variações e são aplicadas desde os cursos de ensino fundamental até os de níveis mais altos.

\subsection{Modelos Pedagógicos que aplicam a Aprendizagem por Resolução de Problemas}

Descoberta Guiada, Resolução de Problemas e Abordagem Investigativa são modelos pedagógico/didáticos centrados no aluno que inserem a resolução de problemas em suas atividades visando seu desenvolvimento substancial.

Gijselaers (1996) explica que a "aprendizagem baseada em problemas" deriva da teoria de que a aprendizagem é um processo no qual quem aprende constrói ativamente o conhecimento.

Ernest (1991) elaborou o Quadro 2 comparando as responsabilidades dos professores e dos alunos nos métodos pedagógicos citados anteriormente.

\begin{tabular}{lll}
\hline Modelo & Papel do professor & Papel do aluno \\
\hline Descoberta Guiada & - Formula o problema ou & - Segue a orientação. \\
& escolhe a situação tendo \\
& o objetivo em mente. \\
& - Conduz o aluno para a \\
& solução ou objetivo. \\
& \\
\hline
\end{tabular}




\begin{tabular}{|c|c|c|}
\hline Resolução de & - Formula o problema. & - Encontra o seu próprio \\
\hline Problemas & $\begin{array}{l}\text { - Deixa o método de } \\
\text { solução em aberto. }\end{array}$ & $\begin{array}{l}\text { caminho para resolver o } \\
\text { problema. }\end{array}$ \\
\hline Abordagem & \multicolumn{2}{|c|}{ - Escolhe uma situação de - Define os seus próprios } \\
\hline Investigativa & $\begin{array}{l}\text { partida (ou aprova a } \\
\text { escolha do aluno) }\end{array}$ & $\begin{array}{l}\text { objetivos de acordo com a } \\
\text { situação. } \\
\text { - Tenta resolver pelo seu } \\
\text { próprio caminho. }\end{array}$ \\
\hline
\end{tabular}

Quadro 2 - Modelos Pedagógicos

Os termos "Aprendizagem por Resolução de Problemas" (ARP) e "Aprendizagem Baseada em Problemas" (ABP), também são utilizados no Brasil para referir-se ao método denominado Problem Based Learning (PBL) sistematizado no inicio da década de 70 pelo Dr. Howard Barrows, professor emérito do Departament of Medical Education - Southern Illinois University School of Medicine.

O modelo ARP foi idealizado para permitir a participação interativa dos alunos nos cursos de medicina. Ao problematizar casos patológicos os professores induzem os alunos a pesquisar e colher dados para encontrar sua solução. Motivados, os estudantes se preparam assim para seu trabalho futuro no exerć́cio da medicina.

Embora o modelo ARP tenha suas origens teóricas na educação médica, ele se expandiu a outras formas de ensino como, por exemplo, nas engenharias. 
Muitas variantes do modelo ARP foram desenvolvidas nos últimos 30 anos, porém seus elementos essenciais permanecem constantes, onde os problemas são incentivos para a necessidade de conhecer o domínio em questão.

De acordo com Oliveira (1988), ARP é um conjunto de eventos no qual seres humanos usam regras para alcançar algum objetivo, o que leva à aprendizagem, uma vez que as capacidades do indivíduo se modificam. Os processos mentais trazem à tona regras conhecidas para a resolução de um problema e criam novas conexões cognitivas.

Pozo e Echeverria (1988) pressupõem que o ensino baseado na resolução de problemas promove aos alunos o domínio de procedimentos, assim como a utilização dos conhecimentos disponíveis, para dar resposta a situações variáveis e diferentes. Nesta proposta, os estudantes estabelecem e exploram o que já conhecem e o que necessitam aprender, de forma a progredir no entendimento do domínio em questão.

"A habilidade adquirida através de técnicas de aprendizado por resolução de problemas, de lidar com situações desconhecidas e recuperar informações, pode ser um importante indicador para a aprendizagem ao longo da vida". (SHIN, 93)

Os elementos chaves de aprendizagem por resolução de problemas são: a formulação de hipóteses que podem ser exploradas através de investigação auto-dirigida e o teste e a revisão destas questões pela aplicação de seus conhecimentos. 
A metodologia para trabalhar com os alunos utilizando o método de aprendizagem por resolução de problemas é oferecê-los de forma gradual, estimulando-os assim a procurar soluções e promover o autoaprendizado.

Para que um problema seja útil ao aprendizado ele deve oferecer uma situação diferente das que já se tenha resolvido, podendo até conter partes similares a outros, porém, se for do mesmo tipo que um resolvido anteriormente, este será apenas um exercício no qual o aluno prove seu conhecimento e não um que possa ser considerado como auxiliar para seu progresso.

Para classificar os problemas, o potencial de cada um deve ser avaliado, bem como os conceitos envolvidos e a sua complexidade. De acordo com Dante (1988) um bom problema deve ser desafiador, mas possível de ser resolvido.

Frederiksen (1984) enfatiza que a classificação de um problema como simples ou complexo depende, em parte, da experiência da pessoa que irá resolvê-lo, ou seja, da sua capacidade em resolver problemas similares.

Com caráter aplicado também em problemas, a teoria da assimilação cognitiva de Ausubel (1980) evidencia a importância que tem a integração dos novos conteúdos nas estruturas cognitivas prévias do 
aprendiz.

"Inicialmente, a teoria de Ausubel intitulava-se teoria da aprendizagem verbal significativa. Após ampliá-la e modificá-la, atribuiu a ela um novo nome: 'teoria da assimilação', porque, segundo suas próprias palavras, esta denominação mais recente destaca o papel interativo que as estruturas cognitivas existentes no aprendiz desempenham no processo de aprendizagem". (PFROMM, 1987)

De acordo com Ausubel (1980), a aprendizagem significativa acontece quando o aprendiz trabalha com material potencialmente significativo para ele, o qual, ao ser manipulado, pode ser relacionado com sua estrutura cognitiva. Sendo assim, aprendizagem é facilitada na medida em que se apóia no que o aluno já sabe.

"Se eu tivesse que reduzir toda psicologia educacional a um único princípio diria isto: o fator isolado mais importante que influencia a aprendizagem é aquilo que o aprendiz já conhece. Descubra o que ele sabe e baseie nisso os seus ensinamentos". (AUSUBEL et all, 1980)

Ausubel denomina subsunçores os "ganchos" cognitivos nos quais os aprendizes ancoram as novas informações. Quando o aluno não dispõe de subsunçores em determinado assunto, os educadores podem recorrer aos organizadores prévios, ou seja, fornecer aos estudantes antecipações do assunto que farão o papel de ponte entre as novas idéias e o conhecimento já solidificado.

Novak (1981) pondera que não é simples a tarefa de identificar previamente os conceitos a serem ensinados para os alunos e, menos ainda, 
a de estabelecer relações hierárquicas entre eles. Sua recomendação é percorrer a hierarquia conceitual várias vezes à medida que novas informações são apresentadas.

"Podemos começar satisfatoriamente com os conceitos mais gerais, mas é preciso ilustrar logo como os conceitos subordinados estão a eles relacionados e, então, voltar, através de exemplos, a novos significados para os conceitos de ordem superior". (NOVAK, 1981)

Novak criou então um esquema para cartografar a estrutura hierárquica dos conceitos de um conhecimento e o chamou de Mapa Conceitual.

Bruner (1976) também sugere a exploração do conteúdo educacional mais de uma vez. Em sua teoria recomenda a aplicação do currículo em espiral, ou seja, percorrê-lo de modo a permitir que o aluno veja o mesmo tópico em diferentes níveis de profundidade. 


\section{ARQUITETURA DO AMBIENTE COMPUTACIONAL DE SUPORTE AO APRENDIZADO DE GEOMETRIA DESCRITIVA}

O ambiente de aprendizado proposto nesta tese foi desenvolvido para apoiar o aluno em sua busca aos conhecimentos de GD. Ele foi elaborado para conduzir o estudante sem o auxílio de tutoria humana e oferece a cada aprendiz uma área de trabalho personalizada.

Além de o sistema permitir a utilização individual e desvinculada de cursos tradicionais, ele também oferece apoio ao ensino presencial possibilitando aos docentes o cadastro e gerenciamento de turmas. Neste caso, as turmas são registradas com senhas, as quais devem ser informadas aos alunos para que estes consigam realizar sua matrícula. A partir do cadastro dos alunos no sistema e do inicio de suas atividades, o docente passa a ter acesso ao histórico de aprendizagem de sua turma, podendo acompanhar a evolução de cada estudante. Os docentes também podem utilizar a biblioteca de exercícios de maneira isolada, fazendo buscas e implementando novos problemas ao acervo existente.

Com base em uma Biblioteca de Exercícios de Geometria Descritiva, em um grafo de relacionamento de pré-requisitos de conceitos de GD e no histórico do Aluno, o Sistema Tutor segue uma estratégia pedagógica para sugerir ações instrucionais ao aprendiz.

Toda entrada, circulação e entrega de dados (interação) é 
gerenciada por uma Interface de Acesso, que é a parte do sistema que o usuário tem contato.

A Interface Computacional foi projetada para ser um ambiente auto-explicativo de fácil navegação. O aluno, ao utilizá-lo, recebe, em forma de um gráfico, informações sobre o resultado de suas ações, de modo que possa acompanhar o seu progresso e verificar as etapas da meta que já foram atingidas. Estas informações permitem ao aprendiz conhecer o caminho que está trilhando motivando-o assim a continuar seu trabalho.

4.1 Requisitos de software para instalação e utilização do Ambiente de Aprendizado de GD

O ambiente está projetado em arquitetura cliente/servidor, como ilustrado na Figura 8, e permite acesso via Internet.

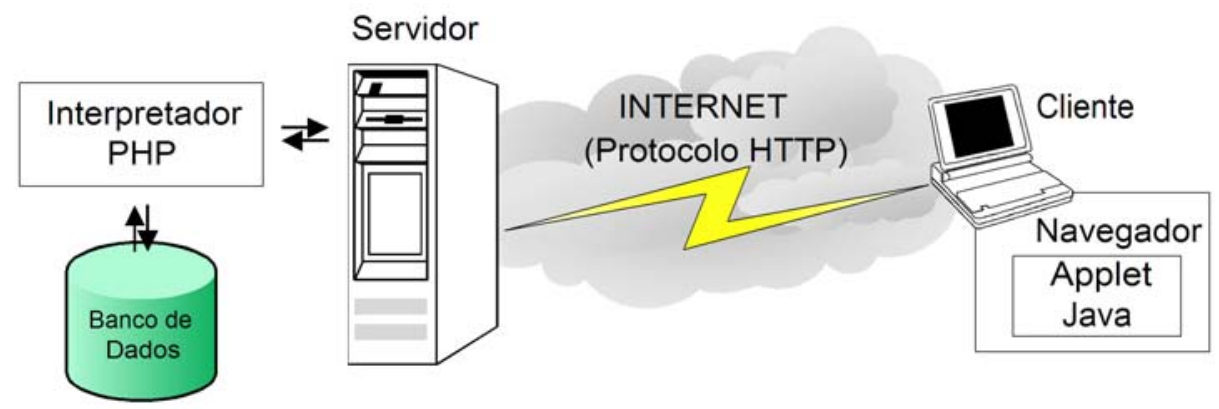

Figura 8 - Esquema Cliente/Servidor

Os programas necessários para a instalação e acesso ao ambiente de aprendizado de GD são enumerados na Tabela 1. 


\begin{tabular}{ll}
\hline Lado Servidor & Lado Cliente \\
\hline Servidor www & Acesso à Internet \\
Interpretador PHP & Navegador com Java instalado \\
PostgreSQL & \\
\hline
\end{tabular}

Tabela 1- Pré-requisitos do Sistema

Servidores www são computadores que hospedam conteúdos, popularmente chamados de sites, que ficam disponíveis para serem acessados a partir de requisições via Internet. Estas requisições podem ser realizadas em micros conectados à Internet, denominados de clientes, por meio dos endereços eletrônicos (URL - Uniform Resource Location) em sistemas navegadores (browser).

Os servidores www, inicialmente exibiam apenas páginas estáticas, ou seja, arquivos prontos com conteúdo previamente elaborado. A linguagem, muito utilizada até hoje, para diagramar este conteúdo é a HTML (HyperText Markup Language), que é uma derivação da SGML (Standard Generalized Mark-up Language).

Com o desenvolvimento do CGI (Common Gateway Interface) os servidores www passaram a oferecer o recurso de processar informações recebidas junto com as requisições (por exemplo: os dados de um formulário) possibilitando assim a montagem de páginas dinâmicas.

O sistema proposto nesta tese foi desenvolvido em HTML e PHP (Hipertext PreProcessor) que é uma linguagem que permite a interação de páginas www com bancos de dados. A diferença entre PHP e CGI é que o 
código PHP fica embutido no próprio HTML, enquanto no outro caso é necessário que o CGI gere todo código HTML.

Um dos fatores que estimulou a escolha do PHP foi o fato de seu interpretador, ou seja, o programa necessário ao servidor para sua execução, não demandar de custos para a instalação. O gerenciamento de banco de dados é feito via PostgreSQL.

O PostgreSQL é um sistema de gerenciamento de banco de dados (SGBD) relacional e orientado a objetos que suporta instruções SQL. Seu código fonte é aberto sendo disponível para utilização sem custos.

Qualquer computador do lado cliente, para acessar o ambiente, deve ter acesso à Internet e um programa para navegação com módulo Java instalado. A razão desta necessidade é que a interface de desenho, na qual os exercícios serão resolvidos, foi desenvolvida como um applet Java. Os navegadores que permitem execução de applets mais comumente utilizados são o Internet Explorer e o Netscape.

\subsection{Módulos que compõem o Ambiente de Aprendizado de GD}

O ambiente de aprendizado descrito nesta tese consiste na integração de vários módulos computacionais que permitem a interação de docentes e aprendizes com um Sistema Tutor de GD. 
Os módulos que integram este o ambiente são:

- Um Modelo de Domínio de GD que contém uma Biblioteca de Exercícios de GD, um grafo de relacionamento de prérequisitos dos conceitos de GD e um repositório ilustrado com explicações teóricas de GD. A Biblioteca de Exercícios contém problemas de diferentes graus de dificuldade e é indexada de modo a permitir seleções específicas pelo Sistema Tutor e de forma independente por usuários autorizados. Ela é aberta aos docentes para que possa ser constantemente ampliada;

- Um Modelo do Aluno que, além de conter informações sobre a identificação de cada aluno, armazena sua trajetória pelo ambiente como: seu histórico com os exercícios executados, os conceitos trabalhados com graus estimados de conhecimento e o tempo que demorou em cada problema. Estas informações são atualizadas a cada interação e, em função do desempenho do aluno na solução dos problemas propostos, fornece subsídios às decisões do Módulo Tutor;

- Um Módulo Tutor, responsável pela análise das resoluções dos exercícios dos alunos. Ele também executa o diagnóstico cognitivo do aprendiz e sugere as ações instrucionais de acordo com as necessidades individuais de cada aluno; 
- Uma Interface de Usuários que permite o acesso e interação das pessoas com o sistema. Ela também inclui um módulo de Administração de Turmas, onde o docente inclui novas turmas, definindo quais tópicos devem ser escopo de estudo de cada uma e monitora o andamento de seus alunos;

- Uma Ferramenta de Desenho (applet Java) que permite aos alunos manipular elementos gráficos para resolver os exercícios e aos docentes a alimentar a Biblioteca de Exercícios.

A Figura 9 representa o relacionamento dos componentes do Ambiente Aprendizado de GD.

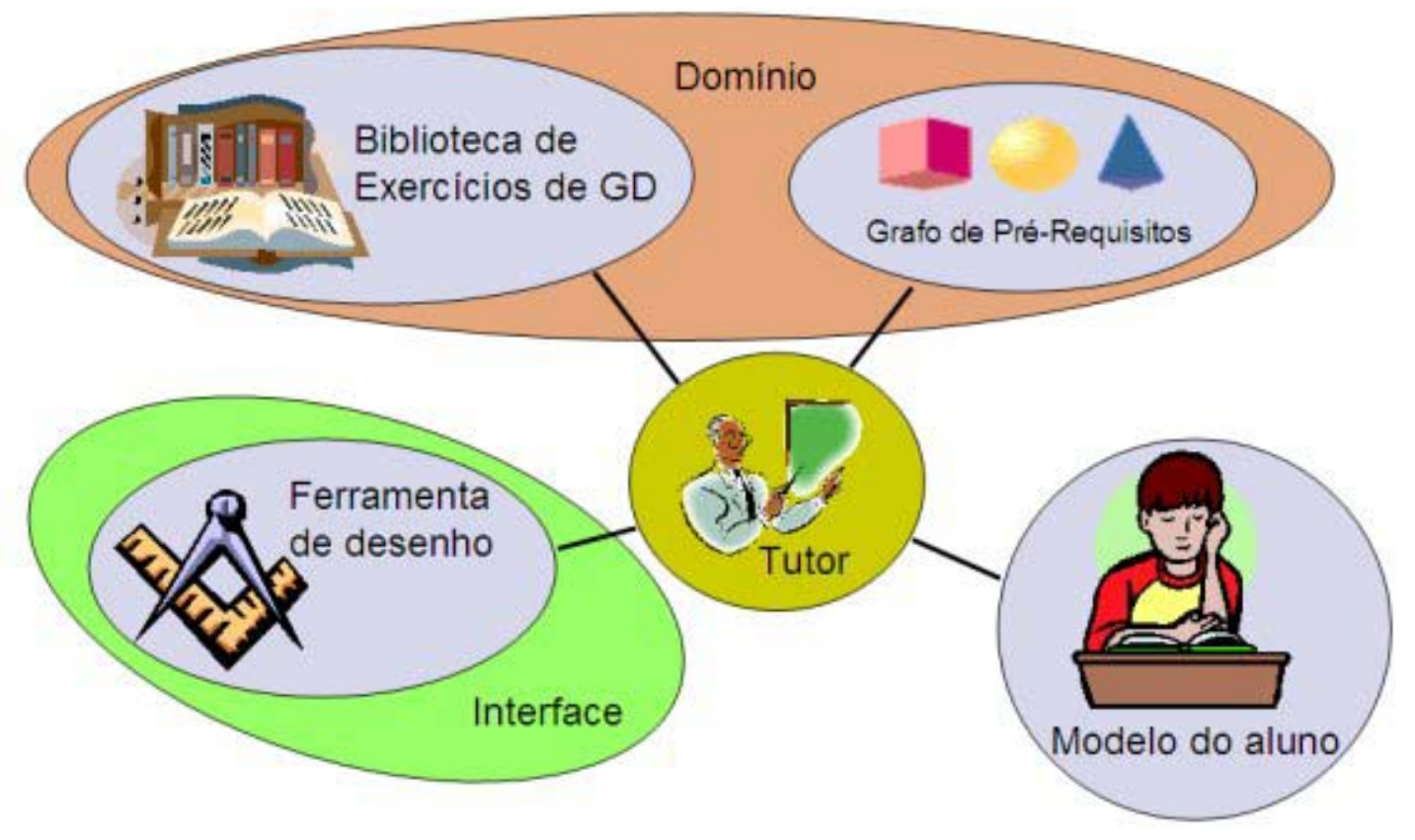

Figura 9 - Módulos que compõe o Ambiente de Aprendizado de GD 
A Figura 10 demonstra, em diagrama de blocos, o relacionamento dos componentes do Ambiente Computacional de Suporte ao Aprendizado de Geometria Descritiva.

O esquema da Figura 10 ilustra o lado Servidor, com os módulos baseados na estrutura padrão de um STI (ver Figura 6), e lado do Cliente:

LADO SERVIDOR

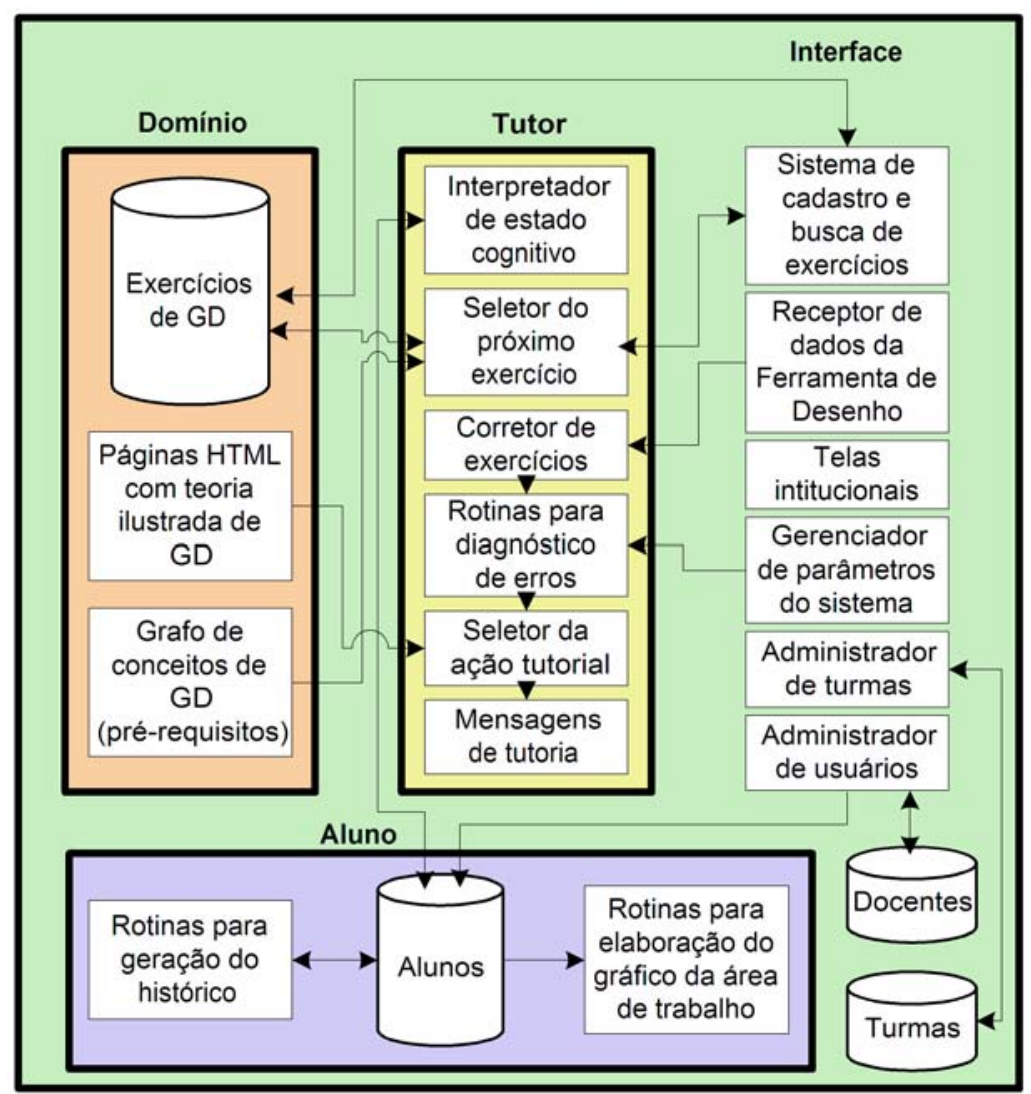

LADO CLIENTE

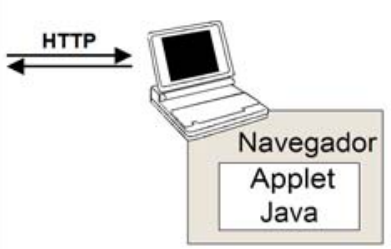

Figura 10 - Diagrama de Blocos do Ambiente Computacional de Suporte ao Aprendizado de GD 


\subsection{Biblioteca de Exercícios de GD}

A Biblioteca de Exercícios de Geometria Descritiva pode ser usada de forma isolada, como ferramenta complementar de fixação às aulas presenciais, ou dentro do ambiente de aprendizado autônomo onde o aluno é guiado pelo módulo pedagógico.

O acesso à Biblioteca de Exercícios é feito via web e mediada pela Ferramenta de Desenho (applet), que está ilustrada na Figura 11.

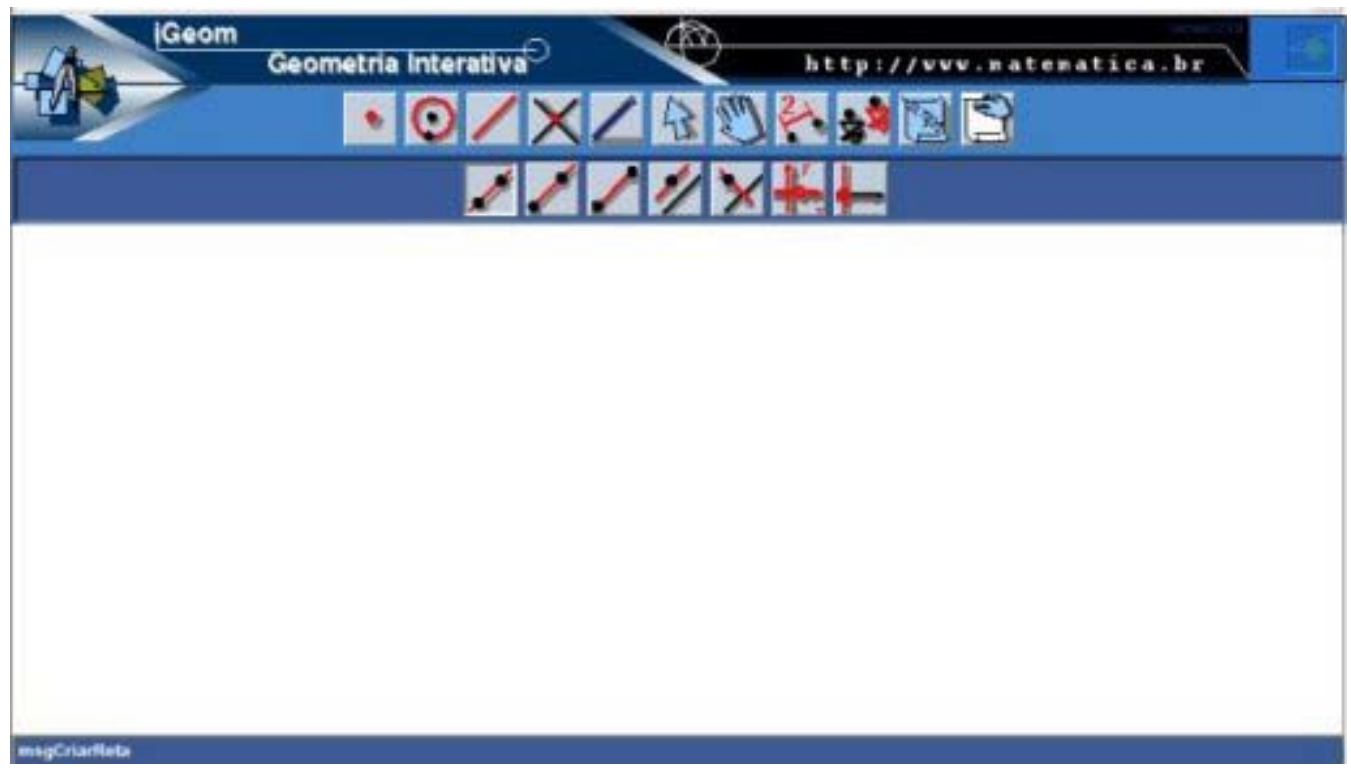

Figura 11 - Tela da Ferramenta de Desenho - applet

No ano de 2000 o Professor Doutor Leônidas de Oliveira Brandão do Departamento de Ciência da Computação do IME - USP iniciou o projeto iGeom no qual esta ferramenta gráfica foi desenvolvida. A partir do segundo semestre ele contou com um aluno de iniciação, o Ricardo Hideo Uehara (http://www.matematica.br/igeom/historico/desenvolvimento1). 
Em 2001, o Professor Doutor Eduardo Toledo Santos, do Departamento de Construção Civil da Escola Politécnica - USP, foi o responsável pela orientação da bolsista Fabiana Piesigilli (PIBIC CNPq) que desenvolveu a primeira versão do "script" do applet.

Há três formas básicas de interação com a Biblioteca de GD:

- Inclusão de exercícios: permitido apenas aos docentes ou alunos especialmente autorizados;

- Consulta aos exercícios resolvidos: o acesso será controlado se o aluno estiver interagindo com o Módulo Pedagógico;

- Resolução de exercícios: o aluno tem a possibilidade de resolver exercícios por meio de um ambiente gráfico.

\subsubsection{Utilização e alimentação da Biblioteca de Exercícios}

A proposta é que a Biblioteca de GD disponível neste ambiente fique aberta para que os docentes cadastrados, além de utilizá-la, possam contribuir com sua evolução, aumentando assim a riqueza de seu conteúdo e o acervo de exercícios.

O repositório de exercícios fica armazenado no servidor de forma que a indexação permita sua classificação por diversos índices. Esta 
organização possibilita aos usuários realizarem pesquisas específicas na biblioteca como, por exemplo, problemas que envolvam determinados conceitos. Para isto, deve-se entrar no modo de seleção de exercícios, clicar sobre os conceitos desejados e iniciar a busca. Exercícios que não contenham conceitos indesejados também podem ser filtrados.

Outros parâmetros que podem ser utilizados em pesquisas na Biblioteca de exercícios de GD são: o número de passos envolvidos na solução, o nível de dificuldade, a data de inclusão e autor. A Figura 12 ilustra algumas opções de busca que o ambiente computacional proposto nesta pesquisa oferece aos usuários no modo de seleção de exercícios:

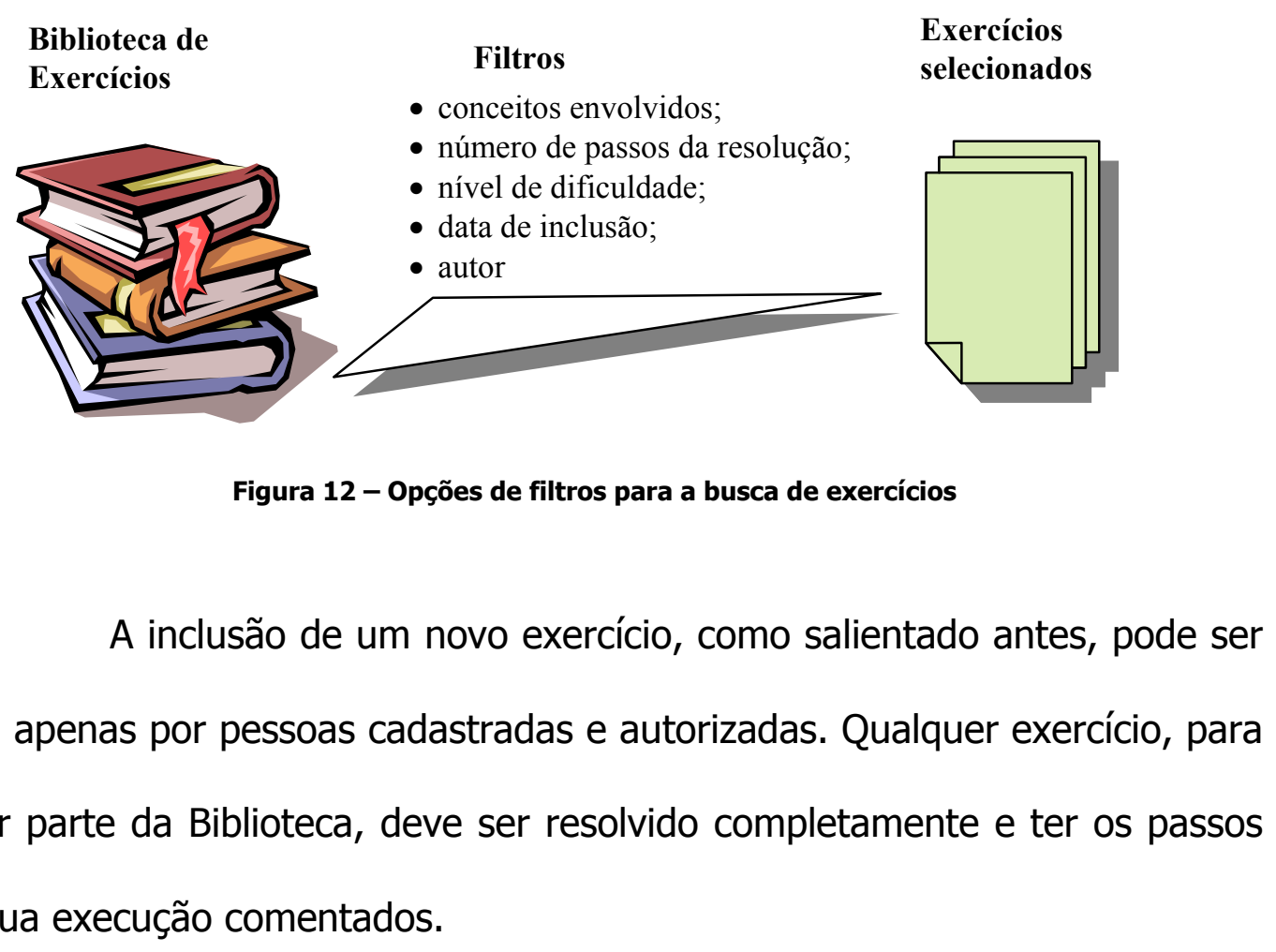


As etapas para cadastrar um novo exercício são (vide item 6.2.2):

- Digitação do enunciado (texto);

- Construção, via ferramenta de desenho (applet), da figura inicial do exercício. Esta figura fará parte do enunciado;

- Resolução do exercício graficamente no applet. A explicação conceitual da resolução deve ser comentada didaticamente. Também precisam ser informados os conceitos envolvidos diretamente na resolução do exercício (para isto basta selecioná-los em uma lista).

Ao final da inclusão de um novo exercício, ficam armazenados e à disposição dos usuários e do sistema tutor: o enunciado (texto e gráfico), a resolução gráfica com a explicação conceitual e a relação dos conceitos envolvidos diretamente para sua solução. 


\section{APRENDIZADO POR RESOLUÇÃO DE EXERCíCIOS COM TUTORIA INFORMATIZADA}

Tradicionalmente, um Sistema Tutor Inteligente atua diagnosticando constantemente o estado cognitivo do estudante: o que ele já conhece e o que ainda necessita aprender.

O ambiente de aprendizado desenvolvido nesta tese, baseado em STI, atua a partir de um universo de exercícios classificados e do perfil do aluno. Suas ações principais são: diagnosticar o conhecimento do aluno e selecionar, em ordem de prioridade, os problemas que podem ser oferecidos a ele a cada momento.

Uma meta importante do processo de tutoria deste sistema é a de gerar questões que levam à aquisição de novos conhecimentos, os quais são construídos e conectados com os já existentes. A ligação entre as informações recentemente adquiridas e os conhecimentos preexistentes promove mecanismos cognitivos para sua recuperação posterior (ver Ausubel 1980, capítulo 3).

\subsection{Desenvolvimento de um Sistema Tutor de Geometria Descritiva}

Elaborar um programa de aprendizado de Geometria Descritiva com tutoria adaptativa e baseado na ARP implica basicamente em quatro grandes tarefas: 
- Classificar os problemas em um repositório;

- Definir a estratégia a ser utilizada para a seleção e oferecimento do problema mais apropriado ao aprendiz em cada momento;

- Definir as ações tutoriais a serem sugeridas quando o aluno não conseguir resolver um problema;

- Definir os parâmetros para diagnosticar o conhecimento do aluno.

Considerando que a ordem do oferecimento dos exercícios depende do conhecimento prévio do aluno e que o repertório intelectual de cada indivíduo se constrói a partir de relacionamentos com elementos já memorizados, pode-se afirmar que cada aluno, de acordo com seu progresso durante a resolução dos exercícios, ou seja, de seus acertos e erros, tende a necessitar de problemas diferentes.

A implementação computacional de um ambiente que ofereça ao aluno o exercício que ele necessita em cada momento exato demanda um sistema de monitoramento de aprendizagem, ou seja, mecanismos que façam o mapeamento da quantidade estimada do conhecimento do aluno em cada tópico do domínio de GD (vide módulo tutor, item 5.8).

Porém, não basta saber o que o aluno já conhece. O sistema necessita ainda de uma rede conceitual na qual os tópicos do conteúdo 
(domínio) são inter-relacionados por pré-requisitos formando uma estrutura lógica com várias possibilidades gradativas para o aprendizado (vide item $5.3)$.

O Quadro 3 sintetiza a metodologia seguida nesta pesquisa para elaborar um ambiente adaptativo baseado em Aprendizagem por Resolução de Problemas para o aprendizado de Geometria Descritiva.

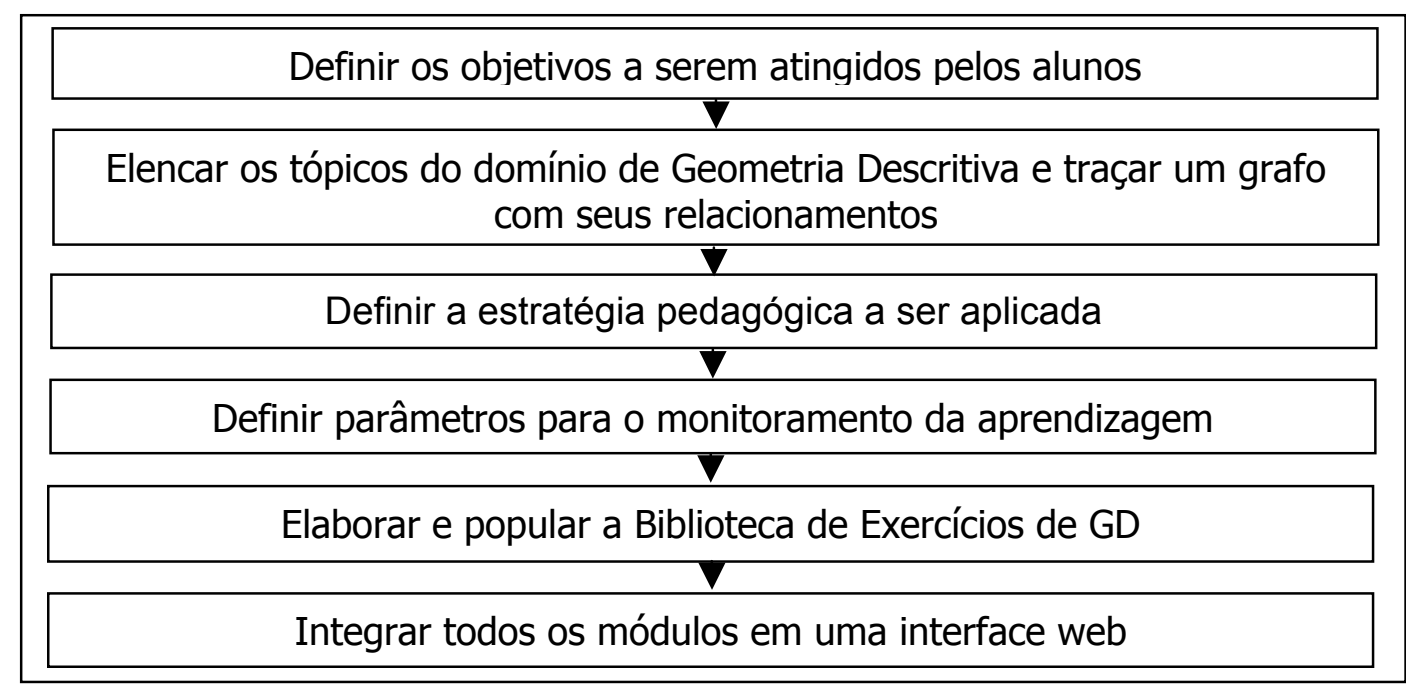

Quadro 3 - Metodologia para o desenvolvimento do ambiente de aprendizagem

\subsection{Domínio de Geometria Descritiva}

Conforme descrito no capítulo 3, o objetivo principal a ser alcançado no estudo da Geometria Descritiva é o desenvolvimento das seguintes competências:

- Visão espacial;

- Capacidade de representar objetos tridimensionais no plano, indicando corretamente sua forma, tamanho e posição;

- Capacidade de interpretar representações gráficas no plano e 
- Resolução de problemas espaciais.

A partir dos objetivos descritos anteriormente (vide Capítulo 3, item 3.3), o conteúdo teórico de GD necessário que o aluno conheça foi relacionado na Tabela 2 e classificado.

\begin{tabular}{ll}
\hline No & Elementos, Operações e Métodos Descritivos \\
\hline 1 & Conceito de ponto \\
2 & Conceito de reta \\
3 & Conceito de posições relativas entre retas \\
4 & Conceito de plano \\
5 & Conceito de posições relativas entre planos \\
6 & Conceito de posições de reta em relação ao plano \\
7 & Indicação de plano \\
8 & Conceito de projeção \\
9 & Conceito de projeção cilíndrica \\
10 & Propriedade da conservação do perpendicularismo \\
11 & Propriedade da conservação do paralelismo \\
12 & Conceito de Verdadeira Grandeza \\
13 & Propriedade da VG \\
14 & Sistema de Projeção Mongeano \\
15 & Conceito de projeções horizontal e vertical \\
16 & Conceito de projeção de ponto \\
17 & Conceito de projeção de reta \\
18 & Conceito de Traço \\
19 & Conceito de traço de reta \\
20 & Conceito de traço de plano \\
21 & Retas em posições particulares e respectivas épuras \\
22 & Planos em posições especiais \\
23 & Conceito de reta de maior declive \\
24 & Conceito de pertinência \\
26 & Propriedades de pertinência \\
\hline
\end{tabular}




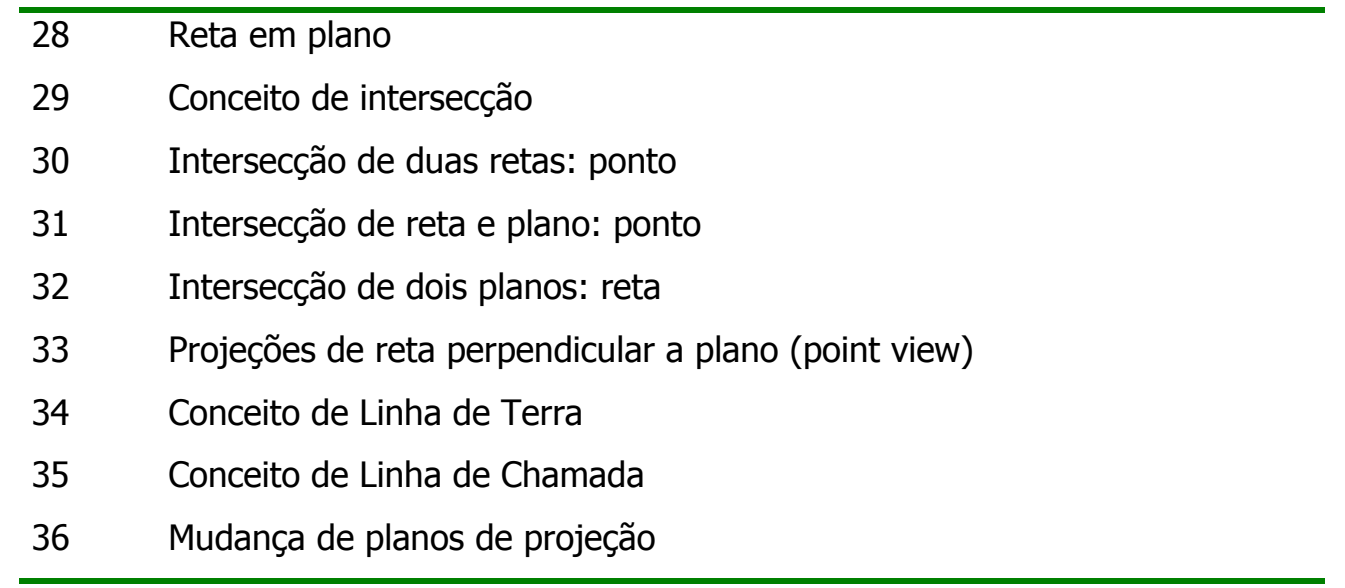

Tabela 2 - Conceitos de Geometria Descritiva

\subsection{Relacionamento entre Conceitos}

Tendo em vista a necessidade de relacionar os tópicos de Geometria Descritiva e estimar suas dependências, elaborou-se a Tabela 3 com o desdobramento do domínio em operações descritivas.

É importante salientar que esta não é a única forma de classificar os tópicos de GD e definir seus relacionamentos, no entanto ela segue uma seqüência lógica e permitirá que o Sistema Tutor inicialmente siga estas referências.

Posteriormente, as estatísticas geradas pela utilização deste ambiente pelos alunos indicarão seqüências diversas de estudo, provavelmente algumas serão mais eficientes. Estes dados possibilitarão a elaboração de novas classificações relacionais dos tópicos de Geometria Descritiva. 


\begin{tabular}{|c|c|c|}
\hline No & Elementos, Operações e Métodos Descritivos & Pré-Requisitos \\
\hline 1 & Conceito de ponto & - \\
\hline 2 & Conceito de reta & 1 \\
\hline 3 & Conceito de posições relativas entre retas & 2 \\
\hline 4 & Conceito de plano & - \\
\hline 5 & Conceito de posições relativas entre planos & 4 \\
\hline 6 & Conceito de posições de reta em relação ao plano & 2,4 \\
\hline 7 & Indicação de plano & 2,4 \\
\hline 8 & Conceito de projeção & 2,4 \\
\hline 9 & Conceito de projeção cilíndrica & 8 \\
\hline 10 & Propriedade da conservação do perpendicularismo & 3,9 \\
\hline 11 & Propriedade da conservação do paralelismo & 3,9 \\
\hline 12 & Conceito de Verdadeira Grandeza & 9 \\
\hline 13 & Propriedade da VG & 6,12 \\
\hline 14 & Sistema de Projeção Mongeano & 9 \\
\hline 15 & Conceito de projeções horizontal e vertical & 14 \\
\hline 16 & Conceito de projeção de ponto & $1,8,9,15,35$ \\
\hline 17 & Conceito de projeção de reta & $2,9,16$ \\
\hline 18 & Conceito de Traço & 14 \\
\hline 19 & Conceito de traço de reta & $2,4,16,18,31$ \\
\hline 20 & Conceito de traço de plano & 17,19 \\
\hline 21 & Retas em posições particulares e respectivas épuras & 6,17 \\
\hline 22 & Planos em posições especiais & 5 \\
\hline 23 & Conceito de reta de maior declive & - \\
\hline 24 & Conceito de pertinência & - \\
\hline 25 & Propriedades de pertinência & 24 \\
\hline 26 & Ponto em reta & 25 \\
\hline 27 & Ponto em plano & 26 \\
\hline 28 & Reta em plano & 25 \\
\hline 29 & Conceito de intersecção & - \\
\hline 30 & Intersecção de duas retas: ponto & 1,29 \\
\hline 31 & Intersecção de reta e plano: ponto & 29 \\
\hline 32 & Intersecção de dois planos: reta & 2,31 \\
\hline 33 & Projeções de reta perpendicular a plano (point view) & - \\
\hline 34 & Conceito de Linha de Terra & 14 \\
\hline 35 & Conceito de Linha de Chamada & 34 \\
\hline
\end{tabular}




36 Mudança de planos de projeção $17,33,34$

Tabela 3 - Pré-requisitos entre os conceitos de GD

As informações fornecidas sobre relacionamentos de conceitos dispostas na Tabela 3 geraram o grafo ilustrado na Figura 13. Os nós, representados por círculos, indicam os conceitos e as setas mostram as relações de dependências conceituais.

No ambiente computacional de aprendizado desenvolvido neste projeto existe uma ferramenta que permite ao administrador do sistema alterar a rede conceitual, gerada pelo grafo, que servirá de referência para o Módulo Tutor.

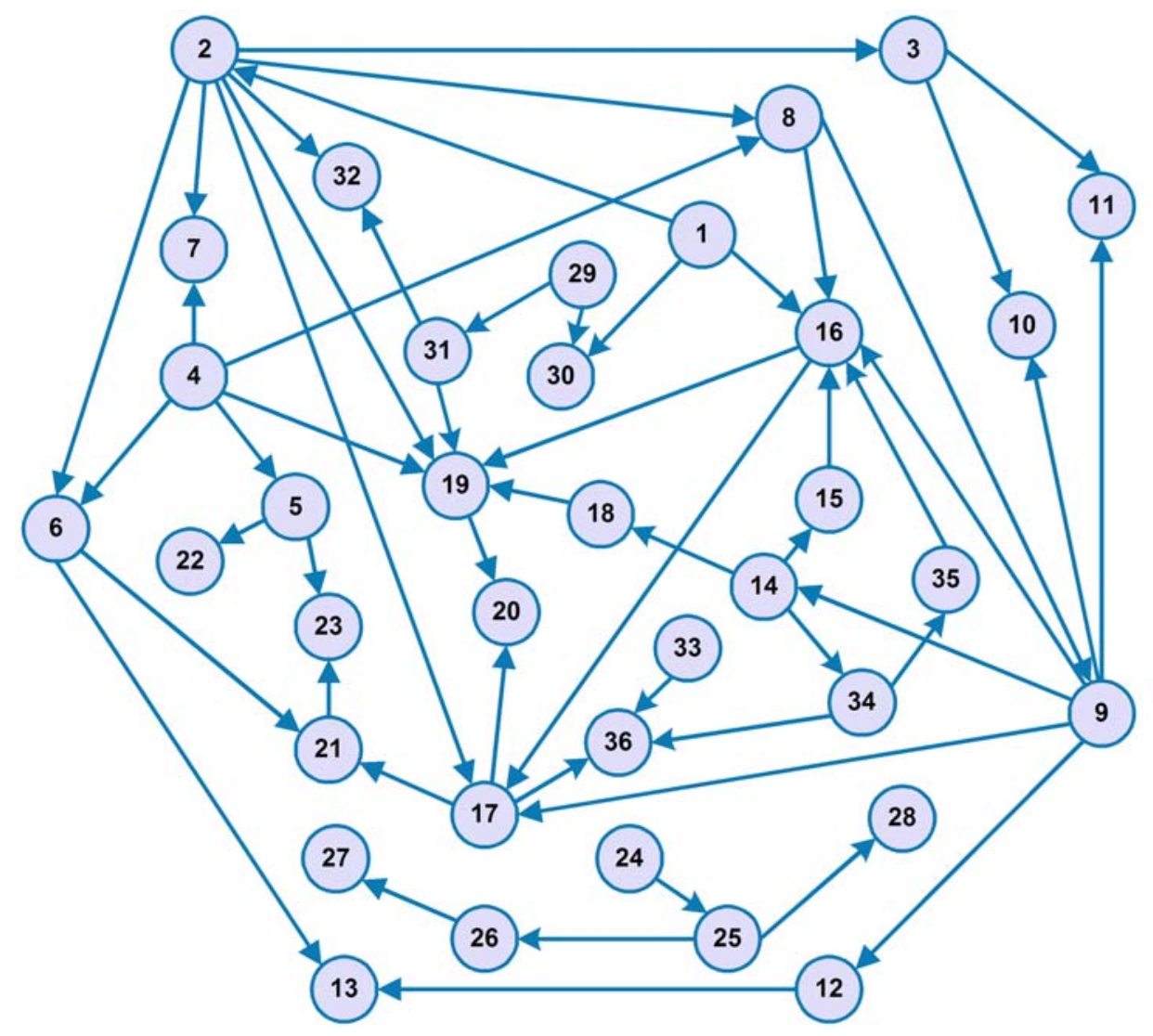

Figura 13 - Grafo dos relacionamentos dos conceitos de GD 
Para facilitar a visualização do relacionamento dos conceitos de GD, o grafo de pré-requisitos está representado na Figura 14 com nomes no lugar dos números.

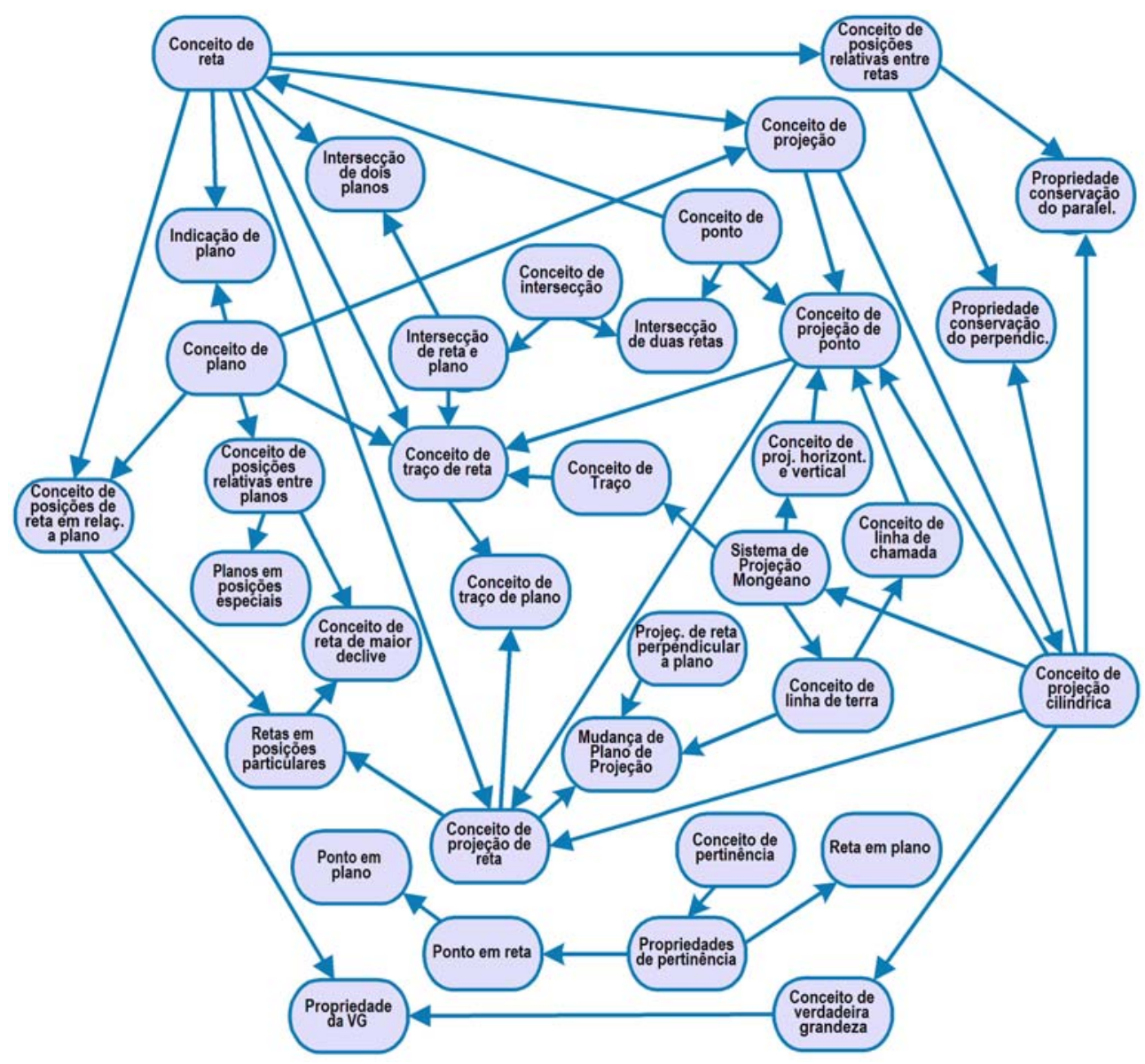

Figura 14 - Relacionamento de Pré-requisitos dos conceitos de GD

\subsection{Modelo do Aluno}

Sistemas de tutoria informatizados, que interagem com os aprendizes sem a interferência de docentes, necessitam de mecanismos para mapear o conhecimento do aluno. Informações sobre o repertório do aprendiz são fundamentais para que o sistema selecione as ações 
instrucionais apropriadas às suas necessidades.

Neste ambiente, baseado na resolução de problemas de GD, todos os passos do aluno tornam-se variáveis importantes. Sempre que o aprendiz realiza uma tarefa, seu sucesso ou fracasso é armazenado e o diagnóstico de seu conhecimento é atualizado.

O Sistema Tutor, dependendo do caso, fornece ao aprendiz instruções didáticas ou novos problemas. Quando o oferecimento de um exercício for a opção mais indicada, a intenção é que o aluno o receba como um desafio para estimular seu crescimento. Apenas são entregues aos alunos exercícios cujos pré-requisitos necessários para solucioná-los são considerados conhecidos.

Tendo em vista que não é possível quantificar, com certeza, o conhecimento do estudante em cada tópico de um domínio, o sistema adaptativo desenvolvido neste projeto se apóia em um sistema no qual cada exercício resolvido (certo ou errado) pelo aluno apenas diminui a incerteza a respeito de seu estado cognitivo sobre os conceitos envolvidos no problema apresentado.

No caso da Geometria Descritiva, além dos exercícios envolverem geralmente mais de um conceito, vários deles possuem caminhos alternativos para a solução correta. Estes fatores tornam ainda mais complexa a identificação do conhecimento do aluno em cada tópico. 
No modelo tradicional de ensino presencial, geralmente, os mecanismos para a medição do conhecimento dos alunos são as provas aplicadas sazonalmente. Nelas, o docente inclui uma série de problemas que abrangem a maior parte possível do conteúdo ministrado e o aluno é considerado apto se acertar uma porcentagem dos exercícios (geralmente 50 ou $70 \%)$.

O sistema de avaliação convencional, utilizado na maioria dos cursos presenciais, permite supor até que ponto da disciplina o aluno conseguiu acompanhar.

Um agravante no sistema tradicional é o número de alunos por turma, que impede que o docente analise constantemente, de forma minuciosa, a trajetória de cada um para oferecer-lhes tratamentos individualizados. Esta análise se faz necessária para identificar especificamente quais conceitos de GD o aluno não domina e quais regras e teoremas ele deveria rever. Por outro lado o docente consegue fazer, presencialmente, um diagnóstico bastante preciso, de forma rápida.

Considerando então a necessidade de estimar o conhecimento do aluno em cada tópico do domínio, esta pesquisa buscou métodos que pudessem ser utilizados para conduzir o diagnóstico do aluno de modo a subsidiar informações para o módulo de tutoria.

Considerando que na biblioteca de exercícios de GD utilizada neste 
ambiente há, propositalmente, vários exercícios envolvendo cada conceito, não seria uma boa estratégia pedagógica exigir que o aluno resolvesse todos os exercícios para ser considerado apto em determinado tópico. Isto seria cansativo e desmotivante. Sendo assim, uma das metas deste tutor é oferecer apenas a quantidade de exercícios necessária ao desenvolvimento do aluno.

Como enfatizado anteriormente (Capítulo 3, item 3.3), o ambiente computacional proposto neste trabalho visa que o aluno atinja os níveis de aprendizado 3 e, se possível, 4 da Taxonomia de Bloom, ou seja, o desenvolvimento de capacidades de Aplicação, e Análise em relação à representação gráfica subsidiada pela Geometria Descritiva. Portanto, deseja-se que o aluno, ao utilizar este ambiente, aprofunde seus conhecimentos e habilidades em GD e não fique simplesmente resolvendo vários exercícios similares para provar os tópicos que já sabe.

Os níveis 1 (conhecimento) e 2 (compreensão) dos conceitos de Geometria Descritiva são pré-requisitos para que o aluno consiga utilizar o ambiente computacional proposto. Sendo assim, a fluência nos dois primeiros estágios é avaliada com pré-testes. Este ambiente não estima de forma progressiva a cognição do aluno nos pré-testes. No modelo do aluno consta a aptidão do estudante de forma binária em cada conceito, ou seja, nestas etapas, consideram-se apenas duas possibilidades: o aluno está apto ou não para prosseguir em cada assunto. 
A Figura 15 ilustra a faixa de evolução cognitiva aplicada ao ambiente de acordo com a Taxonomia de Bloom.

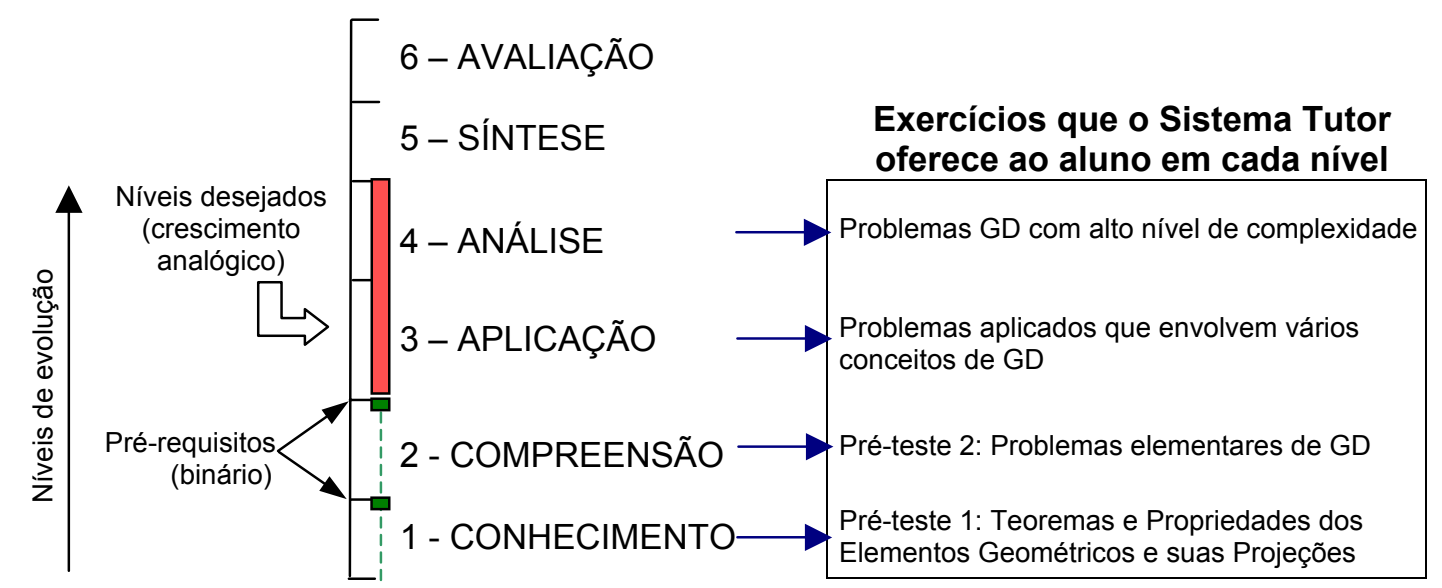

Figura 15 - Faixa de evolução cognitiva aplicada ao ambiente de acordo com a Taxonomia de Bloom

As etapas de pré-testes, elaboradas com tópicos isolados sobre teoria e prática elementar de GD, fornecem dados que possibilitam supor o conhecimento do aluno em cada conceito. Enquanto o aprendiz não possuir estes conhecimentos ele não estará pronto para continuar e resolver exercícios que envolvam aqueles conceitos.

Ao ingressar no sistema, o aluno receberá o Pré-teste 1 , no qual encontram-se perguntas teóricas na forma de testes. Tendo vencida esta etapa com sucesso, ele entrará no Pré-teste 2, no qual resolverá graficamente problemas básicos de GD. Só depois de ter passado por este segundo teste, o sistema abrirá a área de aplicação de conceito ao aluno na qual ele receberá exercícios de modo gradual de acordo com seu desempenho. 


\subsection{Informações que o Modelo do Aluno passa ao Módulo Tutor}

As ações relevantes do aprendiz ficam armazenadas no modelo do aluno e são utilizadas para que o sistema estime o seu estado cognitivo.

As tomadas de decisões sobre as ações tutoriais a serem sugeridas aos alunos dependem da sua trajetória pelo ambiente. Sendo assim, é importante que todos os passos dos aprendizes, inclusive seus insucessos, estejam armazenados.

Tendo em vista que a estrutura de tutoria deste ambiente foi elaborada a partir da unidade "conceito", as informações no modelo do aluno são relacionadas de modo que ele possua um histórico por conceito, fornecendo assim dados para o diagnóstico constante do seu estado cognitivo.

No histórico do aluno, cada conceito pode assumir um dos seguintes estados: "dominado" (mastered), "em estudo" ou "sem prérequisito". Estes estados, relacionados na Tabela 4, são definidos pela desenvoltura do aluno na resolução dos exercícios que o sistema tutor lhe sugere e pelos parâmetros das metas estabelecidas pelo administrador do sistema. 


\begin{tabular}{ll}
\hline $\begin{array}{l}\text { Cada conceito pode ser } \\
\text { considerado }\end{array}$ & quando \\
\hline Dominado & $\begin{array}{l}\text { O aluno já resolveu corretamente exercícios } \\
\text { que contenham o conceito em questão no } \\
\text { mínimo o número de vezes que foi estabelecido } \\
\text { pelo administrador do sistema, ou seja, já } \\
\text { atingiu a meta. }\end{array}$ \\
O sistema já tiver aberto a possibilidade ao \\
aluno de tentar resolver algum exercício que \\
contenha o conceito em questão. \\
O aluno não possui todos os pré-requisitos para \\
tentar resolver exercícios que contenham o \\
conceito em questão.
\end{tabular}

Tabela 4 - Estados assumidos pelos conceitos no histórico do aluno

\subsection{Correção do exercício}

O aluno recebe os exercícios para resolver por meio da ferramenta gráfica (applet), que já se abre com o enunciado do problema. A partir dai, utilizando o mouse, o aluno tenta resolver o exercício na tela. Ao terminar os passos da resolução, o aluno deve marcar os elementos gráficos que acredita pertencer à resposta e submeter estes dados ao sistema.

A resposta enviada pelo aluno é comparada à solução armazenada para aquele exercício. A verificação apenas dos elementos marcados como integrantes da resposta permite identificar se o aluno acertou, mesmo que tenha traçado caminhos distintos aos do docente no cadastramento daquele exercício. 


\title{
Rotina para correção
}

A resolução dos exercícios geram um script do tipo que está representado no Quadro 4.

\author{
\# igeom: http://www.matematica.br \\ [0:1.1, 1:9, 2:0] - iGeom versão 2.6.6 \\ $\{1: 0,0: 0,2: 203.0-184.0,4: A \quad 0.7853981633974483$ 0, 6:1, 3:2 4 5, 5:-16711936, 7:0\} \\ $\{1: 1,0: 0,2: 441.0-153.0,4: B 0.7853981633974483$ 0, 6:1, 3:2, 5:-16711936, 7:0\} \\ $\{1: 2,0: 4,2: 01,4: r 0.50,6: 1,3: 3,5:-16776961,7: 0\}$ \\ $\{1: 3,0: 2,2: 0.57376963805225232,4: C 0.78539816339744830,6: 1,3: 45,5:-16711936$, \\ 7:0\} \\ $\{1: 4,0: 3,2: 03,4: C 00.78539816339744830,6: 1,3: 6$ 7, 5:-16776961, 7:0\} \\ $\{1: 5,0: 3,2: 30,4: C 10.78539816339744830,6: 1,3: 67,5:-16776961,7: 0\}$ \\ $\{1: 6,0: 1,2: 54$ 1, 4:D $0.78539816339744830,6: 1,3: 8,5:-14655424,7: 0\}$ \\ $\{1: 7,0: 1,2: 54$ 2, 4:E 0.7853981633974483 0, 6:1, 3:8, 5:-14655424, 7:0\} \\ $\{1: 8,0: 4,2: 67,4: 50.50,6: 1,3:, 5:-14655424,7: 0\}$ \\ $\{0: 101,\{130 \quad 0: 6 \quad 255.87471537154101-56.84458898150825,0: 7286.68245848489505-$ \\ 293.368552238887187, 4:8 -7.6774193548387215 1907.6129032258098 \}\}
}

Quadro 4 - Script com a resolução de um exercício

Sendo:

- A primeira linha, destacada em negrito, é igual para todos os scripts;

- As linhas seguintes contêm, de maneira codificada, os elementos da resolução do exercício;

- A linha final, destacada em itálico, apesar de aparecer no quadro dividida em duas, não possui quebra de linha e é onde ficam codificados os elementos da resposta. 
A linha de resposta é formada pela seguinte sintaxe:

\{TIPO: SCRIPT, \{MARCAR_RESP TIPO1:ID1 real1 real2, TIPO2:ID2 real1 real2, ... $\}$

Sendo:

- TIPO = 0

- SCRIPT = 101

- MARCAR_RESP $=130$

Cada elemento da resposta contém uma seqüência com os seguintes dados:

- TIPOi = tipo do objeto (circunferência, reta, semi-reta, segmento, ponto)

- IDi = identificador do objeto (utilizado pelo sistema)

- real1, real2, ... = os escalares correspondentes ao objeto

Todo objeto possui um código (TIPOi) e, dependendo do seu tipo, dois ou mais números escalares o representam (real1, real2, ...). Na Tabela 5 consta a relação dos objetos que podem figurar na resposta do exercício, seus códigos, o número de escalares que os representam e o significado de cada valor.

\begin{tabular}{|c|c|c|c|}
\hline Objeto & Tipo (i) & $\mathrm{N}^{\circ}$ de escalares & Significado de cada escalar \\
\hline ponto & 0 & 2: $(x, y)$ & $(\mathrm{x}, \mathrm{y})$ : coordenadas do ponto \\
\hline circunferência & 3 & 3: $(x, y, r)$ & $(x, y)$ e r: coord. do centro e raio \\
\hline reta & 4 & $2:(a, b)$ & $\begin{array}{l}\text { (a,b): } a \text { coef. ângular da reta e } b \\
a=(B \cdot y-A \cdot y) /(\text { B.x-A.x) } \\
b=A \cdot y-a{ }^{*} \text { A.x }\end{array}$ \\
\hline semi-reta & 5 & 4: $(x, y, d x, d y)$ & $\begin{array}{l}(x, y) \text { : coord. do ponto origem } \\
\text { (dx,dy) coord. da direção }\end{array}$ \\
\hline segmento & 6 & 4: (x1,y1,x2,y2) & $\begin{array}{l}(x 1, y 1): \text { coordenadas do ponto } A \\
(x 2, y 2): \text { coordenadas do ponto } B\end{array}$ \\
\hline
\end{tabular}


Ao interpretar a linha de resposta do exemplo do Quadro 4, podese constatar que ela possui três elementos, sendo dois pontos e uma reta.

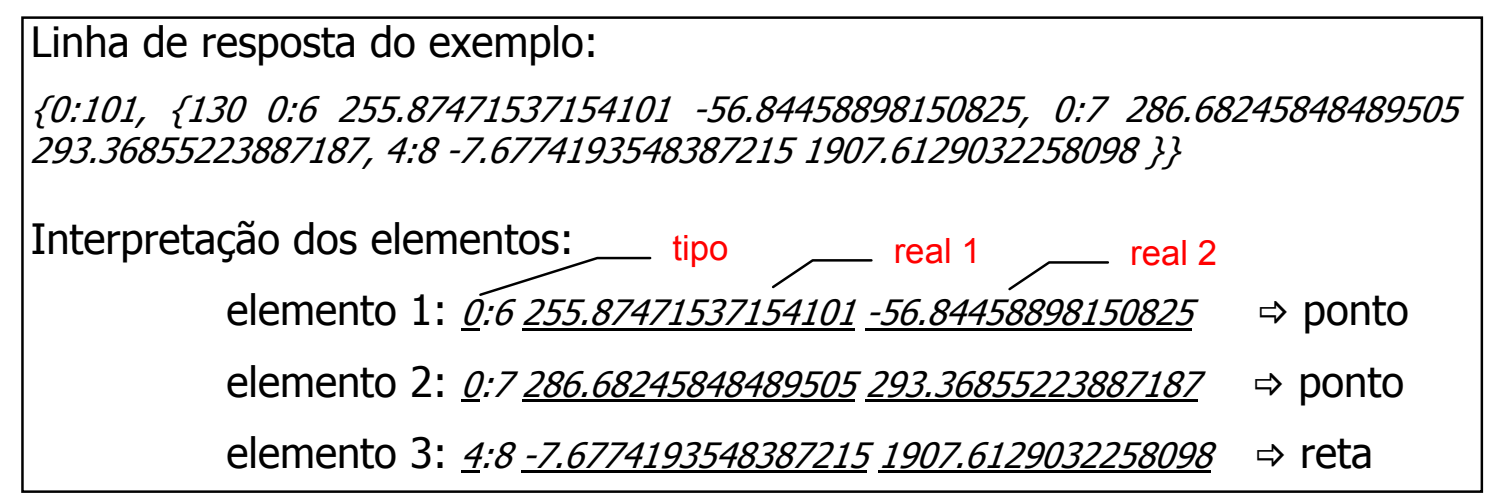

Quadro 5 - Interpretação da resposta do exercício

A correção de um exercício consta na comparação da última linha do script enviado pelo aluno com a última linha do script do exercício gravado pelo docente que o cadastrou.

Como no enunciado do exercício consta, além do texto, a parte gráfica e como esta imagem é fixa, ou seja, o aluno não tem como mover pela tela a figura inicial do exercício, os elementos da resposta deverão estar, geralmente, no mesmo lugar.

Na correção, não importa qual tenha sido o desenvolvimento do exercício pelo aluno, nem se ele é similar ao gerado pelo docente, apenas se os elementos da resposta coincidem.

A verificação da similaridade da resposta do aluno com a do docente implica em considerar os elementos em todas as possíveis posições na última linha dos scripts, ou seja, os elementos podem seguir uma ordem 
na linha de resposta do docente e outra na do aluno.

A rotina de correção identifica, dentre os elementos da resposta do aluno, quais coincidem com as do docente, que pode ser: nenhum, todos ou apenas alguns.

Na comparação das coordenadas, o sistema considera um valor estimado para aproximação, o qual é denominado parâmetro de erro. Este valor é gerenciado pelo administrador do sistema (vide item 6.2.4).

Quando o sistema remete o aluno a um exercício, ele pode obter de volta os resultados relacionados na Tabela 6.

\begin{tabular}{ll}
\hline O exercício é considerado: & quando o aluno: \\
\hline Sem resposta & $\begin{array}{l}\text { aluno visualizou o exercício via applet, mas não } \\
\text { submeteu nenhuma resposta }\end{array}$ \\
Erro & $\begin{array}{l}\text { submeteu a resposta, mas nela não constava } \\
\text { nenhum elemento correto }\end{array}$ \\
Acerto parcial & $\begin{array}{l}\text { submeteu a resposta, e nela constava pelo } \\
\text { menos } 1 \text { elemento correto }\end{array}$ \\
Acerto & $\begin{array}{l}\text { submeteu a resposta, e nela constavam todos os } \\
\text { elementos corretos }\end{array}$ \\
\hline
\end{tabular}

Tabela 6 - Ações possíveis armazenadas por exercício no histórico do aluno 


\subsection{Diagnóstico e Metas}

A proposta deste ambiente computacional de estudo é, a partir de estimativas do conhecimento do aluno em cada conceito de GD, oferecer-lhe novos desafios que estimulem seu desenvolvimento.

No caso de insucesso em uma interação, o sistema analisa o histórico do aluno para diagnosticar as possíveis causas que levaram-no a errar o exercício e, então, aplicar as ações tutoriais indicadas para cada caso.

Como explicado no item 5.3, o sistema não identifica passo a passo o trabalho do aluno no ato da resolução de um exercício. A informação gerada e passada para o Sistema Tutor, após a tentativa de o aluno resolver um exercício, é uma variável que indica uma das quatro situações: "sem resposta", "erro", "acerto parcial" ou "acerto".

Quando o aluno acertar um exercício, o sistema ainda identifica se ele o fez sozinho ou se recebeu algum dos auxílios disponíveis.

O sistema registra também o número de vezes que o aluno tentou resolver cada exercício.

As possíveis interações do aluno em relação aos exercícios estão relacionadas no Quadro 6. 


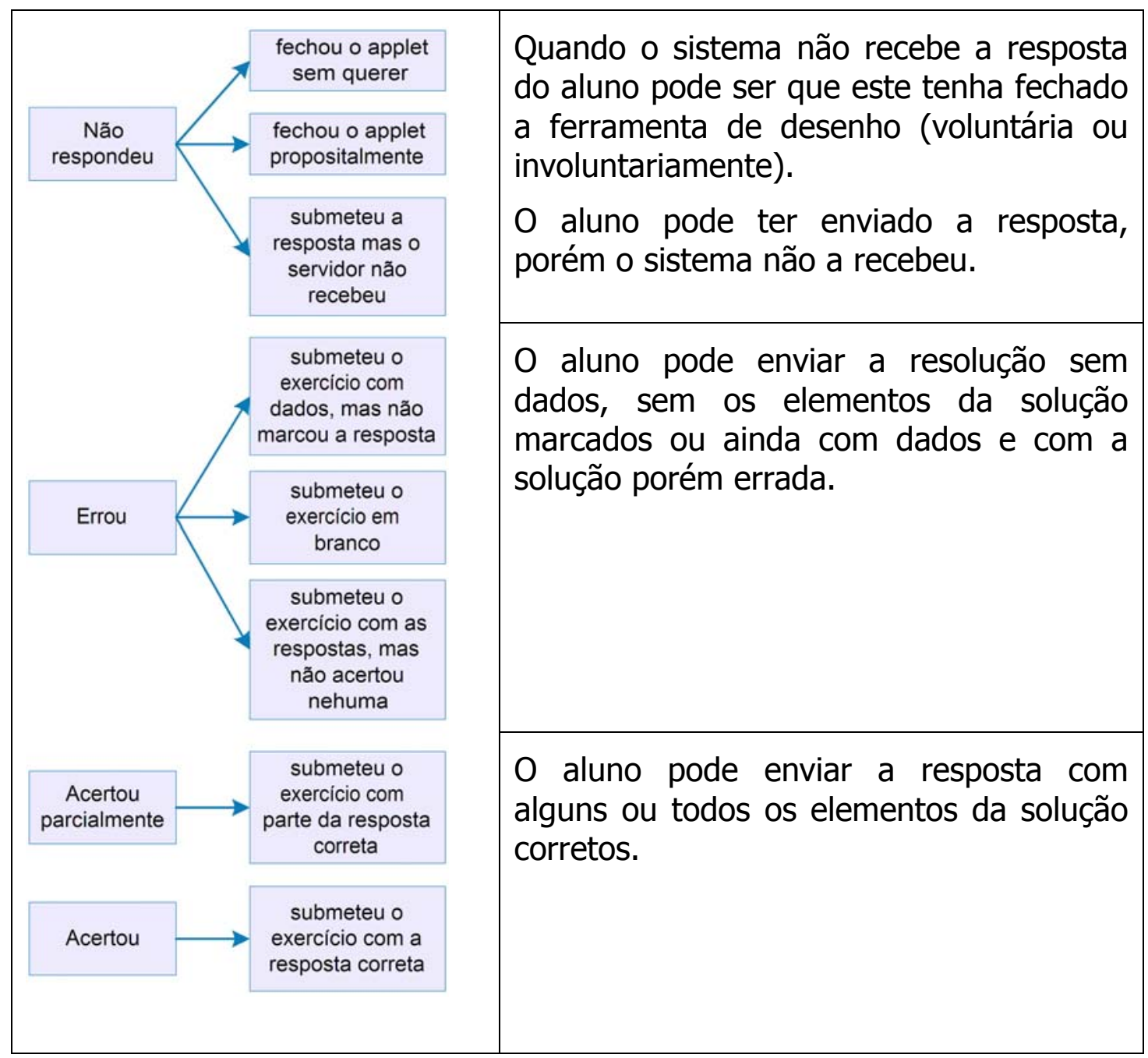

Quadro 6 - Possíveis ações do aluno

Além do resultado da interação do aluno com o exercício, é fundamental para o Módulo Tutor que seja(m) identificada(s) sua(s) provável(eis) causa(s).

Os fatores mais comuns que podem levar os alunos a cometer erros ou necessitar de auxílio durante a resolução dos exercícios, são:

- Não possuir todos os pré-requisitos dos conceitos 
envolvidos;

- Não conhecer suficientemente bem os conceitos envolvidos;

- Não saber como trabalhar em conjunto com os conceitos envolvidos apesar de conhecê-los.

\section{No Quadro 7 constam os relacionamentos das ações dos alunos}

\section{com sua(s) provável(eis) causa(s).}

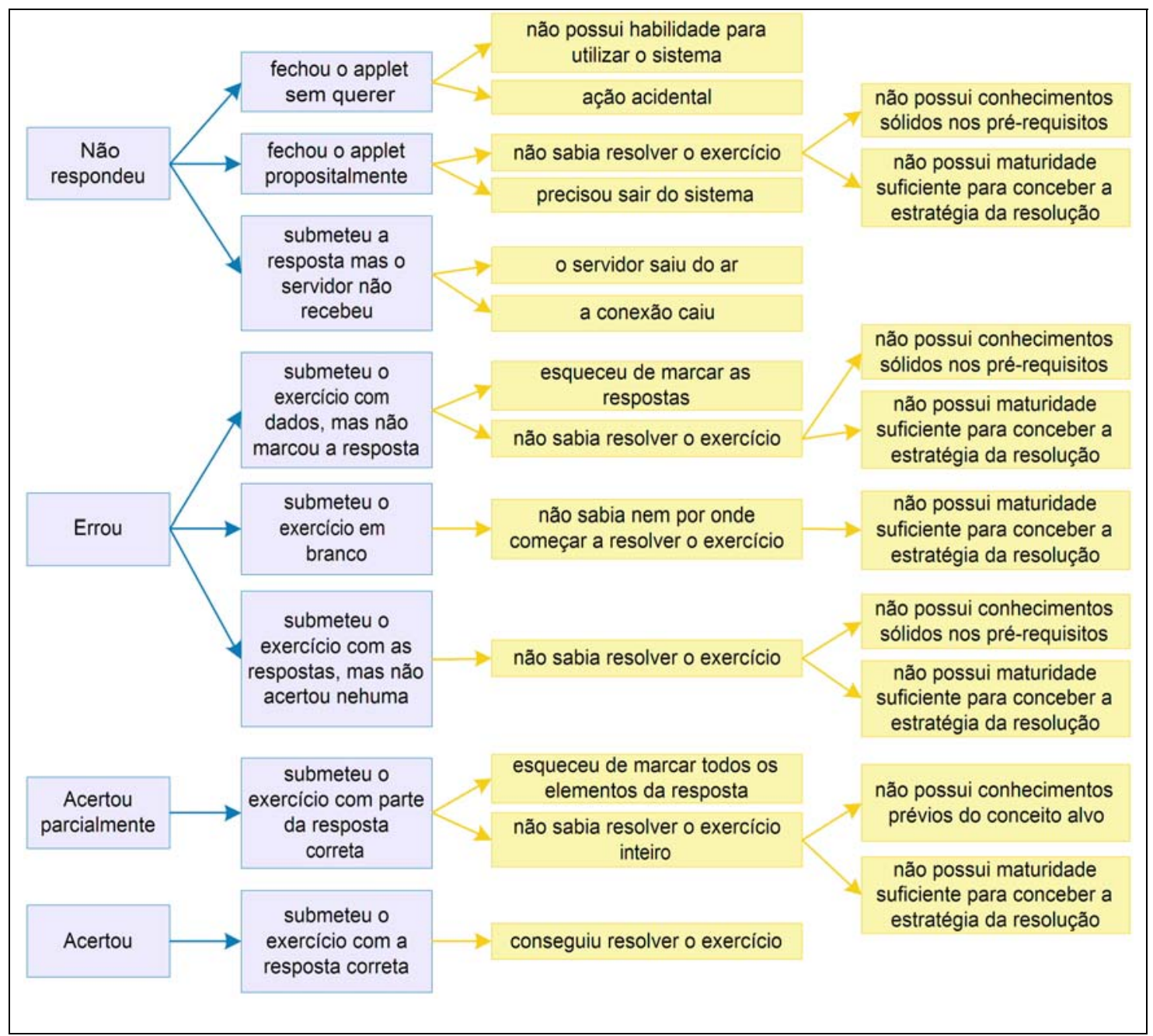

Quadro 7 - Possíveis causas das ações dos alunos 
5.7.1 Etapas de estudo

O ambiente de aprendizado desenvolvido neste projeto acompanha a trajetória do aluno visando que ele ultrapasse dois patamares: o dos pré-testes e da etapa de solidificação dos conhecimentos sobre aplicação dos conceitos de GD.

Após os pré-testes, portanto na segunda etapa, são oferecidos aos alunos exercícios de dificuldade baixa envolvendo os conceitos de GD. O aprendiz permanece neste estágio até demonstrar que os conhece bem e sabe aplicá-los em problemas básicos.

A Figura 16 ilustra um exemplo da trajetória de um aluno. 0 eixo horizontal indica a seqüência dos passos e o vertical as ações executadas.

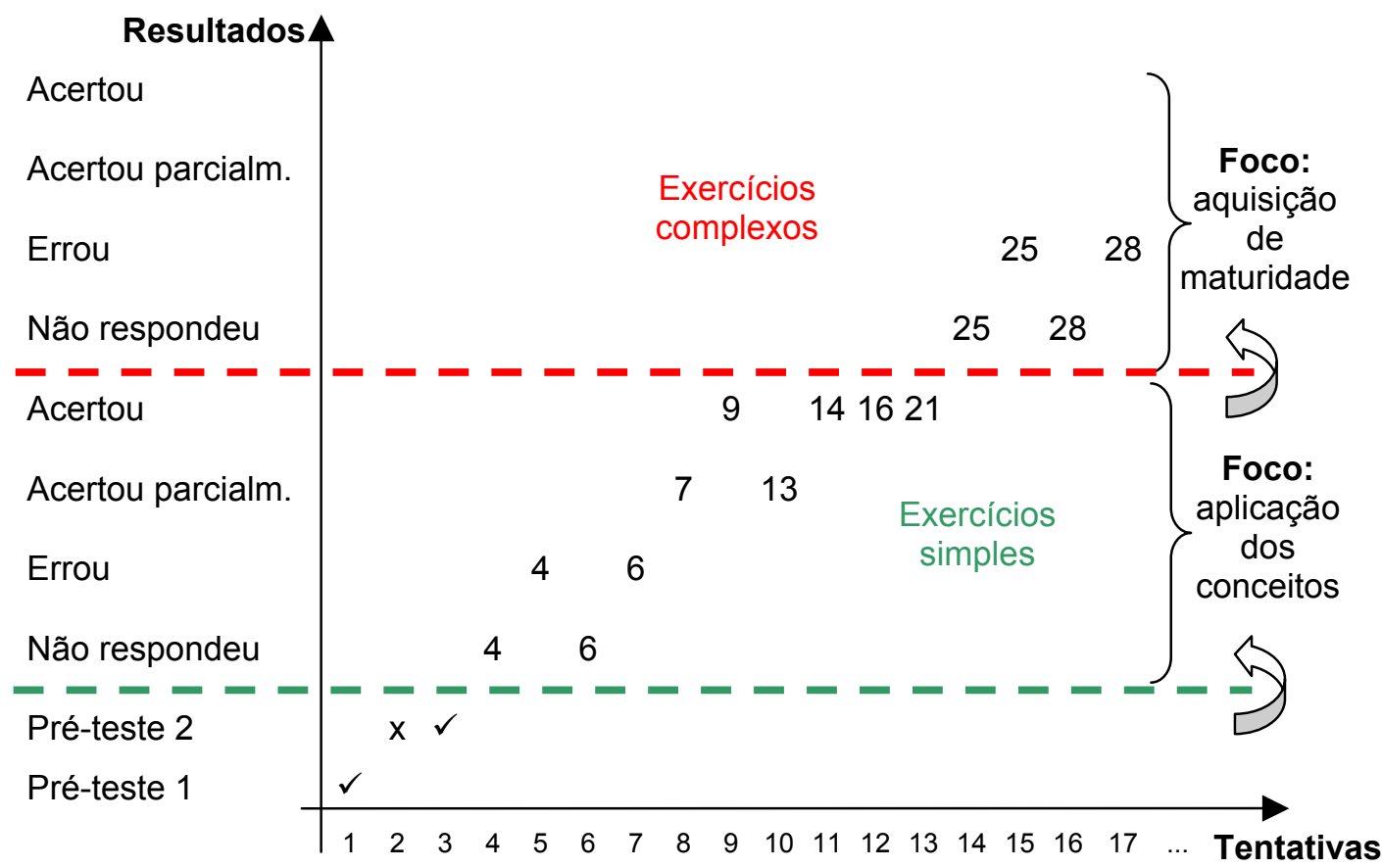

Figura 16 - Exemplo da trajetória de um aluno 
Os valores do corpo do gráfico da Figura 16 indicam os números dos exercícios tentados. Nas etapas de pré-testes, o símbolo " $\checkmark$ " indica que o aluno o executou com sucesso e o "X" que o aluno foi reprovado.

5.7.2 Metas a serem atingidas pelo aluno

Todos os alunos têm quatro metas a atingir:

- Ser aprovado no Pré-teste 1,

- Ser aprovado no Pré-teste 2;

- Passar pela fase de Aplicação de Conceito (AC);

- Passar pela fase de Aquisição de Maturidade (AM), Obs.: esta fase na interface é chamada de Aquisição de Habilidade.

Em todas estas fases ele estudará apenas os conceitos selecionados pelo docente responsável por sua turma (vide item 6.2.3).

O aluno, ao receber as questões do Pré-teste 1 , deve responder todos os testes. Então o sistema Ihe informará a porcentagem de acerto e, dependendo deste número, bloqueará o seu acesso por um tempo aos testes. Este tempo é configurado pelo administrador do sistema (vide item 6.2.4).

Ao final de qualquer tentativa de preenchimento do Pré-teste 1,0 sistema ainda indica quais conceitos o aluno errou e fornece ao aluno um 
link para cada tópico teórico que deve ser estudado.

A meta para a fase de aplicação de conceito é configurada pelo administrador do sistema (vide item 6.2.4). Os parâmetros de referência são:

- número de exercícios que o aluno deve acertar de cada conceito para ser considerado apto em AC;

- número mínimo de acertos que devem ser consecutivos.

A meta para a fase de aquisição de maturidade é configurada pelo docente responsável pela turma (vide item 6.2.3). Os parâmetros de referência são:

- identificação dos exercícios obrigatórios que o aluno deverá acertar;

- número de exercícios trabalhosos que o aluno deverá acertar;

- número de exercícios complexos que o aluno deverá acertar e

- número de exercícios difíceis que o aluno deverá acertar.

Os parâmetros de dificuldade são cadastrados pelo administrador do sistema. Estes dados informam quais as características que configuram um exercício difícil, um exercício trabalhoso e um exercício complexo. Para cada um destes itens (difícil, trabalhoso e complexo), o administrador informa qual deve ser 0 : 
- número mínimo de passos da resolução;

- número mínimo de elementos gráficos;

- número mínimo de conceitos envolvidos;

- Tempo mínimo de resolução.

\subsection{Módulo Tutor}

O Módulo Tutor consulta o Modelo do Aluno e, de acordo com o histórico encontrado, faz a interpretação do estado cognitivo do aprendiz. A partir desta informação, uma ação tutorial é sugerida ao aluno. Normalmente a ação sugerida é a indicação de um exercício para o aluno resolver.

Antes de indicar um exercício, são verificados quais pré-requisitos o aluno já possui e quais as características que o exercício deve ter. Então, o exercício necessário é buscado na biblioteca de exercícios.

Ao receber a resposta do aluno, o sistema a avalia, envia o resultado para o histórico do estudante e gera uma nova ação diagnóstica, a qual é entregue na área de trabalho do aluno (interface).

A Figura 17 ilustra, esquematicamente, o funcionamento do Módulo Tutor deste ambiente. 


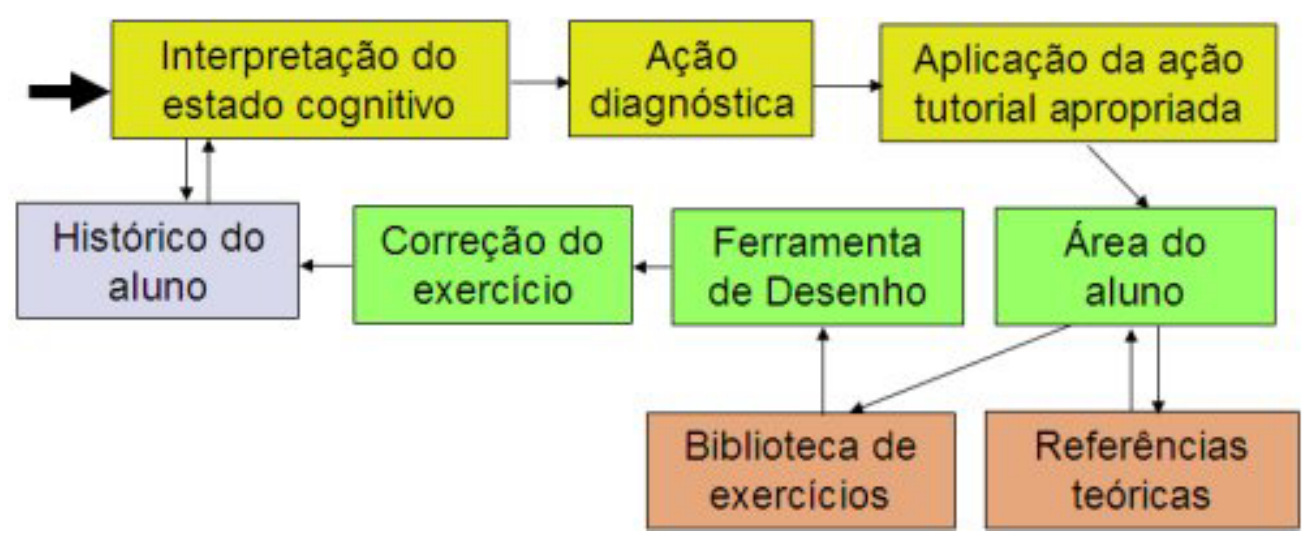

Figura 17 - Esquema do funcionamento do Módulo Tutor

\subsubsection{Ações tutoriais}

Na maior parte das vezes, a ação tutorial é propor um exercício para o aluno resolver. No entanto, quando o sistema detectar que o aprendiz se encontra em dificuldade e necessita de auxílio, ou mesmo quando esta ajuda for solicitada, o procedimento aplicado, dependendo do caso, pode ser, entre outras: indicar para estudo a teoria referente a um conceito, informar ao aluno quais conceitos estão envolvidos no exercício que ele tenta resolver, mostrar a explicação conceitual do exercício ou mostrar a resolução do exercício.

As figuras seguintes ilustram o funcionamento detalhado do sistema de tutoria no ambiente de aprendizado de GD. 


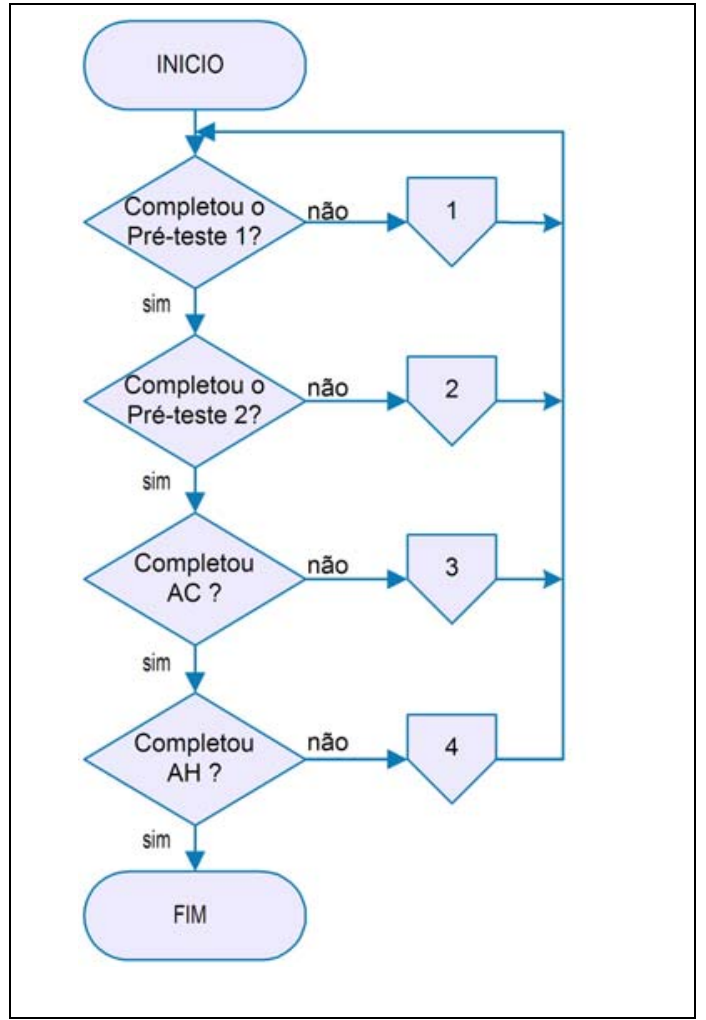

Figura 18 - Diagrama de fluxo de dados do Sistema Tutor - Parte 1 


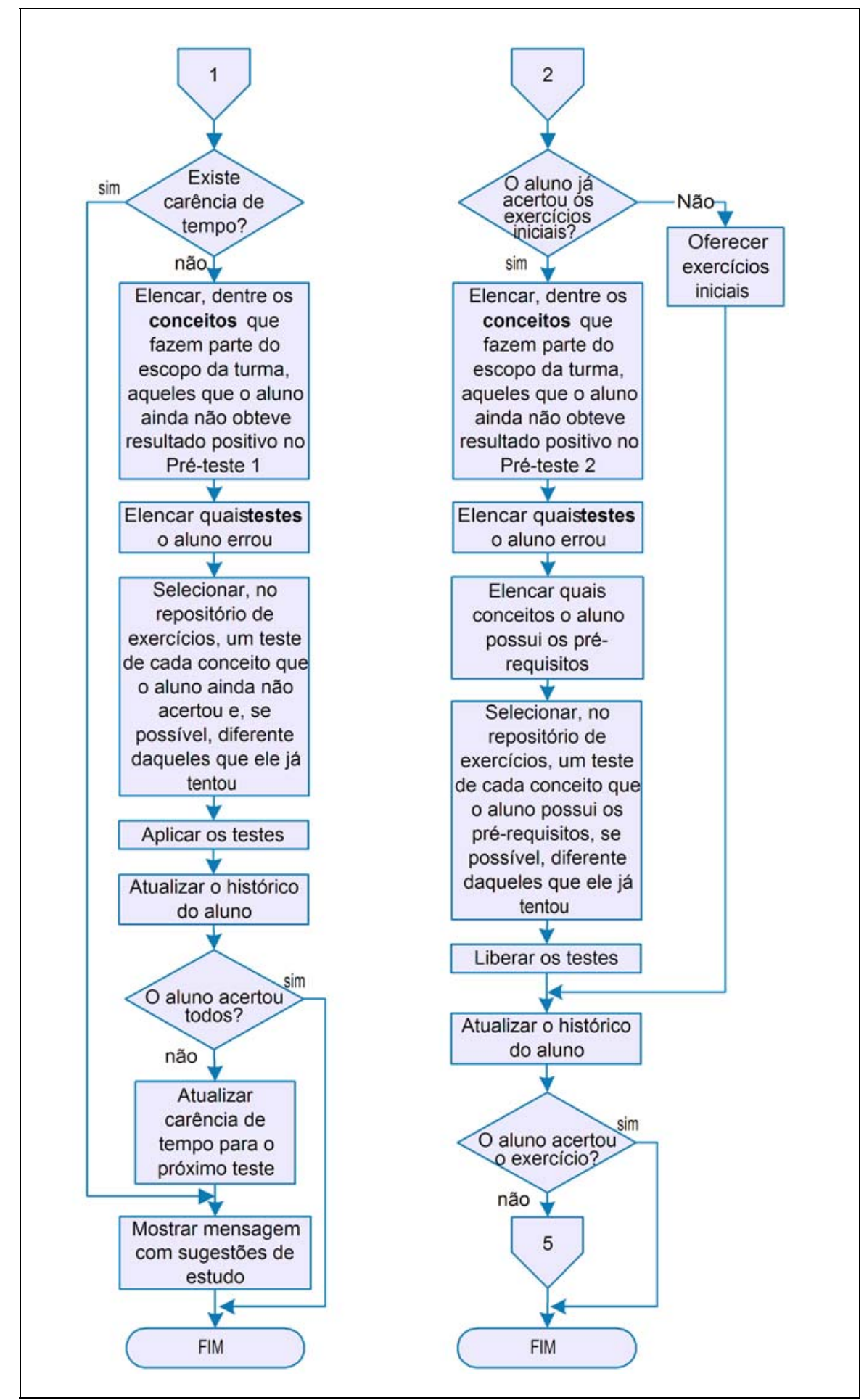

Figura 19 - Diagrama de fluxo de dados do Sistema Tutor - Parte 2 


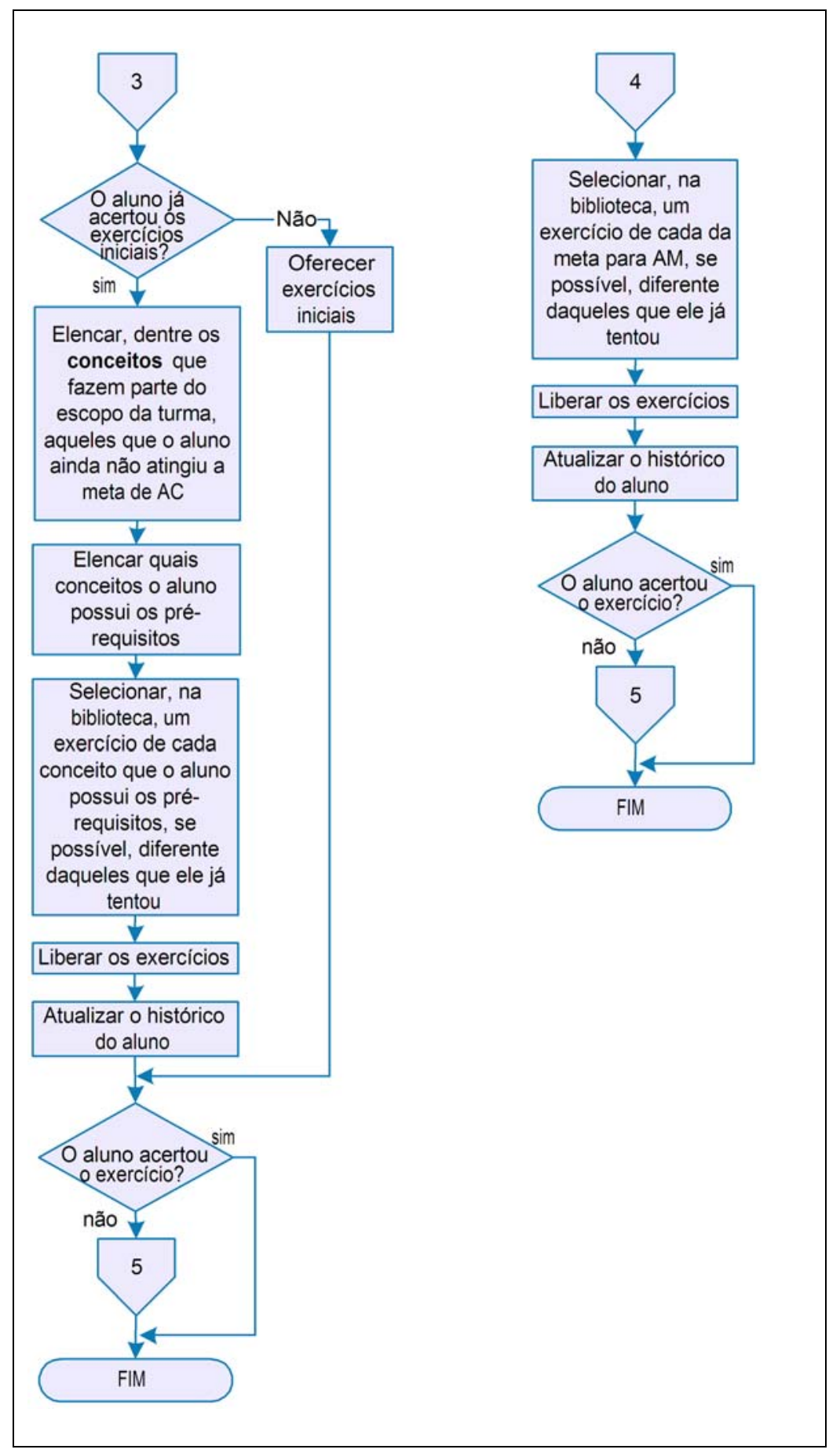

Figura 20 - Diagrama de fluxo de dados do Sistema Tutor - Parte 3 


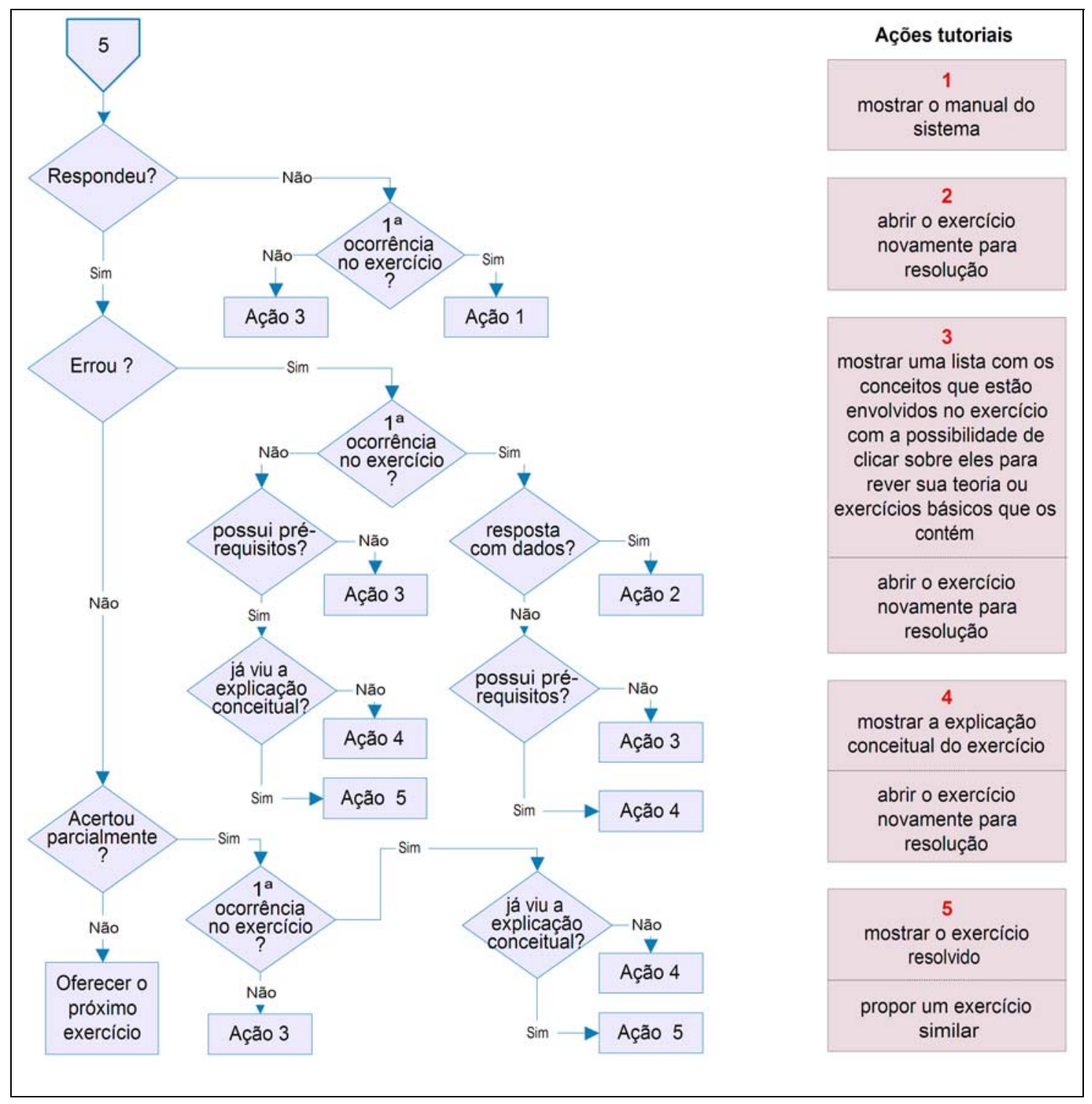

Figura 21 - Diagrama de fluxo de dados do Sistema Tutor - Parte 4 


\section{A INTERFACE WEB}

Os alunos e docentes interagem com o Ambiente de Aprendizado de Geometria Descritiva via uma interface web. Esta interface possui as seguintes áreas:

- Pública (para usuários não cadastrados)

- Restrita (com acesso via login e senha)

A entrada no ambiente se faz pela tela ilustrada na Figura 22.

\begin{tabular}{|cccc|}
\hline Geometria Descritiva & \multicolumn{2}{c|}{ Quinta, 6 de novembro de 2003} \\
$\therefore$ Usuário: visitante & $\therefore$ Cadastre-se & $\therefore$ Login & $\therefore$ Home \\
\hline
\end{tabular}

\section{.: Ambiente :.}

Nossa Proposta

Tipos de Usuários

- Como Utilizar

Ferramenta de Desenho
Ambiente de aprendizado de Geometria Descritiva

Este ambiente é aberto e dedicado aos que buscam ampliar seu conhecimento em GD.

\subsection{A área pública}

A área pública, ilustrada na Figura 22, contém as seguintes opções:

- informações sobre a proposta deste ambiente;

- informações sobre os tipos de usuários que podem se 
beneficiar do sistema;

- informações sobre como utilizar o sistema;

- manual de utilização da ferramenta de desenho;

- entrada para a tela de cadastro;

- entrada para a tela de login;

- entrada para o sistema de e-mail, para enviar uma mensagem ao administrador do sistema;

- informações sobre os créditos do ambiente.

Para utilizar todos os recursos disponíveis no ambiente de aprendizado proposto nesta tese, o usuário deve inicialmente se cadastrar como aluno ou docente. A tela de cadastro está ilustrada na Figura 23.

Imediatamente após se cadastrar, o aluno terá acesso ao ambiente. No entanto, os docentes necessitam da liberação do administrador para utilizar o sistema, isto porque suas possibilidades de interação vão além da utilização receptiva da biblioteca de exercícios, podendo até ampliar seu repositório. 


\section{Cadastro de Usuário}

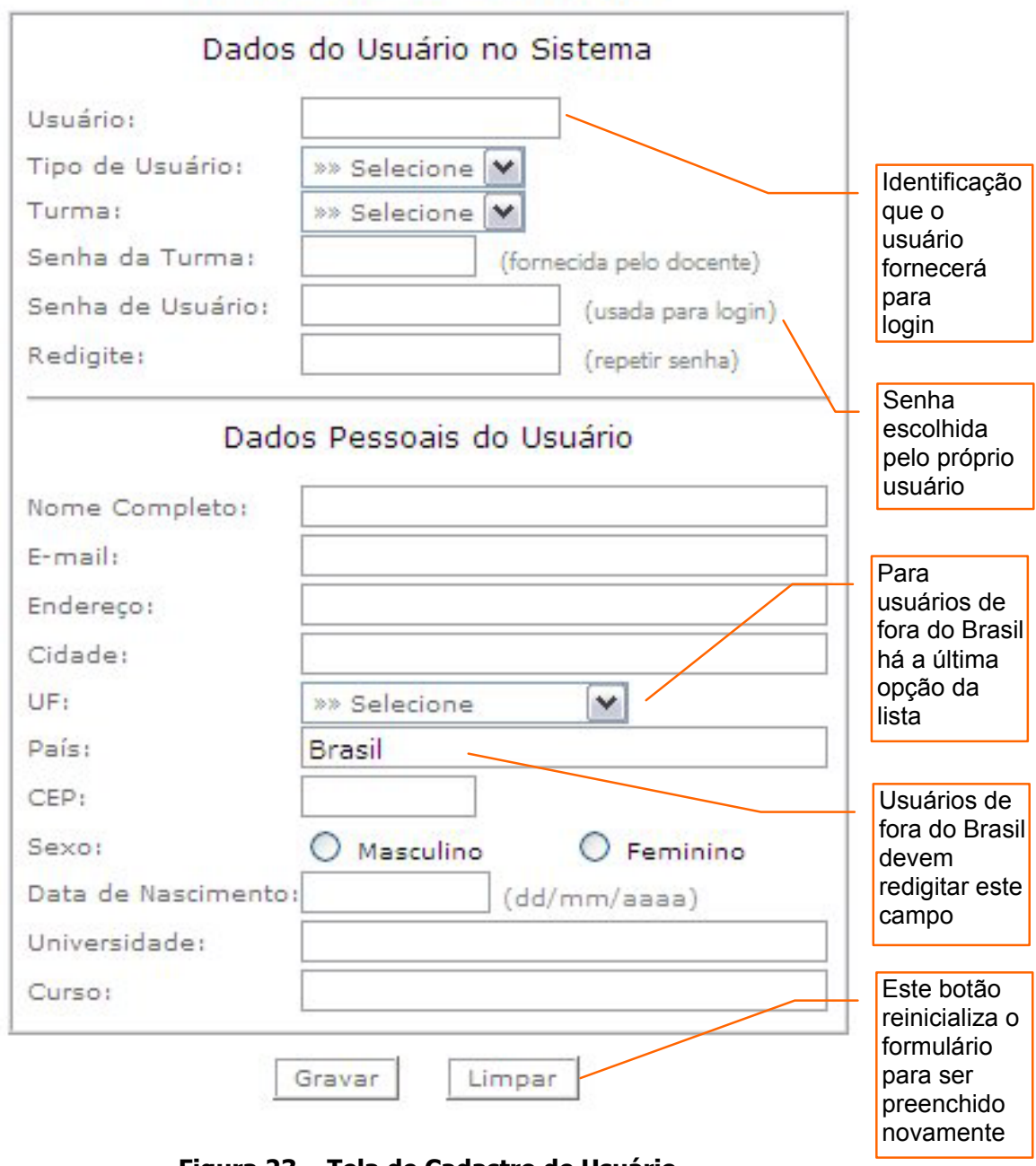

Figura 23 - Tela de Cadastro de Usuário

\subsection{A área restrita}

A área restrita prevê três tipos de usuários:

- Alunos,

- Docentes,

- Administrador do sistema 
Todo usuário entra no sistema pela opção "Login" - Figura 24, que fica no menu superior da tela inicial. Nela o usuário deve digitar sua identificação e sua senha.

Caso o usuário não se lembre da senha, ele deve clicar na opção "esqueci minha senha". Quando isto acontece, o sistema envia um e-mail a ele relembrando sua senha.

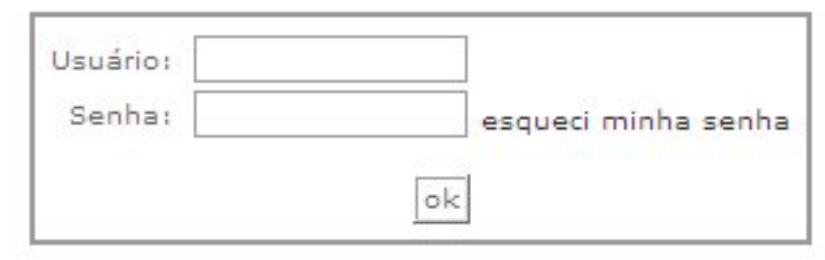

Figura 24 - Tela de Login

6.2.1 Área do aluno

O aluno pode utilizar o sistema fazendo parte de uma turma ou sendo um usuário independente. Para se cadastrar em uma turma, ele deve possuir a senha da mesma, a qual deve ter sido previamente gravada pelo docente responsável daquela turma.

O menu da área do aluno, ilustrado na Figura 25, mostra, além de todas as opções da área aberta, mais dois itens:

- Área de Trabalho, na qual o aluno interage efetivamente, recebe todas as instruções do Sistema Tutor e resolve os exercícios. 
- Busca Teoria, na qual o aluno seleciona o conceito cuja teoria gostaria de rever. Esta opção remete o aluno a páginas HTML do próprio sistema que contém explicações teóricas com animações.

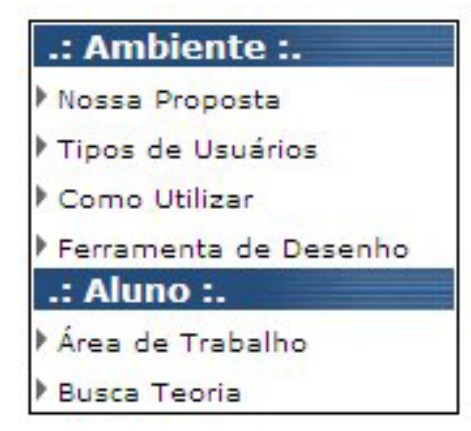

Figura 25 - Menu da área do aluno

Ao entrar na área de trabalho pela primeira vez, o aluno receberá a tela representada na Figura 26.

A área de trabalho do aluno contém um gráfico e uma área de texto. Na primeira vez que o aluno entrar nesta tela ele receberá informações sobre as fases de seu estudo de GD, sobre como acompanhará sua evolução e instruções de como utilizar o sistema.

Cada vez que o aluno é bem sucedido em uma ação, seja ela uma questão do pré-teste ou a resolução de um exercício, um quadradinho é preenchido no gráfico.

Sempre que houver uma área verde no gráfico, ela é sensível ao clique e é a porta de entrada para a resolução de um exercício. 
O gráfico de barras que indica o estágio do aluno é uma tabela gerada dinamicamente pelo sistema. Sua montagem depende das seguintes variáveis:

- O número de linhas do gráfico é determinado pelo número de conceitos de GD que fazem parte do escopo da turma na qual o aluno pertence;

- O número total de colunas da tabela é $3+\mathrm{nAC}$, sendo: 3 a constante que indica as colunas iniciais "Conceitos", "PréTestes Conhecimento" e "Pré-Testes Compreensão" e nAC o número de exercícios que o aluno deve acertar para ser considerado apto em AC. O aluno tem a impressão que a coluna "Aplicação" é uma só e seu preenchimento funciona como uma barra crescente de evolução para cada conceito, porém é esta parte da tabela que possui nAC colunas;

A barra que indica o "Aprimoramento de Habilidade" é outra tabela que possui duas linhas. O número de colunas e determinado pelo número de exercícios que o aluno deverá acertar para ser considerado apto nesta fase (vide item 5.7.2). 


\begin{tabular}{|l|l|l|l|}
\hline \multicolumn{1}{|c|}{ Conceitos } & $\begin{array}{c}\text { Pré-Teste } \\
\text { Conhecimento }\end{array}$ & $\begin{array}{c}\text { Pré-Teste } \\
\text { Compreensão }\end{array}$ & Aplicação \\
\hline Representação do ponto em épura & & & \\
\hline Representação de Plano & & & \\
\hline Traço de Reta & & & \\
\hline Pertinência reta/plano & & & \\
\hline Intersecção reta/plano & & & \\
\hline
\end{tabular}

\section{Seja bem-vindo!}

Você está na sua Área de Trabalho.

Sempre que entrar aqui você verá o gráfico de barras na parte superior da tela e este quadro de texto. 0 gráfico indicará seu estágio de desenvolvimento e no quadro você encontrará sugestões do Sistema Tutor.

Neste sistema, seus estudos de Geometria Descritiva constarão de 4 fases:

- Pré-teste 1: testes do tipo múltipla escolha;

- Pré-Teste 2: exercícios básicos de GD;

- Aplicação de conceitos: exercícios de dificuldade moderada de GD;

- Aprimoramento de Habilidade: exercícios mais elaborados de GD.

O gráfico de barra indicará, por meio de cores, seu sucesso e, especificamente na cor verde, as suas opções de trabalho. A partir da fase 2 você deverá clicar sobre os espaços em verde para que a respectiva atividade se inicie. Quando houver mais de uma possibilidade aberta, você receberá uma sugestão do tutor indicando a mais indicada, porém poderá escolher aquela que desejar.

Nesta área de texto, conforme as dicas do tutor, você também encontrará alguns links. Fique de olho! Agora, para iniciar seu trabalho, clique aqui => Pré-teste 1 .

Bom estudo!!!

Figura 26 - Tela inicial da área do aluno

A Figura 27 ilustra o formato de uma questão do pré-teste 1 que contém apenas texto e a Figura 28 uma que contém imagem. Além destes tipos, podem ser cadastrados no ambiente questões cujas respostas também contém imagens.
O Primeiro
O Segundo
O Terceiro
O Quarto

0 ponto $(-3,4,7)$ está em qual diedro?

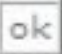

Figura 27 - Questão do Pré-teste 1 sem imagem 


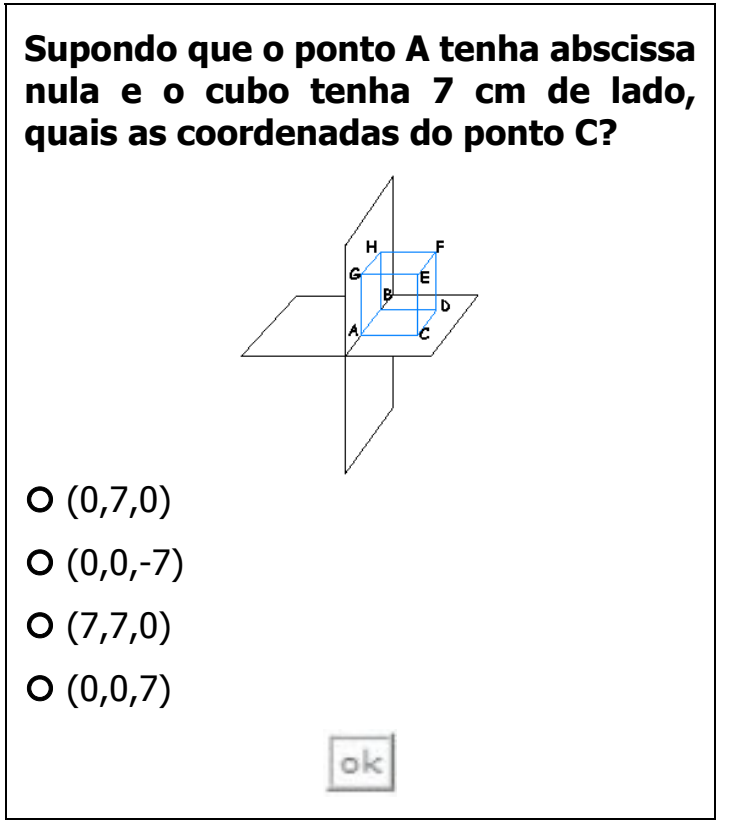

Figura 28 - Questão do Pré-teste 1 com imagem

A Figura 29 ilustra a área do aluno no momento em que ele completa com sucesso o Pré-teste 1 e recebe instruções para o Pré-teste 2.

\begin{tabular}{|l|l|l|l|}
\hline \multicolumn{1}{|c|}{ Conceitos } & $\begin{array}{c}\text { Pré-Teste } \\
\text { Conhecimento }\end{array}$ & $\begin{array}{c}\text { Pré-Teste } \\
\text { Compreensão }\end{array}$ & Aplicação \\
\hline Representação do ponto em épura & & & \\
\hline Representação de Plano & & & \\
\hline Traço de Reta & & & \\
\hline Pertinência reta/plano & & & \\
\hline Intersecção reta/plano & & & \\
\hline \multicolumn{3}{|c|}{ Aprimoramento de Habilidade } \\
\hline
\end{tabular}

\section{Parabéns ! Você já completou o Pré-teste 1 !}

Vamos para a $2^{\mathrm{a}}$ fase.

A partir de agora, você receberá exercícios básicos de Geometria Descritiva e os resolverá por meio da interface gráfica.

Se encontrar dificuldades para utilizar o applet, veja o help que está no menu "Ambiente / Ferramenta de Desenho". Se quiser rever algum conceito de GD, entre no menu "Aluno / Busca Teoria".

Clique sobre os espaços em verde do gráfico acima para que a respectiva atividade se inicie. Quando houver mais de uma possibilidade aberta, você receberá uma sugestão do tutor mostrando a mais indicada, porém poderá escolher aquela que desejar.

Vá em frente!

Figura 29 - Tela do aluno quando completar o pré-teste 1 
A Figura 30 ilustra a área do aluno no momento em que ele completa com sucesso o Pré-teste 2 e recebe instruções para a fase de Aplicação.

\begin{tabular}{|l|l|l|l|}
\hline \multicolumn{1}{|c|}{ Conceitos } & $\begin{array}{c}\text { Pré-Teste } \\
\text { Conhecimento }\end{array}$ & $\begin{array}{c}\text { Pré-Teste } \\
\text { Compreensão }\end{array}$ & Aplicação \\
\hline Representação do ponto em épura & & & \\
\hline Representação de Plano & & & \\
\hline Traço de Reta & & & \\
\hline Pertinência reta/plano & & & \\
\hline Intersecção reta/plano & & & \\
\hline \multicolumn{3}{|c|}{ Aprimoramento de Habilidade } \\
\hline
\end{tabular}

\section{OK! Mais uma fase encerrada !}

A partir de agora você entrará nos exercícios que o auxiliarão a aprimorar e consolidar sua capacidade de aplicação dos conceitos de GD.

Clique sobre os espaços em verde do gráfico acima para que a respectiva atividade se inicie. Quando houver mais de uma possibilidade aberta, você receberá uma sugestão do tutor mostrando a mais indicada, porém poderá escolher aquela que desejar.

\section{Bom trabalho!}

Figura 30 - Tela do aluno quando completar o pré-teste 2

Na fase de Aplicação, cada vez que o aluno resolve um exercício sem sucesso, ele recebe sugestões do Sistema Tutor, a Figura 31 ilustra um exemplo desta situação.

\begin{tabular}{|l|l|l|l|}
\hline \multicolumn{1}{|c|}{ Conceitos } & $\begin{array}{c}\text { Pré-Teste } \\
\text { Conhecimento }\end{array}$ & $\begin{array}{c}\text { Pré-Teste } \\
\text { Compreensão }\end{array}$ & Aplicação \\
\hline Representação do ponto em épura & & & \\
\hline Representação de Plano & & & \\
\hline Traço de Reta & & & \\
\hline Pertinência reta/plano & & & \\
\hline Intersecção reta/plano & & & \\
\hline \multicolumn{2}{|c|}{ Aprimoramento de Habilidade } \\
\hline
\end{tabular}

\section{Sugestões do Tutor:}

Você submeteu o exercício no 36, ele não está correto. Para tentar resolvê-lo novamente clique aqui.

Este exercício envolve os conceitos abaixo, você pode rever a teoria de cada um ou verificar alguns exercícios básicos que os contenham, para isto clique sobre o link referente.

\begin{tabular}{|l|l|l|}
\hline Conceito de posições de reta em relação a plano & teoria & Ex. 16, Ex. 19, Ex. 20, Ex. 25 \\
\hline Conceito de projeção de reta & teoria & Ex. 5, Ex. 6, Ex. 7 \\
\hline
\end{tabular}

Figura 31 - Área do aluno com sugestões do Tutor 
A Figura 36 ilustra a área do aluno no momento em que ele completa com sucesso a fase de Aplicação e recebe instruções para a fase de Aprimoramento de Habilidade.

\begin{tabular}{|l|l|l|l|}
\hline \multicolumn{1}{|c|}{ Conceitos } & $\begin{array}{c}\text { Pré-Teste } \\
\text { Conhecimento }\end{array}$ & $\begin{array}{c}\text { Pré-Teste } \\
\text { Compreensão }\end{array}$ & Aplicação \\
\hline Representação do ponto em épura & & & \\
\hline Representação de Plano & & \\
\hline Traço de Reta & & \\
\hline Pertinência reta/plano & & \\
\hline Intersecção reta/plano & & \\
\hline \multicolumn{2}{|c|}{ Aprimoramento de Habilidade } \\
\hline
\end{tabular}

\section{Estamos quase lá!!!!}

Você completou com sucesso a fase de aplicação de conceitos e agora entrará na de aprimoramento de habilidade. Nesta etapa você encontrará desafios maiores, nos quais os exercícios de GD serão um pouco mais complexos e trabalhosos.

Continue clicando sobre os espaços em verde para entrar no exercício sugerido.

\section{Coragem!!!}

Figura 32 - Tela do aluno quando completar a fase de aplicação de conceito

\subsubsection{Ferramenta de desenho}

A ferramenta de desenho para a resolução de exercícios é um applet Java. A Figura 33 ilustra sua interface.

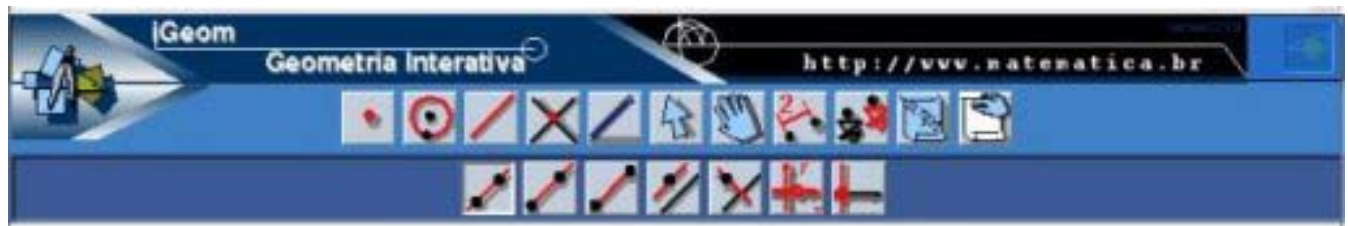

Figura 33 - Ferramenta gráfica para resolução de exercícios 
O programa disponibiliza duas barras de botões. A superior corresponde a opções primárias como criar ponto e criar reta. A inferior mostra um submenu do botão selecionado na barra superior.

Na barra azul inferior da tela do applet existe uma caixa de diálogos, que indica a função do botão sob o mouse.

Atualmente o programa tem opções do tipo "seleção e depois ação" e também "ação e depois seleção". Por exemplo, para criar um ponto, deve-se clicar no primeiro botão do menu superior (ação) e depois clicar na área de desenho onde se deseja colocar o ponto (seleção).

A descrição do funcionamento de cada botão da ferramenta de desenho está na Figura 34. Estes dados foram retirados do site iGeom (http://www.matematica.br/igeom/como-usar-jar.html) e adaptados.

criar circunferência a partir de dois pontos (novos ou pré-existentes)
criar circunferência definida por centro e raio, raio representado por
segmento




\begin{tabular}{|c|c|}
\hline & $\begin{array}{l}\text { naquela posição) } \\
\text { criar perpendicularà reta selecionada passando por ponto dado, primeiro } \\
\text { clique na reta original e depois no ponto (se não existir será criado um } \\
\text { naquele local) } \\
\text { criar eixos cartesianos, com unidade (ao move a unidade todas as distâncias } \\
\text { expressas na tela são recalculadas, mantendo a proporção original com a } \\
\text { unidade); clique neste botão para aparecerem ou desaparecerem os eixos } \\
\text { ao "remover" os eixos todas os construções que os tiveram como origem } \\
\text { serão perdidas }\end{array}$ \\
\hline & $\begin{array}{l}\text { abrir calculadora para efetuar cálculos com medidas (arcos, distâncias ou } \\
\text { outros cálculos) } \\
\text { medir distância entre pontos, com a seta, marque (com } \\
\text { depois clique no ícone medir distância } \\
\text { medir arco determinado por dois pontos numa circunferência, com a seta, } \\
\text { marque o primeiro ponto numa circunferência, a seguir marque o segundo } \\
\text { ponto, em terceiro marque a própria circunferência e depois clique no medir } \\
\text { arco }\end{array}$ \\
\hline$\frac{M}{A}$ & $\begin{array}{l}\text { selecionar/marcar objetos, o primeiro clique sobre um objeto o marca, o segundo o } \\
\text { desmarca }\end{array}$ \\
\hline & $\begin{array}{l}\text { esconder objetos marcados, marque todos os objetos que deseja esconder } \\
\text { depois clique no ícone esconder } \\
\text { remostrar todos os objetos escondidos } \\
\text { rastrear um ponto, clique no botão e depois no ponto que deseja rastrear, } \\
\text { serve para observar o lugar geométrico em estudo } \\
\text { remover algum objeto e seus dependentes, clique no botão e depois no } \\
\text { serão removidos deseja remover, obs.:todos os que dependerem deste também }\end{array}$ \\
\hline
\end{tabular}


envia a imagem gerada para o servidor, ou seja, submete os dados da área de desenho. Após clicar sobre este botão o usuário deverá fechar a janela do applet, ele ainda não possui o comando para fechar automaticamente.

selecionar/marcar objetos, o primeiro clique sobre um objeto, o marca o segundo desmarca. Utilizado para selecionar os elementos da resposta.

Figura 34 - Botões da ferramenta de desenho

\subsection{3 Área do Docente}

O docente, ao utilizar o sistema, pode criar turmas, definir 0 escopo a ser estudado em cada uma delas e acompanhar o desenvolvimento de seus alunos. Além disto o docente pode utilizar a Biblioteca de Exercícios realizando consultas ou incluindo novos problemas.

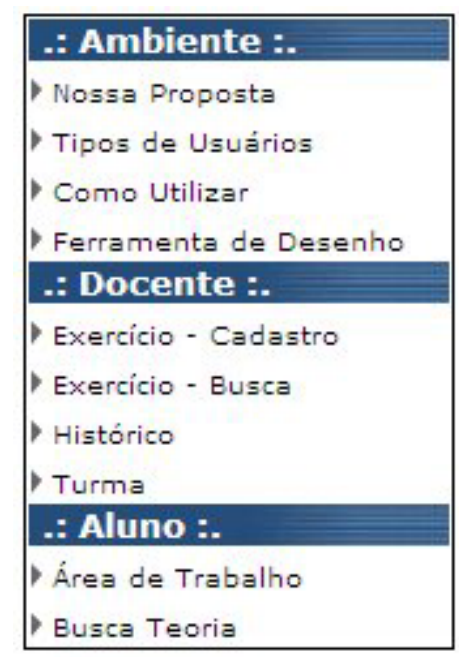

Figura 35 - Menu da área do Docente

O menu da área do docente, ilustrado na Figura 35, mostra, além de todas as opções da área aberta e da área do aluno, mais quatro itens: 
- Cadastro de exercícios, no qual o docente entra para incluir, alterar ou excluir exercícios da biblioteca. Obs.: o docente apenas consegue alterar ou excluir os exercícios cadastrados por ele;

- Busca de exercícios, na qual o docente pode pesquisar, utilizando filtros de seleção, e ver todos os exercícios da biblioteca;

- Histórico, no qual o docente acompanha a evolução dos alunos de sua turma;

- Turma, no qual o docente pode cadastrar novas turmas.

A Figura 36 ilustra a tela para cadastro de turmas, nela o docente pode fazer inclusões ou selecionar aquela que deseja alterar.

Para cadastrar uma turma, o docente deve:

- preencher os campos: código, descrição, senha (que posteriormente ele fornecerá aos alunos para efetuar a matrícula);

- selecionar os conceitos que farão parte do escopo da turma e

- preencher os campos do "Perfil de Meta". 
O docente define a meta para a fase de aprimoramento de habilidade de cada turma, digitando o número (identificação) dos exercícios que os alunos necessariamente devem resolver com sucesso e/ou o número de exercícios trabalhosos, o número de exercícios complexos e o número de exercícios difíceis que o aluno precisa acertar.

\section{Cadastro: Turma}

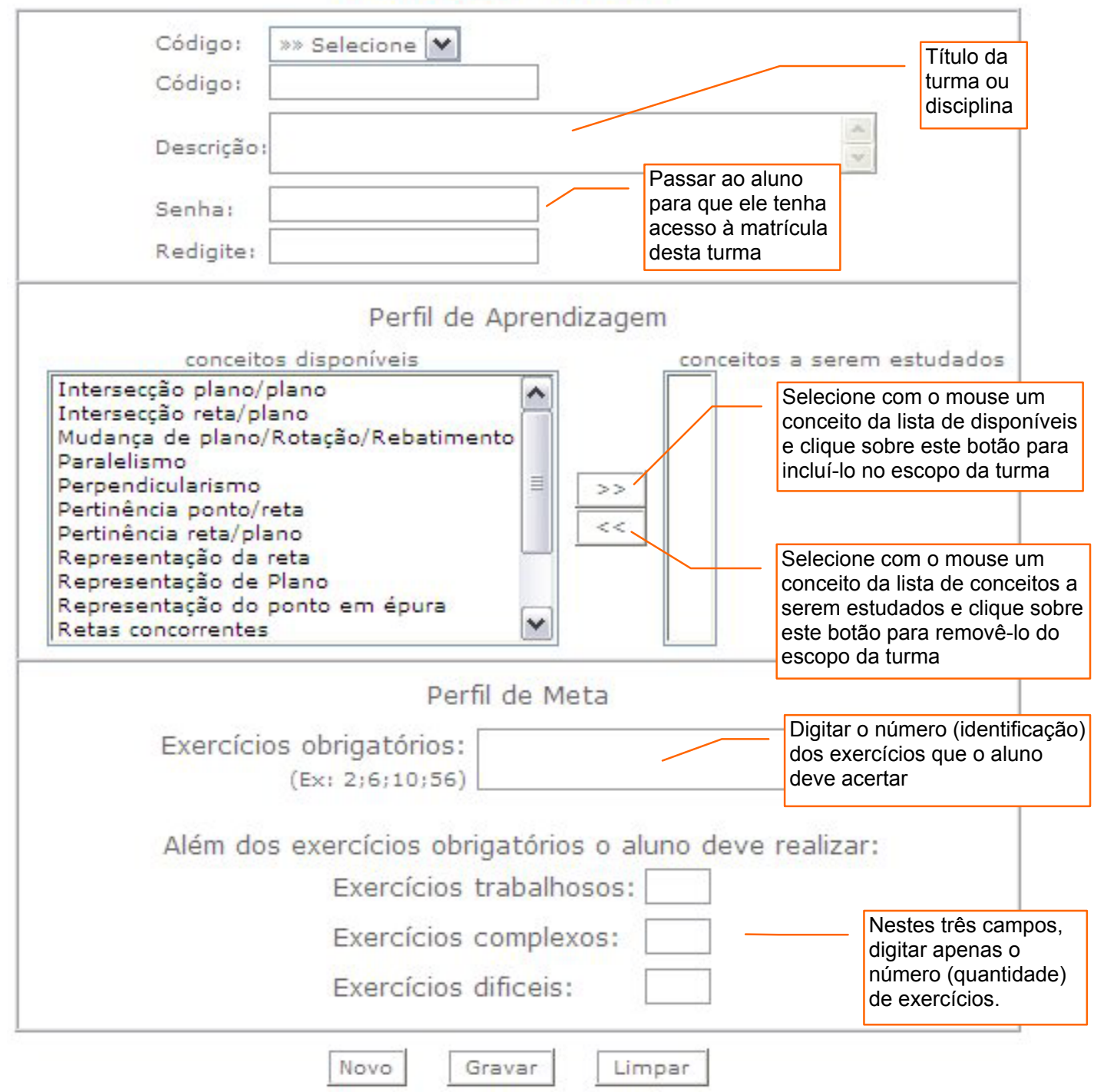

Figura 36 - Tela para cadastro de turmas 
Para exemplificar, a Figura 37 ilustra uma tela de cadastro de turma já preenchida.

Cadastro: Turma

\begin{tabular}{|c|c|c|c|c|c|c|}
\hline \multirow{2}{*}{$\begin{array}{l}\text { Código: } \\
\text { Código: }\end{array}$} & \multicolumn{3}{|c|}{ \#w Selecione $\mathbf{V}$} & & & \multirow[b]{3}{*}{$\frac{a}{2}$} \\
\hline & \multicolumn{3}{|l|}{$5058 \mathrm{~A}$} & & & \\
\hline Descrição: & \multicolumn{3}{|c|}{ Geometria Descritiva I } & & & \\
\hline \multirow{2}{*}{$\begin{array}{l}\text { Senha: } \\
\text { Redigite: }\end{array}$} & \multicolumn{3}{|l|}{$\bullet$} & & & \\
\hline & \multicolumn{3}{|l|}{$\bullet$} & & & \\
\hline \multicolumn{7}{|c|}{ Perfil de Aprendizagem } \\
\hline \multicolumn{4}{|c|}{ conceitos disponíveis } & \multicolumn{3}{|c|}{ conceitos a serem estudados } \\
\hline \multicolumn{3}{|c|}{$\begin{array}{l}\text { Intersecção plano/plano } \\
\text { Interseção reta/plano } \\
\text { Mudança de plano/Rotação/Rebatimento } \\
\text { Paralelismo } \\
\text { Perpendicularismo } \\
\text { Pertinência ponto/reta } \\
\text { Pertinência reta/plano } \\
\text { Representação da reta } \\
\text { Representação de Plano } \\
\text { Representação do ponto em épura } \\
\text { Retas concorrentes }\end{array}$} & 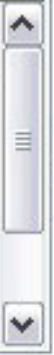 & \multicolumn{3}{|c|}{\begin{tabular}{|l} 
Representação do ponto em épura \\
Representação da reta \\
Pertinência ponto/reta \\
Representação de Plano \\
Pertinência reta/plano \\
Traço de Reta \\
Perpendicularismo \\
Paralelismo \\
Retas concorrentes \\
Intersecção reta/plano \\
\end{tabular}} \\
\hline \multicolumn{7}{|c|}{ Perfil de Meta } \\
\hline \multicolumn{4}{|c|}{$\begin{array}{r}\text { Exercícios obrigatórios: } \\
\text { (Ex: } 2 ; 6 ; 10 ; 56)\end{array}$} & & & $\frac{A}{\nabla}$ \\
\hline \multicolumn{7}{|c|}{ Além dos exercícios obrigatórios o aluno deve realizar: } \\
\hline \multicolumn{7}{|c|}{ Exercícios trabalhosos: 5} \\
\hline \multicolumn{7}{|c|}{ Exercícios complexos: } \\
\hline \multicolumn{7}{|c|}{ Exercícios dificeis: } \\
\hline & Novo & Gra & avar & Lin & npar & \\
\hline
\end{tabular}

Figura 37 - Tela de cadastro de turma preenchida 
Para cadastrar ou alterar um exercício, o docente utiliza a tela

\section{Cadastro de Exercícios que está ilustrada na Figura 38.}

\section{Cadastro: Exercício}

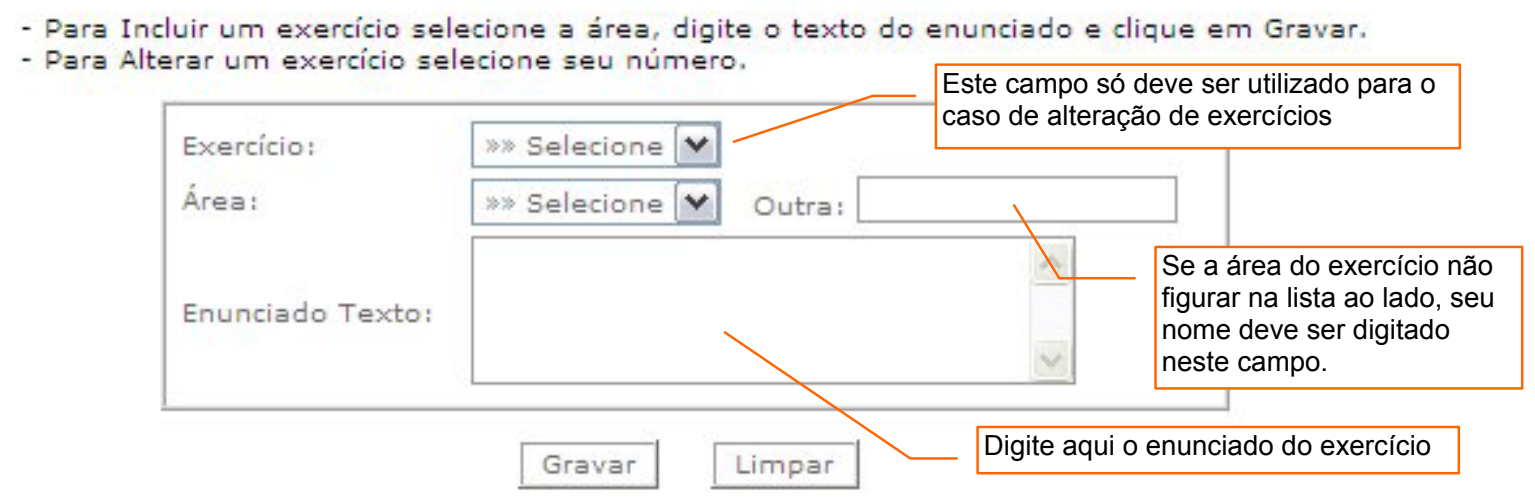

Figura 38 - Tela inicial para cadastro de exercício

Ao clicar no botão gravar abre-se a tela ilustrada na Figura 39.

\section{Cadastro: Exercício}

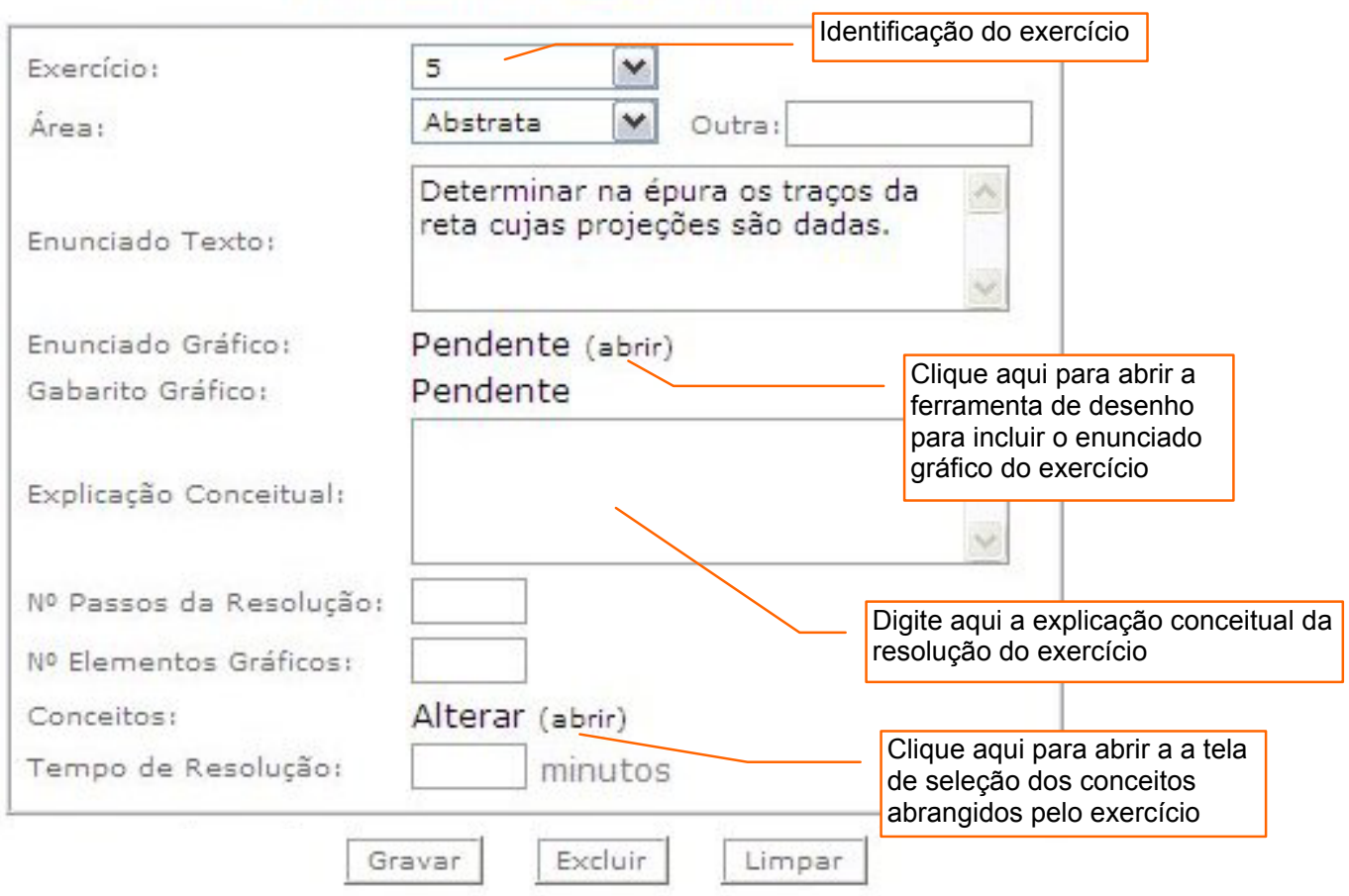

Figura 39 - Tela de cadastro de exercício 
A Figura 40 ilustra a tela da ferramenta de desenho aberta para a inclusão do enunciado gráfico do exercício. A parte superior da tela contém o texto do enunciado.

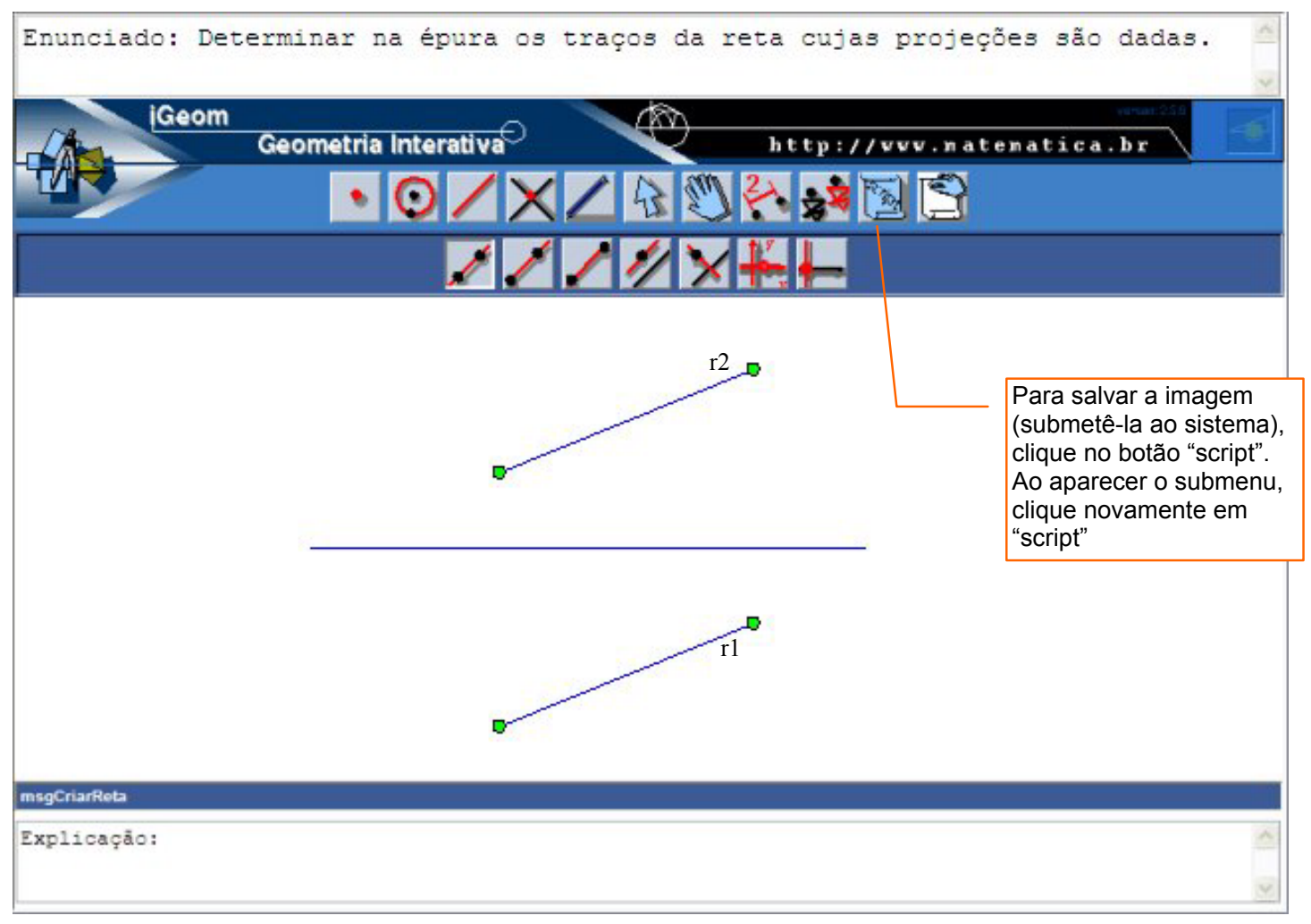

Figura 40 - Inclusão do enunciado gráfico

Ao submeter ao sistema o enunciado gráfico do exercício, aparecerá novamente a tela da Figura 39, desta vez com a palavra "abrir" na frente do campo "Gabarito Gráfico". O docente deverá clicar sobre ela para cadastrar a resolução do exercício. Neste momento a ferramenta de desenho é fornecida ao docente (Figura 41) já com enunciado gráfico para que ele possa desenvolver os passos da resolução. 


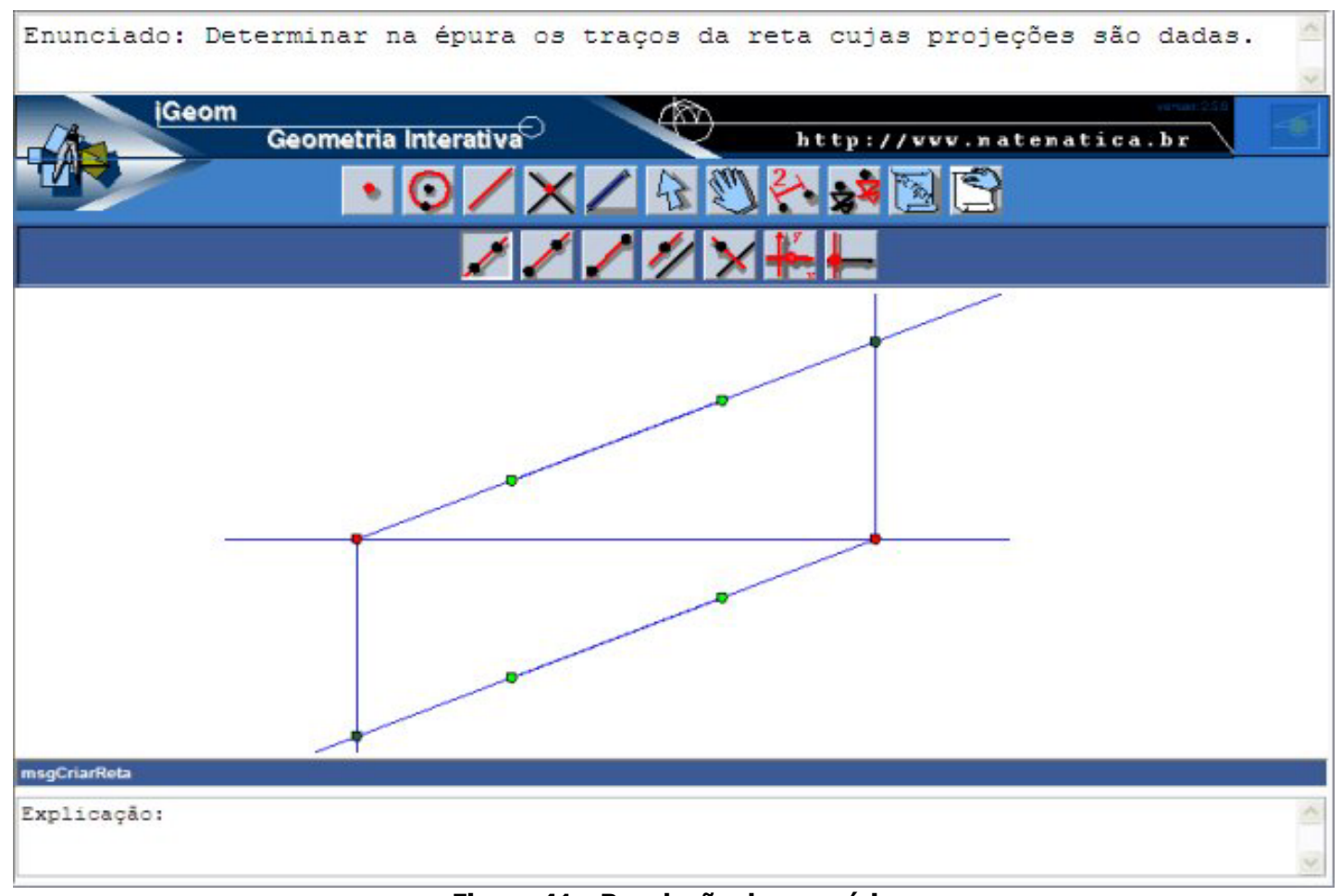

Figura 41 - Resolução do exercício

Após resolver o exercício, o docente deve selecionar os elementos que fazem parte da sua solução. Só então a imagem deve ser submetida ao sistema.

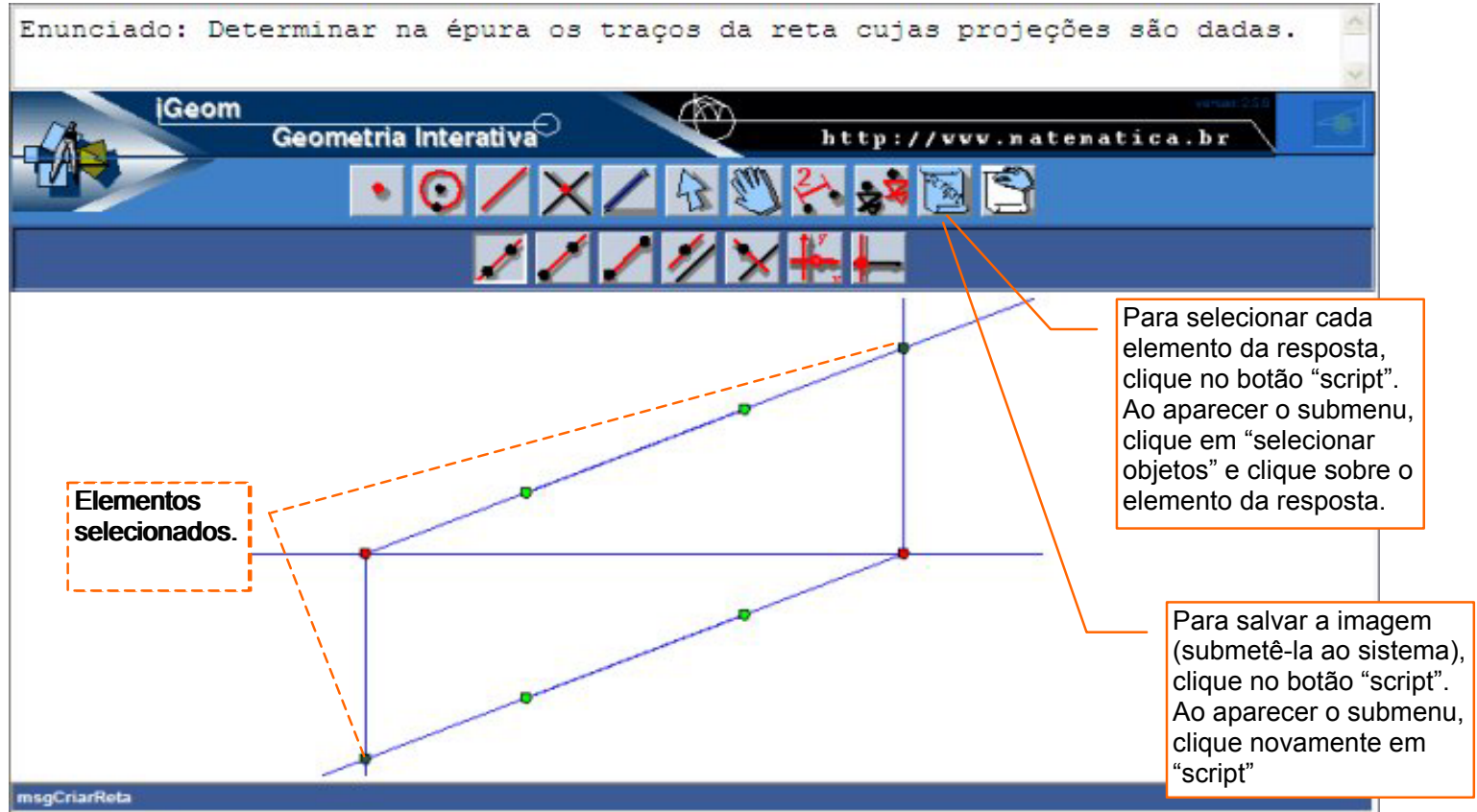

Explicação:

Figura 42 - Seleção do resultado 
A Figura 43 ilustra a tela de seleção dos conceitos englobados pelo o exercício. 0 docente a receberá quando clicar sobre o item "Conceitos (abrir)" da tela de Cadastro de exercícios (Figura 39).

\section{Cadastro Exercício: Conceitos}

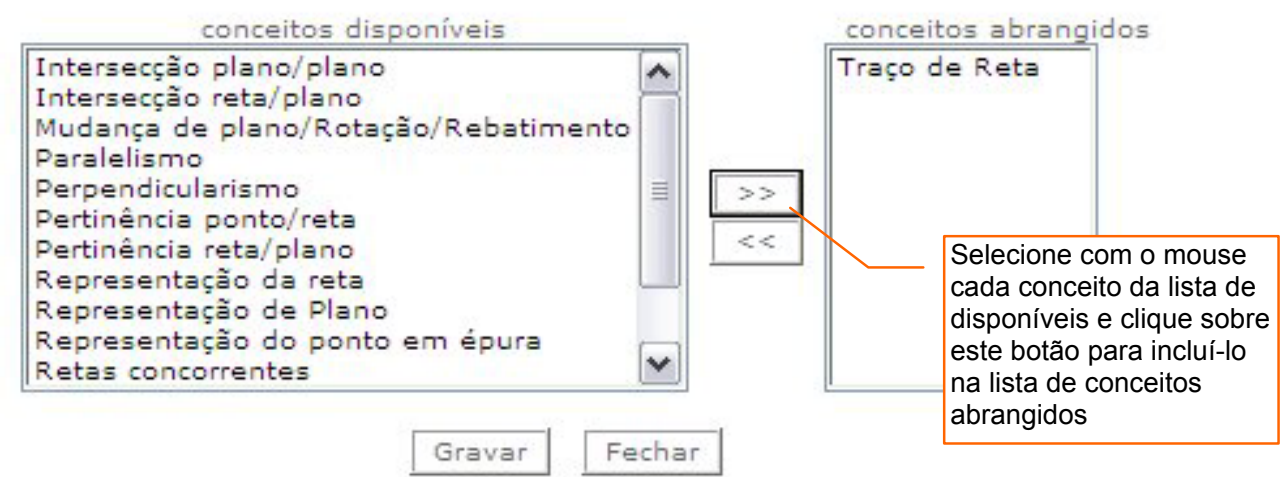

Figura 43 - Seleção de conceitos abrangidos pelo exercício

A Figura 44 ilustra a tela de Busca de Exercícios, ela pode ser acessada pelo docente para realizar pesquisas na biblioteca. Nela o docente deve preencher apenas os campos que deseja filtrar para a busca dos exercícios.

Busca: Exercício

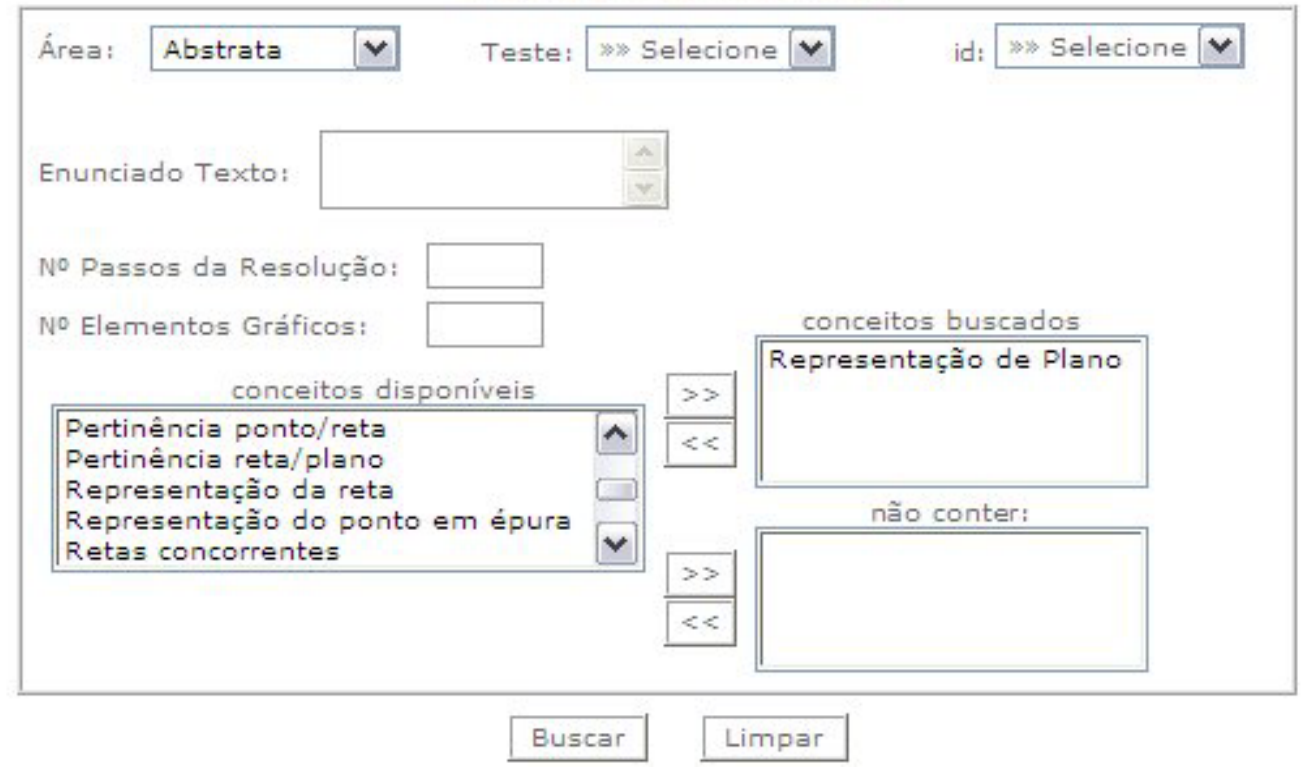

Figura 44 - Busca de exercícios 
6.2.4 Área do Administrador do sistema

O menu da área do administrador, ilustrado na Figura 45, mostra, além de todas as opções da área aberta, da área do aluno e da área do docente, mais dez itens: Pré-teste 1, Parâmetros Pré-teste 1, Parâmetros Dificuldade, Parâmetros Pedagógicos, Parâmetro de Erro, Liberação de Docentes, Área, Conceito, Usuário e Permissão de Acesso.

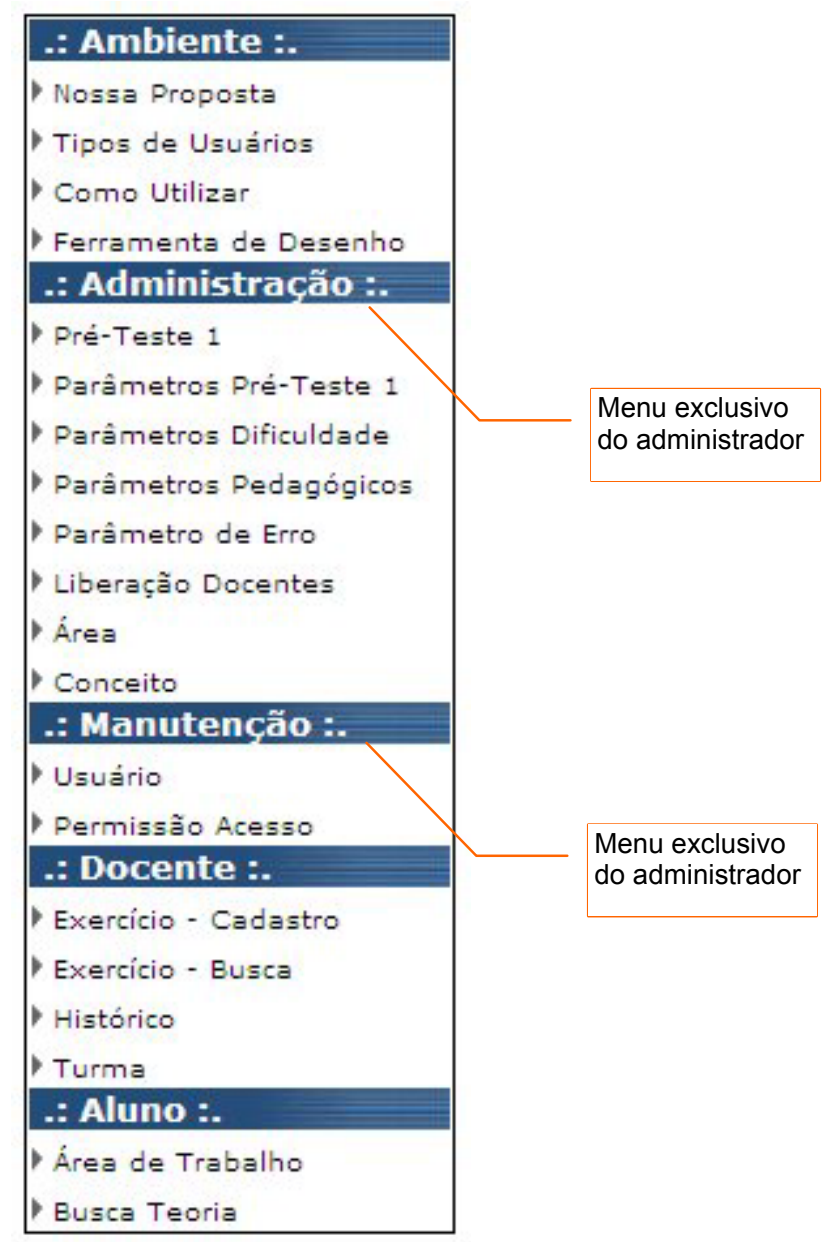

Figura 45 - Menu do administrador 
O item Pré-teste 1 do menu do administrador abre a tela (Figura 46) que permite o cadastro a alteração ou a exclusão das questões, do tipo múltipla escolha, que serão aplicadas aos alunos na fase de Pré-teste 1.

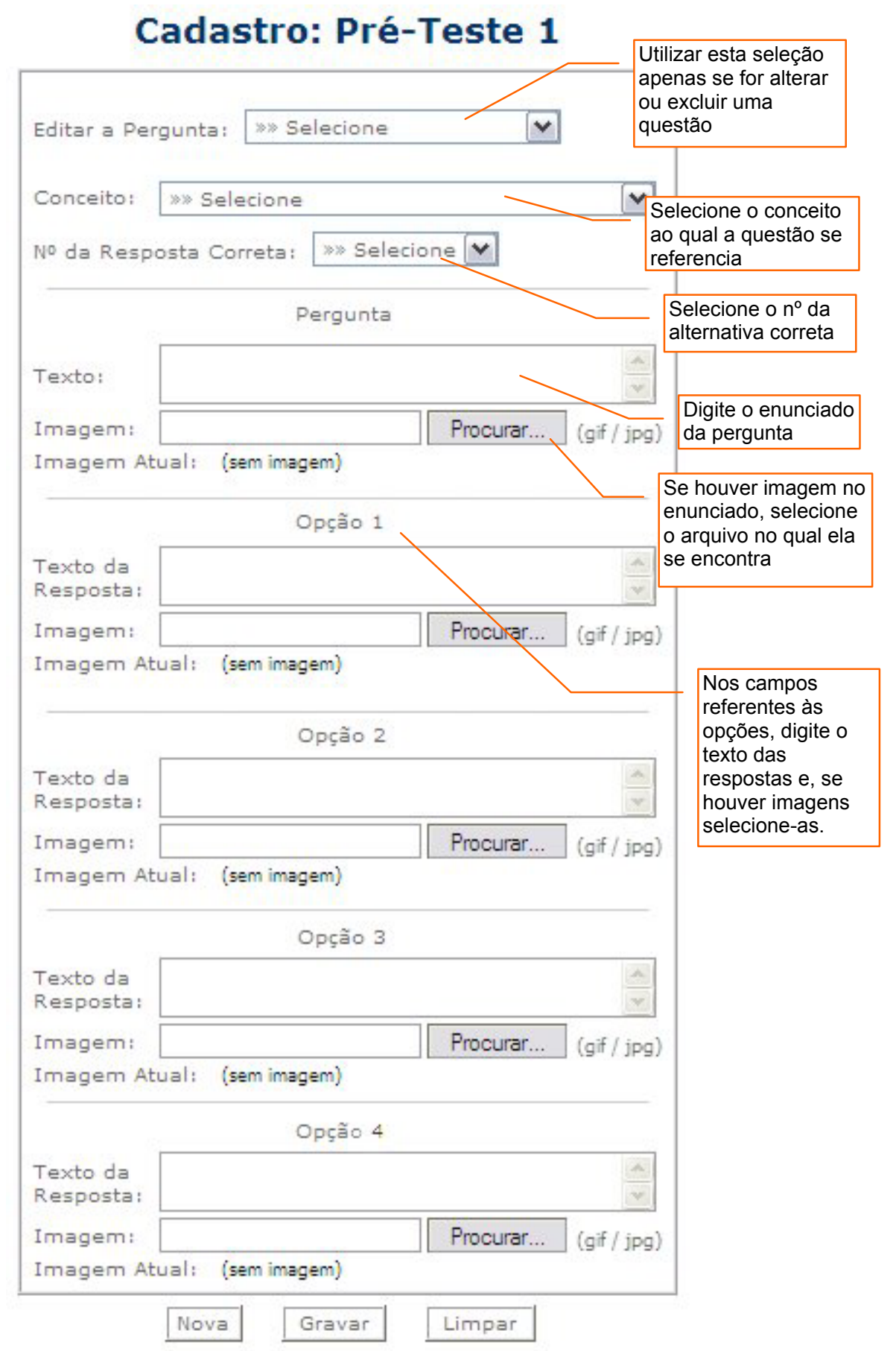

Figura 46 - Cadastro do Pré-teste 1 
Na tela de Parâmetros do Pré-teste 1 (Figura 47), o administrador do sistema configura o tempo que o aluno ficará sem poder acessar os testes novamente dependendo de seu insucesso na tentativa anterior. Durante este "tempo de bloqueio" espera-se que ele estude a teoria indicada pelo tutor.

\section{Cadastro: Parâmetros Pré-Teste 1}

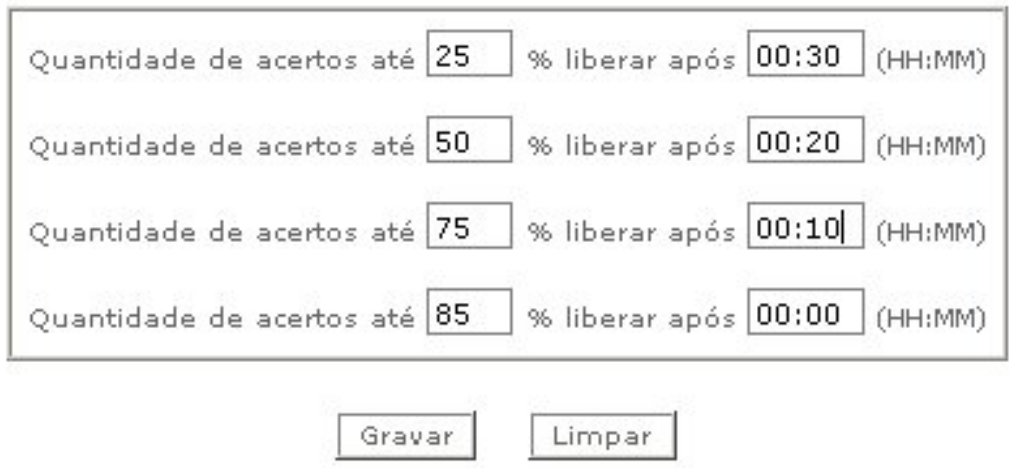

Figura 47 - Parâmetros de tempo para liberação do Pré-teste

Na tela de Parâmetros Pedagógicos (Figura 48), o administrador do sistema configura a meta para a fase de aplicação de conceito.

\section{Cadastro: Parâmetros Pedagógicos}

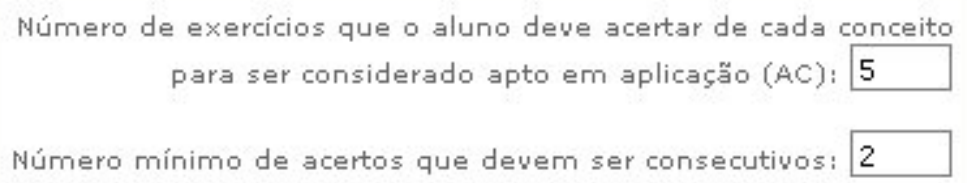

Figura 48 - Parâmetros Pedagógicos 
Na tela de Parâmetros de Dificuldade (Figura 49) o administrador do sistema configura as características "difícil", "trabalhoso" e "complexo" dos exercícios.

\section{Cadastro: Parâmetros Dificuldade}

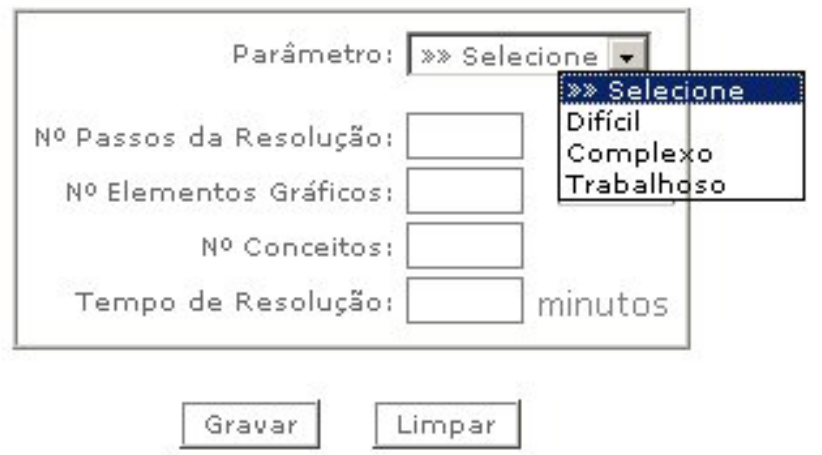

Figura 49 - Parâmetros de Dificuldade

Na comparação das coordenadas, o sistema considera um valor estimado para aproximação, o qual é denominado parâmetro de erro.

\section{Cadastro: Parâmetro de Erro}

Valor para aproximação das coordenadas dos elementos gráficos na resolução dos exercícios: 2

Gravar Limpar

Figura 50 - Parâmetros de Erro para correção do exercício 


\section{CONCLUSÕES E TRABALHOS FUTUROS}

Esta pesquisa fundamentou e implementou um projeto piloto de um Ambiente Computacional de Suporte ao Aprendizado de Geometria Descritiva adaptável à trajetória do aluno.

No sistema desenvolvido, o aluno pode interagir via Internet e desenvolver seu aprendizado por meio da resolução de exercícios de Geometria Descritiva.

A cada interação do aluno, o sistema avalia quais conceitos o mesmo domina e, com base nestes dados, sugere novos exercícios de modo gradual. Quando for o caso, é oferecido ao aprendiz uma lista com as teorias a serem estudadas e exemplos de exercícios resolvidos.

O ambiente desenvolvido pode ser utilizado individualmente e a partir de computadores ligados à Internet, isto possibilita ao estudante ter o tempo que necessitar para a solidificação de sua aprendizagem.

O domínio de Geometria Descritiva, implementado inicialmente no sistema, foi modelado de uma forma lógica e organizado hierarquicamente gerando um grafo de pré-requisitos o qual subsidia o módulo de tutoria do ambiente.

A pesquisa desenvolvida permitiu a definição de uma estratégia pedagógica para ser implantada no Sistema Tutor do ambiente de 
aprendizado, sua validação depende da utilização efetiva pelos alunos das disciplinas que contenham GD, fato que espera-se que ocorra no próximo ano letivo.

A aplicação do sistema desenvolvido pode gerar publicações nas áreas de educação, educação à distância, representação gráfica e engenharia sobre o funcionamento deste ambiente de aprendizado, no intuito de contribuir positivamente para a elaboração de novos programas de ensino.

A partir deste trabalho, podem ser realizadas pesquisas sobre a análise dos históricos dos alunos e a comparação de suas trajetórias. Isto permitirá a verificação de quais caminhos seguidos foram mais breves e eficientes.

Sugere-se também a implementação de rotinas de inteligência artificial no sistema para que acompanhe e corrija a resolução dos exercícios em cada passo dos estudantes.

Tendo como princípio do aprendizado a motivação, a área do aluno do Ambiente de Aprendizado de Geometria Descritiva pode ser transformada em um jogo, o Jornada-GD.

\subsection{O Jornada-GD}

Este ambiente de aprendizado poderia ser comparado com o "Caminho de Santiago de Compostela", no qual os peregrinos vão do sul da 
França ao noroeste da Espanha, porque, além da forma tradicional, existem vários modos de trilhá-lo. No entanto, o objetivo neste caso não seria chegar a um local, mas sim atingir uma meta cognitiva que seria o domínio em aplicações da Geometria Descritiva.

Como no Caminho de Santiago, neste jogo o aprendiz percorreria uma jornada solitária, trabalhosa e muitas vezes cansativa, contudo, aquele que chegasse ao final teria como recompensa a aquisição do conhecimento buscado.

Durante a jornada do aluno, um mestre virtual o acompanharia, ora lançando desafios e ora indicando o caminho mais seguro. Sempre que se fizesse necessário, o mestre forneceria instruções e dicas teóricas que serviriam de ferramentas úteis durante a construção do conhecimento.

O caminho do aprendiz não seria uma trilha reta, ele seria uma rede formada por vários pontos referenciais interligados. Os nós seriam os locais onde aconteceriam os desafios e os ensinamentos. Estes locais forneceriam os suprimentos necessários para que o peregrino pudesse seguir adiante.

Os desafios enviados pelo mestre seriam problemas de GD que precisam ser solucionados. A cada obstáculo superado o aluno poderia adquirir mais força para seguir adiante. Antes de desafiar o aluno, o mestre verificaria qual o repertório por ele conhecido, analisando para isso seu 
histórico com os problemas já solucionados bem como seus insucessos.

Existiriam três níveis de dificuldades para os desafios de cada local. Quanto mais alto o nível do exercício resolvido, mais caminhos se abririam à frente. Quando o aprendiz resolvesse com êxito um problema, ele receberia um "frasco de conhecimento". De acordo com o nível, este frasco poderia ser verde (básico), azul (intermediário) ou violeta (avançado).

O aluno cadastrado, ao entrar no jogo, receberia do Mestre as instruções iniciais (regras do jogo), um pergaminho com o mapa dos pontos referenciais da jornada, um guia de como utilizar a ferramenta de desenho, um manual com a teoria de GD, um diário (onde ficaria seu histórico) e um baú com alguns desafios solucionados (link para a busca de problemas resolvidos). Tudo isto ficaria em um repositório (bagagem).

\subsection{A jornada}

Para jogar, o aluno deveria abrir o mapa que estaria em sua bagagem. Ele viajaria se reportando ao ponto no qual clicasse. Observação: os pontos do mapa iriam se abrindo para acesso na medida que o aluno obtivesse sucesso em seus desafios. Em cada ponto ele receberia do Mestre três desafios, geralmente cada um de um nível diferente de dificuldade (básico, intermediário, avançado). O aluno opta por qual irá tentar resolver clicando sobre ele. 


\subsection{Utilizando seu repositório}

O aluno teria sempre acesso aos itens de seu repositório, sendo assim, ele poderia a qualquer momento:

- pesquisar a teoria de GD folheando o manual;

- verificar a resolução de exercícios abrindo o baú e procurando com uma ferramenta de busca;

- verificar seu diário;

- $\quad$ ler o guia de referência da ferramenta de desenho.

Todos os itens do repositório, fora o diário, poderiam ser sugeridos pelo Mestre a cada insucesso do aluno. Ele indicaria qual item da bagagem utilizar para obter a ajuda necessária naquela etapa da jornada, ou seja, qual teoria deveria ser estudada ou qual exercício verificar sua resolução. 


\section{REFERÊNCIAS BIBLIOGRÁFICAS}

AUSUBEL, D. P., NOVAK, J. D., HANESIAN, H. Psicologia educacional. Interamericana, Rio de Janeiro, 1980.

BARROS, L. N. ; SANTOS, E. T. Um Estudo da Modelagem do Domínio de Geometria Descritiva para a Construção de um Sistema Tutor Inteligente. Anais do XI Simpósio Brasileiro de Informática Educativa (SBIE'2000), p. 259-66, Maceió-AL, nov. 2000.

BECK, J.; STERN, M.; HAUGSJAA, E. Applications of AI in education: the ACM's first electronic publication. Endereço: <http:// www.acm.org/crossroads/xrds3-1/aied.html>

BLOOM, B. S., ENGELHART, M. D., FURST, E. J., HILL, W. H., KRATHWOHL, D. R. Taxonomia de objetivos educacionais. Domínio Cognitivo. Globo, Porto Alegre, 1972.

BRUNER, J. S. Uma nova Teoria da Aprendizagem. Ed. Bloch, Rio de Janeiro, 1976.

BRANFORD, J. D., BROWN, A. L., COCKING, R. R. How people learning: brain mind, experience and school. National Academy of Sciences. National Academy Press, Washington, D.C. 2000.

CHANDRASEKARAN, B.; JOSEPHSON, J. R.; BENJAMINS, V. R. What are ontologies, and why do we need them? IEEE Intelligent Systems. 1999.

DANTE, Luiz Roberto. Criatividade e resolução de problemas na prática educativa matemática. Rio Claro: Instituto de Geociências e Ciências Exatas, Tese de Livre Docência, 1988. 
DASHIEL, J. F. Fundaments of general psychology. Houghton, Boston, 1937.

DIB, C. Z, Tecnologia da Educação e sua aplicação à aprendizagem de Física. Ed. Primavera, São Paulo, 1974.

DIB, C. Z. Afinal, o que você efetivamente mede quando sua avaliação é referenciada pela distribuição normal? BIFUSP Boletim Informativo de Física da USP, Ano XXI, no 18, 21/06/2002.

DUINEVELD, A. J.; STOTER, R.; WEIDEN, M. R.; KENEPA, B.; BENJAMINS, V. R. Wondertools? A comparative study of ontological engineering tools. Proceedings of the $12^{\text {th }}$ Workshop on Knowledge Acquisition, Modeling and Management (KAW'99), p 4.6.1-4.6.20, Banff, Canada, 1999.

ERNEST, P. The philosophy of mathematics education. London. The Falmer Press.

FARQUHAR, A.; FIKES, R.; AND RICE, J. The Ontolingua Server: a Tool for Collaborative Ontology Construction. Technical Report KSL-9626, Computer Science Department, Stanford University, 1996.

FREDERIKSEN, N. Implications of cognitive theory for instruction in problem solving. Review of Educational Research, 54 (3):363-407. 1984

GENESERETH, M. R.; FIKES, R. E. (Editors). Knowledge Interchange Format, Version 3.0 Reference Manual. Technical Report Logic-92-1, Computer Science Department, Stanford University, June 1992.

GIJSELAERS,W.H., New Directions For Teaching and Learning. JosseyBass Publishers, 1996. Cap.2, p. 15-29. 
GIRAFFA, L.M. Fundamentos de Teorias de ensino-aprendizagem e sua aplicação em Sistemas Tutores Inteligentes. Porto Alegre: UFRGS, 1995.

GROSSO, W. E.; ERIKSSON, H.; FERGERSON, R. W.; GENNARI, J. H.; TU, S. W.; MUSEN, M. M. Knowledge Modeling at the Millennium -- The Design and Evolution of Protégé-2000. Proceedings of the $12^{\text {th }}$ International Workshop on Knowledge Acquisition, Modeling and Management (KAW'99), Banff, Canada, 1999.

GRUBER, T. R. Ontolingua: A Mechanism to Support Portable Ontologies. Knowledge Systems Laboratory, Technical Report KSL 9166, Stanford University, 1992.

GRUBER. T. R. Towards Principles for the Design of Ontologies used for Knowledge Sharing. International Journal of Human-Computer Studies, 43 (5/6), p.907-928, 1995.

HAWK, M. C. Descriptive Geometry. McGraw-Hill, New York, 1962.

LERMEN, A.L.; BÔAS, C. J.V. Uma Ferramenta para construção de Sistemas Tutores Inteligentes. Porto Alegre : PUCRS, 1994.

MAGER, R. F. Preparing instructional objectives. Palo Alto, Ca. Fearon Publ, 1962.

MARMO, C. Curso de Desenho. São Paulo, Ed. Moderna, 1974.

MCARTHUR, D.; LEWIS, M.; BISHAY, M. The roles of artificial intelligence in education: current progress and future prospects. Santa Monica, USA, 1993. 
MORAN, J. M. Pedagogia integradora do presencial - virtual. Rio de Janeiro, setembro de 2002. Disponível em:

http://www.abed.org.br/congresso2002/trabalhos/texto50.htm

MURRAY, T. Authoring Intelligent Tutoring Systems: An analysis of the state of the art. International J. of Artificial Intelligence in Education, Vol 10, pp. 98-129. 1999

NEWELL, A., SHAW, J. C., SIMON, H. A. 1958. Elements of a theory of human problem solving. Psycological Review, 65:151-166. 1958.

NOY, N. F. Ontology Development 101: A Guide to Creating Your First Ontology. SMI Technical Report SMI-2001-0880, Stanford University, March 2001.

OHLSSON, S. Constraint-based student modeling. Journal of Artificial Intelligence and Education, 3(4), 429-447. 1992

OLIVEIRA, F.M. Critérios de Equilibração para Sistemas Tutores Inteligentes. Porto Alegre: CPGCC/UFRGS,1994. (Tese de Doutorado).

OLIVEIRA, João Batista Araújo \& CHADWICK, Clifton B., Tecnologia Educacional, Teorias da Instrução. Editora Vozes, Petrópolis, RJ, 1988.

PEREIRA, Aldemar A. Geometria Descritiva. Ed. Quartet, Rio de Janeiro. 2001

POLSON, M.C., Richardson, J.J. Foundations of Intelligent Tutoring Systems. New Jersey, Lawrence Erlbaum Associates, Inc, 1988

POZO, J. I., ECHEVERRIA, M. P. Aprender a solucionar problemas, solucionar problemas para aprender. Madri. Santillana, 1988 
RONDON, Miguel Velido. Aplicações da Geometria Descritiva no Desenho Técnico. Bauru, São Paulo, 1994.

SANTOS, Eduardo Toledo \& ROJAS-SOLA, José Ignacio. An On-Line Library of Descriptive Geometry Problems. In: Proceedings of the 9th International Conference on Geometry and Graphics, v.1, p. 295-299, Johannesburg, South Africa, July 2000.

SANTOS, Eduardo Toledo. Un applet Java ${ }^{\mathrm{TM}}$ para hacer disponibles ejercicios de Geometría Descriptiva en Internet. In: Actas del II Congreso Iberoamericano de Expresión Gráfica, v.1, p.144-149, Salta, Argentina, Septiembre 1999.

SANTOS, Eduardo Toledo e RODRIGUES, Marcos. Educação à Distância Conceitos, Tecnologias, Constatações, Presunções e Recomendações. Escola Politécnica da Universidade de São Paulo, 1999.

SHIN, J. H., HAYNES, R. B., JOHNSTON, M. The effect of a problembased self-directed undergraduate education on life-longlearning. Canadian Medical Association Journal 148:969-976. 1993.

TUMA, D. T. e REIF, F. Problem solving and education. Issues in teaching and research, Hillsdale, Erlbaum, 1980.

ULBRICHT, Vânia Ribas. Modelagem de um ambiente hipermídia de construção do conhecimento em Geometria Descritiva. Tese de Doutorado, Florianópolis, 1997.

VAN LEHN, K.. Conceptual and Meta Learning during Coached Problem Solving. In C. Frasson, G. Gauthier \& A. Lesgold (Eds.), ITS'96: Proceedings the Third International Conference on Intelligent Tutoring Systems. New York: Springer-Verlag, 1996. 
VICCARI, R.M. ; MOUSSALLE, N. Tutores Inteligentes para o Ensino da Linguagem Prolog. Rio de Janeiro: SENAC,1991. 


\section{ANEXO 1 - Base de Dados do Sistema}

A seguir estão descritas as tabelas utilizadas no Ambiente de Aprendizado de GD.

\section{Tabela area}

\begin{tabular}{|c|c|c|c|c|}
\hline Field & Type & Length & Not Null & Default \\
\hline id_area & int4 & 4 & Yes & nextval('public.area_id_area_seq'::text) \\
\hline area & varchar & var & No & \\
\hline status & int4 & 4 & No & 1 \\
\hline data_cad & date & 4 & No & ('now'::text):::date \\
\hline data_alt & date & 4 & No & ('now'::text)::date \\
\hline hora_alt & time & 8 & No & ('now'::text)::time(6) with time zone \\
\hline
\end{tabular}

$\begin{array}{llll}\text { Keyname } & \text { Unique } & \text { Primary } & \text { Field } \\ \text { area_id_area_key } & \text { No } & \text { No } & \text { id_area } \\ \text { area_pkey } & \text { Yes } & \text { Yes } & \text { id_area }\end{array}$

\section{Tabela cfgsis}

\begin{tabular}{|c|c|c|c|c|}
\hline Field & Type & Length & Not Null & Default \\
\hline id_cfgsis & int4 & 4 & Yes & nextval('public.cfgsis_id_cfgsis_seq'::text) \\
\hline parametro & varchar & var & No & \\
\hline valor & varchar & var & No & \\
\hline descricao & varchar & var & No & \\
\hline status & int4 & 4 & No & 1 \\
\hline data_cad & date & 4 & No & ('now'::text):::date \\
\hline data_alt & date & 4 & No & ('now'::text):::date \\
\hline hora_alt & time & 8 & No & ('now'::text)::time(6) with time zone \\
\hline \multicolumn{2}{|c|}{ Keyname } & Unique & Primary & Field \\
\hline \multirow{2}{*}{\multicolumn{2}{|c|}{$\begin{array}{l}\text { cfgsis_id_cfgsis_key } \\
\text { cfgsis_pkey }\end{array}$}} & No & No & id_cfgsis \\
\hline & & Yes & Yes & id_cfgsis \\
\hline
\end{tabular}

\section{Tabela conceito}

\begin{tabular}{l|l|r|l|l|l|}
\multicolumn{1}{c|}{ Field } & Type & Length & Not Null & \multicolumn{1}{c}{ Default } \\
\hline id_conceito & int4 & 4 & Yes & nextval('public.conceito_id_conceito_seq'::text) \\
\hline conceito & varchar & var & No &
\end{tabular}




\begin{tabular}{l|l|r|r|l|l|}
\hline descricao & varchar & var & No & & \\
\hline arquivo & varchar & var & No & \\
nivel & int4 & 4 & No & 0 \\
\hline status & int4 & 4 & No & 1 \\
\hline data_cad & date & 4 & No & ('now'::text)::date \\
\hline data_alt & date & 4 & No & ('now'::text)::date \\
\hline hora_alt & time & 8 & No & ('now'::text)::time(6) with time zone
\end{tabular}

\section{Keyname Unique Primary Field}

conceito_id_conceito_key No No id_conceito

conceito_pkey Yes Yes id_conceito

\section{Tabela depconceito}

\begin{tabular}{|c|c|c|c|c|}
\hline Field & Type & Length & $\begin{array}{l}\text { Not } \\
\text { Null }\end{array}$ & Default \\
\hline id_depconceito & int4 & 4 & Yes & nextval('public.depconceito_id_depconceito_seq'::text) \\
\hline conceito & int4 & 4 & No & \\
\hline dependencia & int4 & 4 & No & \\
\hline status & int4 & 4 & No & 1 \\
\hline data_cad & date & 4 & No & ('now'::text):::date \\
\hline data_alt & date & 4 & No & ('now'::text)::date \\
\hline hora_alt & time & 8 & No & ('now'::text)::time(6) with time zone \\
\hline
\end{tabular}

\begin{tabular}{llll}
\multicolumn{1}{c}{ Keyname } & Unique & Primary & \multicolumn{1}{c}{ Field } \\
depconceito_id_depconceito_key & No & No & id_depconceito \\
depconceito_pkey & Yes & Yes & id_depconceito
\end{tabular}

\section{Tabela exercicio}

\begin{tabular}{|l|l|r|l|l|l|}
\multicolumn{1}{|c|}{ Field } & Type & Length & Not Null & \multicolumn{1}{c|}{ Default } \\
\hline id_exercicio & int4 & 4 & Yes & nextval('public.exercicio_id_exercicio_seq'::text) \\
\hline id_area & int4 & 4 & No & \\
\hline id_usuario & int4 & 4 & No & \\
\hline teste & int4 & 4 & No & \\
\hline enunciadote & varchar & var & No & \\
\hline enunciadogr & varchar & var & No & \\
\hline gabaritogr & varchar & var & No & \\
\hline explicacao & varchar & var & No & \\
\hline passos & varchar & var & No & \\
\hline
\end{tabular}




\begin{tabular}{l|l|r|l|l|l|}
\hline elementos & varchar & var & No & \\
\hline conceitos & varchar & var & No & \\
\hline tempo & varchar & var & No & \\
\hline visualizacoes & varchar & var & No & \\
\hline tentativas & varchar & var & No & \\
\hline acertos & varchar & var & No & \\
\hline status & int4 & 4 & No & 2 \\
\hline data_cad & date & 4 & No & ('now'::text):::date \\
\hline data_alt & date & 4 & No & ('now'::text)::date \\
\hline hora_alt & time & 8 & No & ('now'::text)::time(6) with time zone \\
\hline
\end{tabular}

\begin{tabular}{|c|c|c|c|}
\hline Keyname & Unique & Primary & Field \\
\hline & No & No & rcicio \\
\hline 0 & Yes & Yes & id_exercicio \\
\hline
\end{tabular}

Tabela exercicio_conceito

\begin{tabular}{|c|c|c|c|c|}
\hline Field & Type & Length & $\begin{array}{l}\text { Not } \\
\text { Null }\end{array}$ & Default \\
\hline id_exercicio_conceito & int4 & 4 & Yes & nextval('public.exercicio_conceito_id_exercicio_conceito_seq':.te \\
\hline id_exercicio & int4 & 4 & No & \\
\hline id_conceito & int4 & 4 & No & \\
\hline status & int4 & 4 & No & 1 \\
\hline data_cad & date & 4 & No & ('now'::text)::date \\
\hline data_alt & date & 4 & No & ('now'::text)::date \\
\hline hora_alt & time & 8 & No & ('now'::text)::time(6) with time zone \\
\hline
\end{tabular}

\section{Keyname Unique Primary Field}

exercicio_conceito_id_exercicio_conceito_key No No id_exercicio_conceito exercicio_conceito_pkey Yes Yes id_exercicio_conceito

\section{Tabela grupotela}

\begin{tabular}{l|l|r|l|l|l|}
\multicolumn{1}{|c|}{ Field } & Type & Length & Not Null & \multicolumn{1}{c|}{ Default } \\
\hline id_grupotela & int4 & 4 & Yes & nextval('public.grupotela_id_grupotela_seq'::text) \\
\hline rotulo & varchar & var & No & \\
\hline ordem & int4 & 4 & No & \\
\hline status & int4 & 4 & No & 1 \\
\hline data_cad & date & 4 & No & ('now'::text)::date \\
\hline data_alt & date & 4 & No & ('now'::text)::date \\
\hline
\end{tabular}


\begin{tabular}{l|l|l|l} 
hora_alt & time & 8 & No
\end{tabular}

\begin{tabular}{|c|c|c|c|}
\hline Keyname & Unique & Primary & Field \\
\hline otela_id_g & No & No & id grupotela \\
\hline ela_pkey & Yes & Yes & id_grupotela \\
\hline
\end{tabular}

Tabela historico

\begin{tabular}{l|l|r|l|l|l|l|}
\multicolumn{1}{|c|}{ Field } & Type & Length & Not Null & \multicolumn{1}{c}{ Default } \\
\hline id_historico & int4 & 4 & Yes & nextval('public.historico_id_historico_seq'::text) \\
\hline id_usuario & int4 & 4 & No & \\
\hline id_preteste1 & int4 & 4 & No & \\
\hline id_preteste2 & int4 & 4 & No & \\
\hline id_exercicio & int4 & 4 & No & \\
\hline gabaritogr & varchar & var & No & \\
\hline status & int4 & 4 & No & 1 \\
\hline data_cad & date & 4 & No & ('now'::text):::date \\
\hline data_alt & date & 4 & No & ('now'::text):::date \\
\hline hora_alt & time & 8 & No & ('now'::text):::time(6) with time zone \\
\hline
\end{tabular}

\begin{tabular}{|c|c|c|c|}
\hline Keyname & Unique & Primary & Field \\
\hline historico_id_historico_key & No & No & istorico \\
\hline historico_pkey & Yes & Yes & id_historico \\
\hline
\end{tabular}

Tabela mensagem

\begin{tabular}{l|l|r|l|l|l|}
\multicolumn{1}{|c|}{ Field } & Type & Length & $\begin{array}{l}\text { Not } \\
\text { Null }\end{array}$ & \multicolumn{1}{c}{ Default } \\
\hline id_mensagem & int4 & 4 & Yes & nextval('public.mensagem_id_mensagem_seq'::text) \\
\hline remetente & int4 & 4 & No & \\
\hline destinatario & int4 & 4 & No & \\
\hline assunto & varchar & var & No & \\
\hline mensagem & varchar & var & No & \\
\hline data & date & 4 & Yes & ('now'::text):::date \\
\hline hora & time & 8 & Yes & ('now'::text)::time(6) with time zone \\
\hline status & int4 & 4 & No & 1 \\
\hline
\end{tabular}

$\begin{array}{llll}\text { Keyname } & \text { Unique } & \text { Primary } & \text { Field } \\ \text { mensagem_id_mensagem_key } & \text { No } & \text { No } & \text { id_mensagem } \\ \text { mensagem_pkey } & \text { Yes } & \text { Yes } & \text { id_mensagem }\end{array}$


Tabela parametrodificuldade

\begin{tabular}{|c|c|c|c|c|}
\hline Field & Type & Length & $\begin{array}{l}\text { Not } \\
\text { Null }\end{array}$ & Default \\
\hline id_parametrodificuldade & int4 & 4 & Yes & $\begin{array}{l}\text { nextval('public.parametrodificuldade_i } \\
\text { d_parametrodificuldade_seq'::text) }\end{array}$ \\
\hline parametro & varchar & var & No & \\
\hline passos & varchar & var & No & \\
\hline elementos & varchar & var & No & \\
\hline conceitos & varchar & var & No & \\
\hline tempo & varchar & var & No & \\
\hline data & date & 4 & Yes & ('now'::text):::date \\
\hline hora & time & 8 & Yes & ('now'::text)::time(6) with time zone \\
\hline status & int4 & 4 & No & 1 \\
\hline
\end{tabular}

\section{Keyname}

parametrodificuldade_id_parametrodificuldade _key

parametrodificuldade_pkey

\section{Unique Primary}

No No id_parametrodificuldade

Yes Yes id_parametrodificuldade

Tabela parametroerro

\begin{tabular}{l|l|r|l|l|}
\multicolumn{1}{c|}{ Field } & \multicolumn{1}{c}{ Type } & Length & \multicolumn{1}{c}{$\begin{array}{c}\text { Not } \\
\text { Null }\end{array}$} & \multicolumn{1}{c}{ Default } \\
\hline id_parametroerro & int4 & 4 & Yes & $\begin{array}{l}\text { nextval('public.parametroerro_id_parametroe } \\
\text { rro_seq'::text) }\end{array}$ \\
\hline erro & $\begin{array}{l}\text { varcha } \\
\text { r }\end{array}$ & var & No & \\
\hline data & date & 4 & Yes & ('now'::text):::date \\
\hline hora & time & 8 & Yes & ('now'::text)::time(6) with time zone \\
\hline status & int4 & 4 & No & 1
\end{tabular}

\begin{tabular}{lllll}
\multicolumn{1}{c}{ Keyname } & Unique & Primary & \multicolumn{1}{c}{ Field } & Action \\
parametroerro_id_parametroerro_key & No & No & id_parametroerro Drop \\
parametroerro_pkey & Yes & Yes & id_parametroerro Drop
\end{tabular}


Tabela parametropedagogico

\begin{tabular}{|c|c|c|c|c|c|c|}
\hline Field & Type & Length & Not Null & \multicolumn{3}{|r|}{ Default } \\
\hline $\begin{array}{l}\text { id_parametropeda } \\
\text { gogico }\end{array}$ & int4 & 4 & Yes & \multicolumn{3}{|c|}{$\begin{array}{l}\text { nextval('public.parametropedagogico_id_para } \\
\text { metropedagogico_seq'::text) }\end{array}$} \\
\hline acertos & $\begin{array}{l}\text { varch } \\
\text { ar }\end{array}$ & var & No & & & \\
\hline $\begin{array}{l}\text { acertosconsecutiv } \\
\text { os }\end{array}$ & $\begin{array}{l}\text { varch } \\
\text { ar }\end{array}$ & var & No & & & \\
\hline data & date & 4 & Yes & \multicolumn{3}{|c|}{ ('now'::text)::date } \\
\hline hora & time & 8 & Yes & \multicolumn{3}{|c|}{ ('now'::text)::time(6) with time zone } \\
\hline status & int4 & 4 & No & \multicolumn{3}{|l|}{1} \\
\hline \multicolumn{4}{|c|}{ Keyname } & Unique & Primary & Field \\
\hline \multicolumn{4}{|c|}{$\begin{array}{l}\text { parametropedagogico_id_parametropeda } \\
\text { gogico_key }\end{array}$} & No & No & $\begin{array}{l}\text { id_parametropedagogic } \\
\text { o }\end{array}$ \\
\hline \multicolumn{4}{|c|}{ parametropedagogico_pkey } & Yes & Yes & $\begin{array}{l}\text { id_parametropedagogic } \\
\text { o }\end{array}$ \\
\hline
\end{tabular}

\section{Tabela parametropedagogico}

\section{Field Type Length Not Null}

id_parametropeda gogico

acertos

acertosconsecutiv

os

data

hora

status

\section{int4}

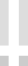

varch

ar

varch

ar

date

time

int4
4 Yes

var

var No

4 Yes

8 Yes

4 No

\section{Default}

nextval('public.parametropedagogico_id_para metropedagogico_seq'::text)

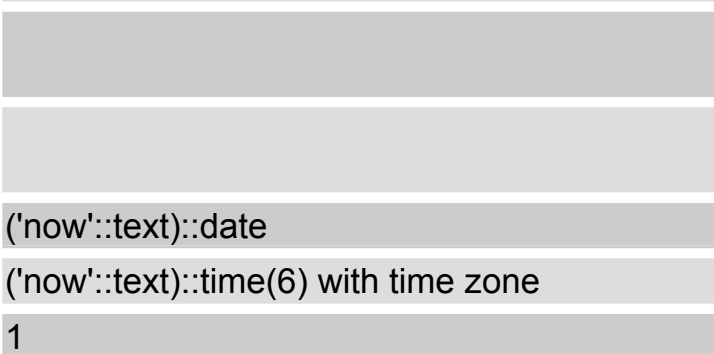

\section{Keyname}

parametropedagogico_id_parametropedagogico _key

parametropedagogico_pkey

\section{Unique Primary}

No No

Yes Yes

\section{Field}

id_parametropedagogic o

id_parametropedagogic

\section{Tabela parametropreteste1}

\begin{tabular}{|c|c|c|c|c|}
\hline Field & Type & Length & Not Null & Default \\
\hline $\begin{array}{l}\text { id_parametropret } \\
\text { este1 }\end{array}$ & int4 & 4 & Yes & $\begin{array}{l}\text { nextval('public.parametropreteste1_id_para } \\
\text { metropreteste1_seq'::text) }\end{array}$ \\
\hline acertoate & varch & var & No & \\
\hline
\end{tabular}




\begin{tabular}{|c|c|c|c|c|c|}
\hline & ar & & & & \\
\hline liberaapos & $\begin{array}{l}\text { varch } \\
\text { ar }\end{array}$ & var & No & & \\
\hline data & date & 4 & Yes & ('now'::text)::date & \\
\hline hora & time & 8 & Yes & ('now'::text)::time( & (6) with time zone \\
\hline status & int4 & 4 & No & 1 & \\
\hline & \multicolumn{3}{|c|}{ Keyname } & Unique Primary & Field \\
\hline \multicolumn{4}{|c|}{ parametropreteste1_id_parametropreteste1_key } & No & id_parametropreteste1 \\
\hline \multicolumn{4}{|c|}{ parametropreteste1_pkey } & Yes & id_parametropreteste1 \\
\hline
\end{tabular}

\section{Tabela permissao}

\begin{tabular}{l|l|r|l|l|l}
\multicolumn{1}{|c|}{ Field } & \multicolumn{1}{c}{ Type } & Length & \multicolumn{1}{c}{$\begin{array}{c}\text { Not } \\
\text { Null }\end{array}$} & \multicolumn{1}{c}{ Default } \\
\hline id_permissao & int4 & 4 & Yes & nextval('public.permissao_id_permissao_seq'::text) \\
\hline id_tela & int4 & 4 & No & \\
\hline id_rotina & int4 & 4 & No & \\
\hline tipo & varchar & 2 & No & \\
\hline id_chave & int4 & 4 & No & \\
\hline permissao & int4 & 4 & No & \\
\hline status & int4 & 4 & No & 1 \\
\hline data_cad & date & 4 & No & ('now'::text):::date \\
\hline data_alt & date & 4 & No & ('now'::text):::date \\
\hline hora_alt & time & 8 & No & ('now'::text)::time(6) with time zone \\
\hline
\end{tabular}

\begin{tabular}{|c|c|c|c|}
\hline Keyname & Unique & Primary & Field \\
\hline ey & No & No & id_pe \\
\hline _pkey & Yes & Yes & id_permissao \\
\hline
\end{tabular}

Tabela preteste1

\begin{tabular}{|c|c|c|c|c|}
\hline Field & Type & Length & Not Null & Default \\
\hline id_preteste1 & int4 & 4 & Yes & nextval('public.preteste1_id_preteste1_seq'::text) \\
\hline pergunta & varchar & var & No & \\
\hline perguntaimg & varchar & var & No & \\
\hline id_conceito & int4 & 4 & No & \\
\hline resposta & int4 & 4 & No & \\
\hline resposta1 & varchar & var & No & \\
\hline resposta1img & varchar & var & No & \\
\hline
\end{tabular}




\begin{tabular}{|c|c|c|c|c|}
\hline resposta2 & varchar & var & No & \\
\hline resposta2img & varchar & var & No & \\
\hline resposta3 & varchar & var & No & \\
\hline resposta3img & varchar & var & No & \\
\hline resposta4 & varchar & var & No & \\
\hline resposta4img & varchar & var & No & \\
\hline data & date & 4 & Yes & ('now'::text)::date \\
\hline hora & time & 8 & Yes & ('now'::text)::time(6) with time zone \\
\hline status & int4 & 4 & No & 1 \\
\hline
\end{tabular}

\section{Keyname Unique Primary Field}

preteste1_id_preteste1_key No No id_preteste1

preteste1_pkey Yes Yes id_preteste1

\section{Tabela rotina}

\begin{tabular}{l|l|r|r|l|l|}
\multicolumn{1}{|c|}{ Field } & \multicolumn{1}{c|}{ Type } & Length & Not Null & \multicolumn{1}{c|}{ Default } \\
\hline id_rotina & int4 & 4 & Yes & nextval('public.rotina_id_rotina_seq'::text) \\
\hline rotina & varchar & var & No & \\
\hline descricao & varchar & var & No & \\
\hline status & int4 & 4 & No & 1 \\
\hline data_cad & date & 4 & No & ('now'::text):::date \\
\hline data_alt & date & 4 & No & ('now':::text):::date \\
\hline hora_alt & time & 8 & No & ('now'::text)::time(6) with time zone \\
\hline
\end{tabular}

\begin{tabular}{llll} 
Keyname & Unique & Primary & \multicolumn{1}{c}{ Field } \\
rotina_id_rotina_key & No & No & id_rotina \\
rotina_pkey & Yes & Yes & id_rotina
\end{tabular}

\section{Tabela tipousu}

\begin{tabular}{l|l|r|l|l|l|}
\multicolumn{1}{r|}{ Field } & Type & Length & Not Null & \multicolumn{1}{c}{ Default } \\
id_tipousu & int4 & 4 & Yes & nextval('public.tipousu_id_tipousu_seq'::text) \\
tipo & varchar & var & No & \\
\hline status & int4 & 4 & No & 1 \\
\hline data_cad & date & 4 & No & ('now'::text):::date \\
\hline data_alt & date & 4 & No & ('now'::text):::date \\
\hline hora_alt & time & 8 & No & ('now'::text)::time(6) with time zone
\end{tabular}

\section{Keyname Unique Primary Field}


tipousu_id_tipousu_key No No id_tipousu

tipousu_pkey Yes Yes id_tipousu

Tabela turma

\begin{tabular}{l|l|r|r|r|r|}
\multicolumn{1}{|c|}{ Field } & Type & Length & Not Null & \multicolumn{1}{|c}{ Default } \\
\hline id_turma & int4 & 4 & Yes & nextval('public.turma_id_turma_seq'::text) \\
\hline codigo & varchar & var & No & \\
\hline descricao & varchar & var & No & \\
\hline docente & int4 & 4 & No & \\
\hline exobrigatorios & varchar & var & No & \\
\hline extrabalhosos & varchar & var & No & \\
\hline excomplexos & varchar & var & No & \\
\hline exdificeis & varchar & var & No & \\
\hline senha & varchar & var & No & \\
\hline status & int4 & 4 & No & 1 \\
\hline data_cad & date & 4 & No & ('now'::text):::date \\
\hline data_alt & date & 4 & No & ('now'::text)::date \\
\hline hora_alt & time & 8 & No & ('now'::text)::time(6) with time zone
\end{tabular}

\begin{tabular}{clll}
\multicolumn{1}{c}{ Keyname } & Unique & Primary & Field \\
turma_id_turma_key & No & No & id_turma \\
turma_pkey & Yes & Yes & id_turma
\end{tabular}

Tabela turma_conceito

\begin{tabular}{l|l|l|l|l|l|}
\multicolumn{1}{|c|}{ Field } & Type & Length & $\begin{array}{l}\text { Not } \\
\text { Null }\end{array}$ & \multicolumn{1}{c}{ Default } \\
\hline id_turma_conceito & int4 & 4 & Yes & nextval('public.turma_conceito_id_turma_conceito_seq'::text) \\
\hline id_turma & int4 & 4 & No & \\
\hline id_conceito & int4 & 4 & No & \\
\hline status & int4 & 4 & No & 1 & \\
\hline data_cad & date & 4 & No & ('now'::text):::date \\
\hline data_alt & date & 4 & No & ('now'::text):::date \\
\hline hora_alt & time & 8 & No & ('now'::text)::time(6) with time zone
\end{tabular}

\section{Keyname Unique Primary Field}

turma_conceito_id_turma_conceito_key No No id_turma_conceito

turma_conceito_pkey Yes Yes id_turma_conceito 
Tabela usuario

\begin{tabular}{l|l|r|r|r|}
\multicolumn{1}{|c|}{ Field } & \multicolumn{1}{|c|}{ Type } & Length & Not Null & \multicolumn{1}{|c}{ Default } \\
\hline id_usuario & int4 & 4 & Yes & nextval('public.usuario_id_usuario_seq'::text) \\
\hline usuario & varchar & var & No & \\
\hline senha & varchar & var & No & \\
\hline id_tipousu & int4 & 4 & No & \\
\hline id_turma & int4 & 4 & No & \\
\hline nome & varchar & var & No & \\
\hline email & varchar & var & No & \\
\hline endereco & varchar & var & No & \\
\hline cidade & varchar & var & No & \\
\hline uf & varchar & var & No & \\
\hline pais & varchar & var & No & \\
\hline cep & varchar & var & No & \\
\hline sexo & char & 1 & No & \\
\hline data_nascimento & date & 4 & No & \\
\hline universidade & varchar & var & No & \\
\hline curso & varchar & var & No & \\
\hline preteste1 & varchar & var & No & \\
\hline preteste2 & varchar & var & No & \\
\hline administrador & int4 & 4 & Yes & 0 \\
\hline status & int4 & 4 & Yes & 1 \\
\hline data_cad & date & 4 & No & ('now'::text):::date \\
\hline data_alt & date & 4 & No & ('now'::text):::date \\
\hline hora_alt & time & 8 & No & ('now'::text):::time(6) with time zone \\
\hline
\end{tabular}

\section{Keyname Unique Primary Field}

usuario_id_usuario_key No No id_usuario

usuario_pkey Yes Yes id_usuario

\section{Table usuturma}

\section{Field Type Length Not Null Default}

\begin{tabular}{|c|c|c|c|c|}
\hline id_usuturma & int4 & 4 & Yes & nextval('public.usuturma_id_usuturma_seq'::text) \\
\hline id_usuario & int4 & 4 & No & \\
\hline id_turma & int4 & 4 & No & \\
\hline data_cad & date & 4 & No & ('now'::text)::date \\
\hline data_alt & date & 4 & No & ('now'::text)::date \\
\hline hora_alt & time & 8 & No & ('now'::text)::time(6) with time zone \\
\hline
\end{tabular}




\section{Keyname}

Unique Primary

Field

usuturma_id_usuturma_key No

No

id_usuturma

usuturma_pkey

Yes Yes

id_usuturma 


\section{Telas do Sistema}

As principais telas do sistema estão relacionadas na lista abaixo. Suas descrições estão logo a seguir.

- aluno_principal.php

- area_cadastro.php

- area_lista.php

- conceito_cadastrol.php

- config_cadastro.php

- dependencia.php

- docentependente_lista.php

- exercicicio_cadastro.php

- exercicio_enunciado_cadastro.php

- exercicio_gabarito_cadastro.php

- exercicio_lista.php

- grupotela_cadastro.php

- mensagem.php

- mensagem_lista.php

- operacao_cadastro.php

- operacaoconceito_lista.php

- permissao_cadastro.php

- rotina_cadastro.php

- sessao_lista.php

- tela_cadastro.php

- telarotina_lista.php

- tipousu_cadastro.php

- turma_cadastro.php

- turmaXusuario_lista.php

- usuario_cadastro.php

- usuario_lista.php

\section{Descrição das telas}

- aluno_principal.php

Tela que contém o ambiente personalizado do aluno. É a partir dela que o aprendiz interage com o tutor, recebendo informações e acessando os recursos do sistema. 
- area_cadastro.php

Tela de cadastro para áreas (civil, elétrica, mecânica, naval, arquitetura, etc), contém apenas o rótulo da área e se esta está ativa ou inativa.

- conceito_cadastro.php

Tela para cadastro dos conceitos. Ela contém o rótulo do conceito, uma descrição detalhada e o diretório onde se encontram as páginas que explicaram a teoria do conceito para o aluno.

- config_cadastro.php

Cadastro de configurações do sistema, contém os campos Parâmetro, Valor e Descrição. Estes campos são utilizados na customização do sistema, por exemplo: o parâmetro tempo_sessao contém o valor 60 , este é utilizado para estipular o tempo limite da sessão, no caso 60 minutos.

- dependencia.php

Listagem das dependências imediatas das operações. Esta tabela possibilita a construção do grafo com os tópicos de GD.

- docentependente_lista.php

Listagem dos docentes pendentes, com um link para a modificação dos dados cadastrais para cada docente bem como a possibilidade de ativálos ou desativá-los.

- exercícios

Cadastro de exercícios (em fase de desenvolvimento).

- grupotela_cadastro.php

Cadastro do grupo de telas, contém os campos rótulo e ordem. Este grupo é utilizado na montagem do menu lateral para cada tipo de usuário. Por exemplo, os menus dos alunos são diferentes dos de docentes e do administrador. Cada usuário vê apenas as opções que Ihe são permitidas. 
- grupotela_lista.php

Listagem dos grupos de telas cadastrados, com links para a modificação dos dados de cada grupo.

- mensagem.php

Tela para o envio de mensagens, contém os campos: Para, Assunto e Mensagem.

- mensagem_lista.php

Caixa de entrada do usuário. Contém as mensagens recebidas. Nesta tela as mensagens podem ser lidas a partir de um clique no assunto da mensagem, bem como a redação e o envio de respostas.

- operacao_cadastro.php

Cadastro de operações descritivas, esta tela contém o rótulo da operação, sua descrição, o diretório onde ficam os arquivos com a teoria que a explica, os conceitos envolvidos e as suas dependências.

- permissao_cadastro.php

Cadastro de permissões de acesso, esta tela contém um select Tela, para que sejam selecionadas as permissões de acesso às telas, outro select Rotina para selecionar a Rotina de configuração para as telas e os campos Tipo de Usuário, Turma e Usuário que contém as permissões passíveis de alterações.

- rotina_cadastro.php

Cadastro de rotinas, contém o rótulo das rotinas e suas descrições. As rotinas são utilizadas para identificar as permissões de acesso.

- sessao_lista.php

Listagem das sessões abertas bem como do usuário, IP, data e hora da mesma. 
- tela_cadastro.php

Esta tela efetua o cadastro de telas novas no sistema, ela contém o nome do arquivo da tela, o rótulo, a descrição, um campo que indica o grupo a qual ela fará parte, um outro para indicar a ordem na qual ela aparecerá neste grupo no menu, também há um campo para indicar as rotinas que cada tela possui.

- telarotina_lista.php

Listagem de telas e das rotinas que estão cadastradas na mesma, com um link para a modificação dos dados cadastrais para cada tela e para cada rotina.

- tipousu_cadastro.php

Cadastro dos tipos de usuários, ela contém o tipo e o status padrão de cada usuário. Dois campos são dispostos nesta tela, o campo tipo que é o rótulo do tipo e o status.

- turma_cadastro.php

Cadastro de turmas, esta tela é dividida em duas: perfil da turma e perfil de aprendizagem. No perfil de turma aparecem os dados gerais, como rótulo da turma, descrição e senha. No perfil de aprendizagem constam os tópicos que os alunos cadastrados nesta turma deverão trabalhar. Quando as operações são selecionadas, o sistema automaticamente seleciona seus pré-requisitos.

- turmaXusuario.php

Listagem das turmas e dos usuários que estão cadastrados em cada uma, com links para modificar seus dados.

- usuario_cadastro.php

Cadastro de usuários. Se a tela for acionada pelo administrador, campos como Status, e Administrador aparecerão na tela. O auto-cadastro do aluno em alguma turma apenas será bem sucedido se ele possuir a senha para aquela opção (o docente, ao cadastrar uma nova turma inclui uma senha que deverá ser passada posteriormente aos seus alunos). Se 
algum aluno desejar utilizar o sistema de modo individual, ou seja, sem participar de turma alguma, ele não precisará de senha para se cadastrar.

- usuario_lista.php

Listagem de usuários e das suas principais características, vista de modo completo apenas pelo administrador do sistema e parcial pelos docentes. Ela contém links para modificar os dados cadastrais de cada usuário. 


\section{ANEXO 2 - Funções do Sistema}

Funções Utilizadas:

- function fChecaLogin()

- function fRetornaDadosUsuario(\$id_usuario)

- function fExtraiUlt_Login()

- function fFormataData(\$dData)

- function fFormataHora(\$tHora)

- function fRecebeMensagem()

- function fRetornalD(\$sTabela)

- function fRetornaValorBanco(\$sTabela, \$sCampo, \$aChave)

- function fRetornaStatus(\$iStatus)

As principais funções utilizadas no sistema estão relacionadas na lista abaixo. Suas descrições estão logo a seguir.

- função fChecaLogin

Função que checa se o usuário está logado ou não, para isto ela captura o cookie do último usuário a entrar no sistema. A partir deste cookie ela identifica o id deste usuário e realiza a consulta no banco que irá mostrar se o usuário está ou não logado.

Se trata de uma função boleana, retorna True se o usuário está logado, senão false.

Exemplo de uso:

// checagem se o usuário está logado.

if (fChecaLogin()) \{ instruções $\}$

- função fRetornaDadosUsuario (\$id_usuario)

Função que recebe como parâmetro um id. Ela busca no banco os seguintes dados do usuário com o id obtido: nome do usuário (campo usuario), id do tipo de usuário (campo id_tipousu), id da turma a qual este usuário está cadastrado (campo id_turma), campo char que indica se o usuário é ou não um administrador (campo administrador), status do usuário (campo status). Estes dados são retornados na forma de um vetor. 
Exemplo de uso:

// obtendo os dados do último usuário logado

\$aDadosUsuario = fRetornaDadosUsuario(\$aUlt_Login["id_usuario"]); // capturando os dados do vetor

\$sUsuario = \$aDadosUsuario["usuario"];

\$iTipo = = $=$ aDadosUsuario["id_tipousu"];

\$iTurma = \$aDadosUsuario["id_turma"];

\$iAdministrador $=$ \$aDadosUsuario["administrador"];

\$iStatus = \$aDadosUsuario["status"];

- função fExtraiUlt_Login()

Função que extrai o id do último usuário logado no sistema a partir do computador em uso, obtém esta informação por um cookie criado pelo sistema.

Exemplo de uso:

\$aUlt_Login = fExtraiUlt_Login();

- função fFormataData(\$dData)

Função que recebe como parâmetro uma data e a formata usando uma máscara aceitável pelo banco de dados.

Exemplo de uso:

$\$ \mathrm{dData}=$ fFormataData $(\$ \mathrm{dData}) ;$

- função fFormataHora(\$hHora)

Função que recebe como parâmetro uma hora e a formata usando uma máscara aceitável pelo banco de dados. Esta função se faz necessária devido ao banco de dados em uso acrescentar 6 casas de precisão na hora, o que para a vista humana é inadequado.

Exemplo de uso:

\$hHora = fFormataHora $($ hHora $)$; 
- função fRecebeMensagem()

Função que checa no banco se o usuário que está logado no sistema recebeu novas mensagens, se sim a função mostra as mensagens ao usuário por um alert.

Exemplo de uso:

fRecebeMensagem();

- função fRetornalD(\$tabela)

Função que retorna o id do último registro alterado pelo banco da tabela passada por parâmetro.

Exemplo de uso:

// comando SQL (inserção de um registro na tabela usuário)

\$sSql="INSERT INTO usuario (usuario, senha, id_tipousu, id_turma, nome, email, endereco, cidade, uf, cep, pais, sexo, data_nascimento, universidade, curso, id_area, administrador, status) VALUES ("'.\$sUsuario."', "'.\$sSenhaMd5."', "'.\$id_tipousu."', "'.\$id_turma."', "'.\$sNome."', "'.\$sEmail."', "'.\$sEndereco."', "'.\$sCidade."', "'.\$iUf."', '".\$sCep."', "'.\$iPais."', "'.\$cSexo."', "'.fFormataData(\$dData_nascimento)."', "'.\$sUniversidade."', '".\$sCurso."', "'.\$id_area."', "'.\$iAdministrador."', "'.\$iStatus."')"; adodb)

// execução do comando (usando a classe de abastração

\$SqIResult_4 = \$db->Execute(\$sSql) or die(\$sSql."<br>".\$db$>$ ErrorMsg());

// uso da função

\$id_usuario = fRetornalD("usuario");

- função fRetornaValorBanco(\$sTabela, \$sCampo, \$aChave)

Função genérica que, a partir da tabela passada por parâmetro, obtém o valor do campo desejado (\$sCampo) utilizando para isto a Chave passada por parâmetro (\$aChave).

Exemplo de uso:

// instrução para obter do banco o campo administrador da tabela usuário em que o campo id_usuário seja igual a variável \$aUlt_Login["id_usuário"];

\$iAdministrador = fRetornaValorBanco("usuario", "administrador", array("id_usuario" => \$aUlt_Login["id_usuario"])); 
- função fRetornaStatus(\$iStatus)

Função que retorna a string equivalente ao valor passado por parâmetro.

Exemplo de uso:

\$sStatus = fRetornaStatus $($ \$S Status $) ;$ 